Associate Editor: M. Belvisi

\title{
Resolution of inflammation: Mechanisms and opportunity for drug development
}

\author{
Ana L. Alessandri a , Lirlândia P. Sousa ${ }^{\text {b,c }}$, Christopher D. Lucas ${ }^{\text {a }}$, Adriano G. Rossi a \\ Vanessa Pinho ${ }^{\mathrm{c}, \mathrm{d}}$, Mauro M. Teixeira ${ }^{\mathrm{c}, *}$ \\ a Medical Research Council Centre for Inflammation Research, Queen's Medical Research Institute, University of Edinburgh, Edinburgh, United Kingdom \\ b Departamento de Análises Clínicas e Toxicológicas, Faculdade de Farmácia, Universidade Federal de Minas Gerais, Belo Horizonte, Brazil \\ c Imunofarmacologia, Departamento de Bioquímica e Imunologia, ICB, Universidade Federal de Minas Gerais, Belo Horizonte, Brazil \\ d Departamento de Morfologia, Instituto de Ciências Biológicas, Universidade Federal de Minas Gerais, Belo Horizonte, Brazil
}

\section{A R T I C L E I N F O}

\section{Keywords:}

Inflammation

Resolution

Granulocyte apoptosis

Signaling pathways

Tissue repair

\begin{abstract}
A B S T R A C T
Inflammation is a beneficial host reaction to tissue damage and has the essential primary purpose of restoring tissue homeostasis. Inflammation plays a major role in containing and resolving infection and may also occur under sterile conditions. The cardinal signs of inflammation dolor, calor, tumor and rubor are intrinsically associated with events including vasodilatation, edema and leukocyte trafficking into the site of inflammation. If uncontrolled or unresolved, inflammation itself can lead to further tissue damage and give rise to chronic inflammatory diseases and autoimmunity with eventual loss of organ function. It is now evident that the resolution of inflammation is an active continuous process that occurs during an acute inflammatory episode. Successful resolution requires activation of endogenous programs with switch from production of pro-inflammatory towards pro-resolving molecules, such as specific lipid mediators and annexin A1, and the non-phlogistic elimination of granulocytes by apoptosis with subsequent removal by surrounding macrophages. These processes ensure rapid restoration of tissue homeostasis. Here, we review recent advances in the understanding of resolution of inflammation, highlighting the pharmacological strategies that may interfere with the molecular pathways which control leukocyte survival and clearance. Such strategies have proved beneficial in several pre-clinical models of inflammatory diseases, suggesting that pharmacological modulation of the resolution process may be useful for the treatment of chronic inflammatory diseases in humans.
\end{abstract}

(c) 2013 Elsevier Inc. All rights reserved.

\section{Contents}

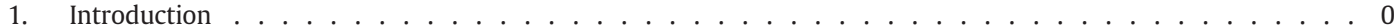

2. Evidence for natural and drug-induced resolution of inflammation . . . . . . . . . . . . . . . . . . 0

3. Concluding remarks . . . . . . . . . . . . . . . . . . . . . . . . . . 0

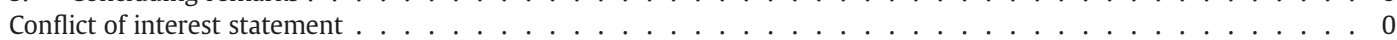

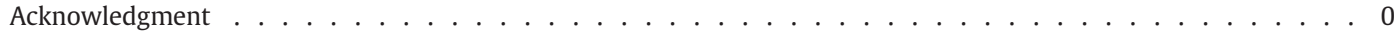

References . . . . . . . . . . . . . . . . . . . . . . . . . . . . . . 0

\footnotetext{
Abbreviations: $\alpha$-MSH, $\alpha$-melanocyte-stimulating hormone; AA, arachidonic acid; AnxA1, annexin A1: AP-1, activating protein 1; ATL, aspirin-triggered lipoxin; Bcl-2, B-cell

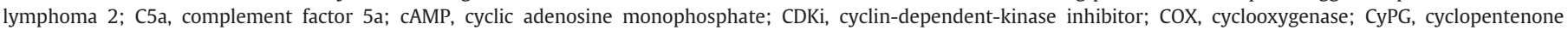

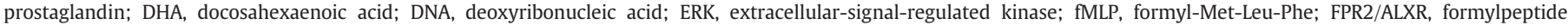

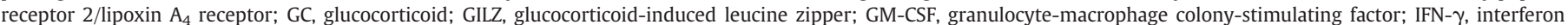

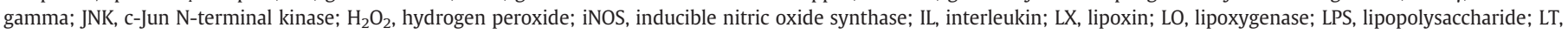

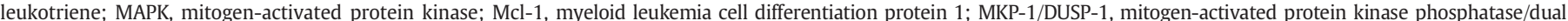

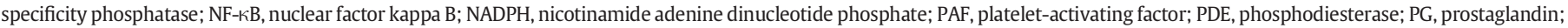

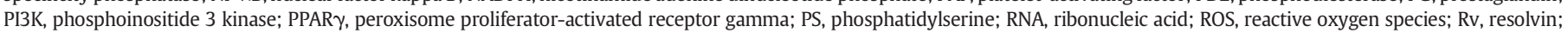
SOD, superoxide dismutase; SCFA, short chain fatty acid; TGF- $\beta$, transforming growth factor- $\beta$; TLR, toll-like receptor; TNF- $\alpha$, tumor necrosis factor alpha.

* Corresponding author at: Av. Antonio Carlos, 6627-Pampulha, 31270-901, Belo Horizonte, MG, Brazil. Tel./fax: + 553134092651.

E-mail address: mmtex@icb.ufmg.br (M.M. Teixeira).
} 


\section{Introduction}

Inflammation is a salutary host response against invading pathogens or following sterile tissue injury. The inflammatory response is a spatially and temporally orchestrated event in which cells and mediators collaborate to neutralize and eliminate the damaging stimuli to allow maintenance of homeostasis (Cotran et al., 1999; Medzhitov, 2010). Although inflammation is primarily a physiological and beneficial process, non-resolving inflammatory processes may be involved in the pathogenesis and progression of many inflammatory diseases, including asthma, atherosclerosis, rheumatoid arthritis, multiple sclerosis, rhinitis and ischemia-reperfusion injury (McFarland \& Martin, 2007; Waldburger \& Firestein, 2009; Nathan \& Ding, 2010; Eltzschig \& Eckle, 2011; Mandhane et al., 2011; Van-Assche et al., 2011; Chung, 2012).

Traditionally, anti-inflammatory therapies have focused on strategies to decrease or neutralize the level of pro-inflammatory mediators and/or inhibit the recruitment of leukocytes and their activation. These therapies include non-steroidal anti-inflammatory drugs (NSAID), glucocorticoid (GC) receptor agonists (synthetic GCs) and antibodies or inhibitors targeting specific pro-inflammatory cytokines, such as tumor necrosis factor (TNF)- $\alpha$ and interleukin (IL)-1. However, in the past few years, it has been recognized that pro-resolution-based strategies have potential for the treatment of multiple inflammatory conditions (Gilroy et al., 2004; Rossi et al., 2007; Hallett et al., 2008; Serhan et al., 2008; Duffin et al., 2010). Indeed, resolution of inflammation is regarded as a targetable process that is distinct from targeting acute inflammatory processes. Resolution is an active process involving biochemical mediators and signaling pathways controlling 1 ) termination of the inflammatory response (mainly by diminishing granulocyte recruitment and reversing vasodilatation and vascular permeability); 2) switching from pro-inflammatory mediator generation to production of pro-resolution mediators; 3 ) turning off signaling pathways associated with cytokine production and leukocyte survival; 4) apoptosis of recruited inflammatory cells; 5) phagocyte clearance of apoptotic cells (especially by macrophages in a non-phlogistic process) and; 6) switching from pro-inflammatory cell phenotypes to pro-resolution phenotypes (especially relevant to macrophages).

There are defined molecular pathways that promote leukocyte survival (or prevent death) once non-resident inflammatory cells migrate into tissue. Thus, understanding mechanisms that regulate apoptosis is vital in providing clues as to which molecular pathways can be pharmacologically modulated. In this review, we will discuss important signaling pathways involved in the control of apoptosis, with a focus on key pharmacological agents that are able to manipulate those pathways in vivo and are therefore potentially relevant as therapies for the treatment of autoimmune and chronic inflammatory diseases.

\subsection{General aspects of acute inflammation}

Macroscopically the inflammatory reaction is recognized by the cardinal signs of calor (heat), rubor (redness), tumor (swelling), dolor (pain) and loss of function, the first four of which were described by Cornelius Celsus in the first century. The first step of the inflammatory cascade is primarily a vascular response with hyperemia and increase in permeability of the vessel wall. Initially, transient arteriolar vasoconstriction is observed and promoted by the contraction of vascular smooth muscles. Subsequently, arteriolar vasodilatation leads to increased blood flow into the damaged area resulting in local hyperemia. At this early stage, alterations in the vascular endothelium are readily detectable with consequent exudation of plasma proteins and fluid from the blood into the tissue. This is followed by migration of leukocytes from the circulation into tissue (Cotran et al., 1999; Lawrence et al., 2002).

In response to an appropriate stimulus (e.g. infection, mechanical trauma, ischemia, toxins, minerals, crystals, chemicals, and antigens), circulating leukocytes interact with post-capillary venule endothelial cells (or capillary endothelial cells in the pulmonary circulation). This process is mediated predominantly by selectins (glycoprotein adhesion molecules) present on leukocytes (e.g. L-selectin) and on endothelial cells (e.g. P and E-selectin) and their carbohydrate ligands (PSGL-1, ESL-1 and CD34) (Kubes, 2002; Petri et al., 2008). Leukocytes rolling on the endothelium are now capable of interacting with chemoattractant factors, including complement factor 5a (C5a), IL-8/CXCL8, platelet-activating factor (PAF), eotaxin/CCL11 and leukotriene (LT) $\mathrm{B}_{4}$, which sit on the luminal surface of the endothelium. The activation of relevant chemoattractant receptors on the rolling leukocyte results in up-regulated expression and affinity of integrins (CD11/CD18 family; very late antigen-4, VLA-4) (Baggiolini, 1998; Baggiolini \& Loetscher, 2000; Sallusto \& Baggiolini, 2008). Integrins promote firm adhesion of activated leukocytes to endothelial cells by binding to their ligands, including intercellular adhesion molecule 1 (ICAM-1) and vascular cell adhesion molecule 1 (VCAM-1). Subsequently, leukocytes crawl on endothelial cells until they find appropriate spots where they migrate into the interstitium (Phillipson et al., 2006). Migration into tissue relies on integrins and other cell adhesion molecules, including platelet endothelial cell adhesion molecule 1 (PECAM-1) present in intercellular junctions (Kubes, 2002; Petri et al., 2008). Once in the tissue, leukocytes can be further activated and become an important source of a range of substances which include colony stimulating factors, cytokines, chemokines, lipid mediators and reactive oxygen species (ROS). Besides promoting the elimination of injurious stimuli, the inflammatory process itself may contribute to damage of adjacent tissues and can therefore enhance the severity of symptoms (Cara et al., 2000).

Apoptosis of granulocytes followed by recognition and removal by surrounding phagocytes, such as macrophages, are important events in the resolution of acute inflammation. The latter events limit tissue injury caused by leukocytes at sites of inflammation and are important for switching macrophage phenotype towards pro-resolution (discussed later). Ideally, the initial inflammatory response to protect the host is self-limiting and progresses to complete resolution (Hallett et al., 2008). However, if dysregulated acute inflammation can progress to a more chronic situation that can eventually result in scarring and fibrosis. Thus, the induction of granulocyte apoptosis could be of potential benefit in the control of acute inflammatory diseases (Savill, 1997; Gilroy et al., 2004; Rossi et al., 2007; Hallett et al., 2008; Sousa et al., 2009, 2010; Alessandri et al., 2011; Vago et al., 2012). Fig. 1 highlights the different phases of acute inflammatory processes towards successful resolution.

\subsection{Mechanisms of leukocyte death}

The accumulation of leukocytes in tissue depends not only on the number of cells being recruited at any particular time, but also on the number of cells that are cleared or leave the tissue (Gilroy et al., 2004; Hallett et al., 2008; Duffin et al., 2010). Inflammatory cells can be eliminated by systemic re-circulation, lymphatic drainage or local cell death. Different modalities of cell death, based on morphological, molecular and functional criteria, have been described. Examples include apoptosis, excitotoxicity, pyroptosis, necrosis, necroptosis and NET-osis (Kroemer et al., 2009; Han et al., 2011).

Granulocytes in particular undergo apoptosis during both physiological and inflammatory conditions. However, leukocytes may also die by autophagy, NET-osis and necrosis, with the mode of cell death impacting on the process of inflammation (Mitroulis et al., 2010; Geering \& Simon, 2011). Our groups and others have examined a number of key molecules and pathways involved in maintenance of leukocyte survival or apoptotic death, including nuclear factor kappa B (NF-КB), phosphoinositide-3-kinase (PI3K), myeloid leukemia cell differentiation protein 1 (Mcl-1) and cyclic adenosine monophosphate (cAMP). Studies with these molecules or pathways have highlighted the importance of the subsequent regulated clearance of apoptotic cells by inflammatory macrophages in vitro and in vivo (Rossi et al., 1998; Ward et al., 2002; Duffin et al., 2009; Sousa et al., 2010; 


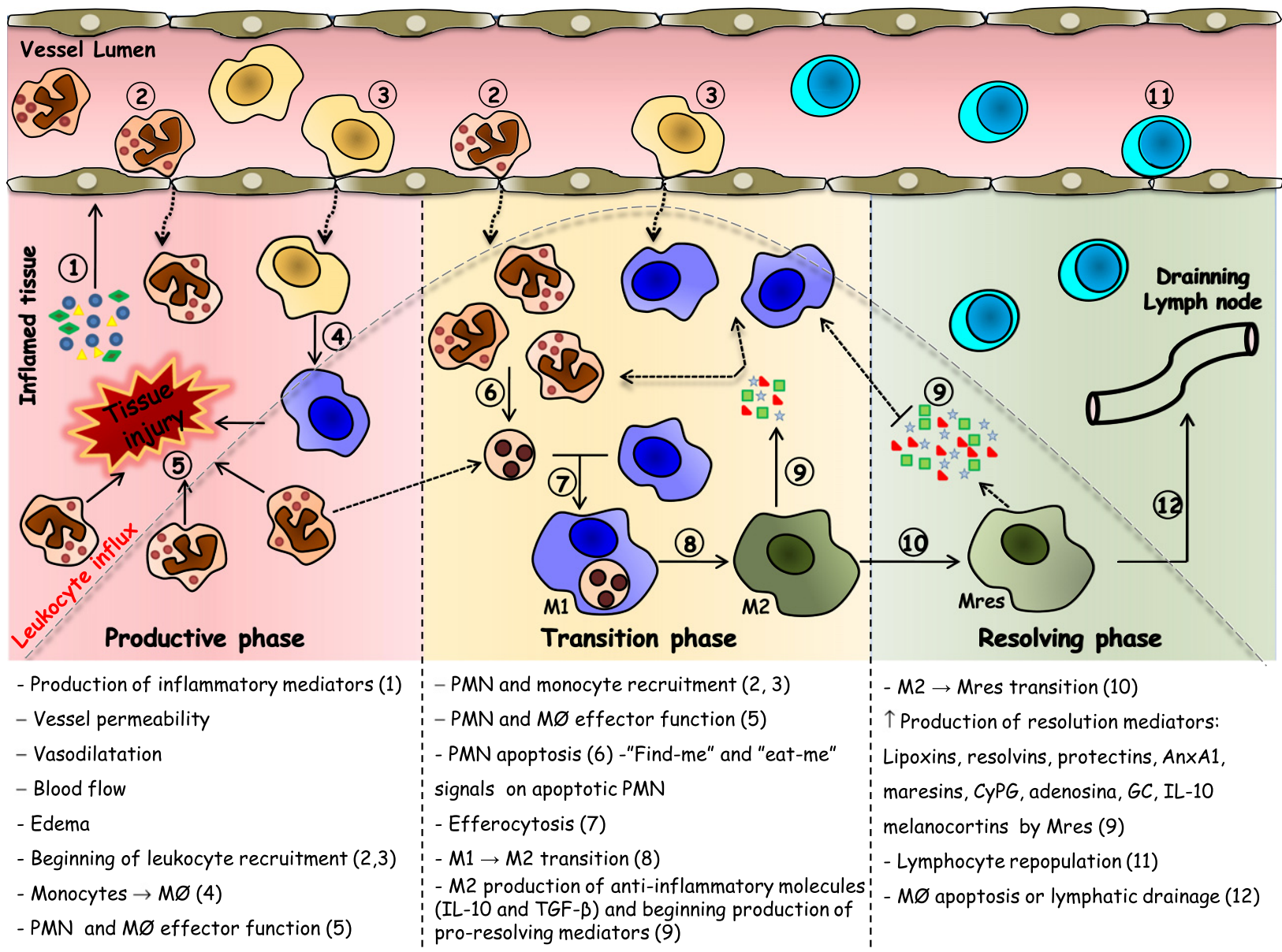

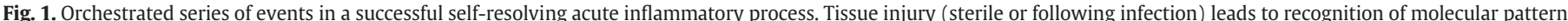

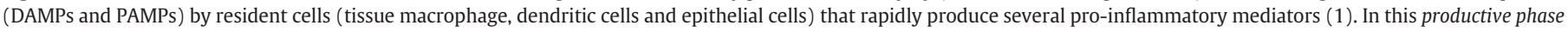

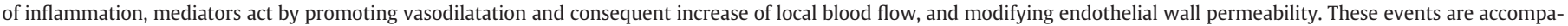

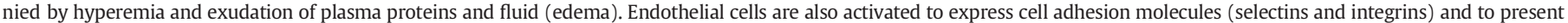

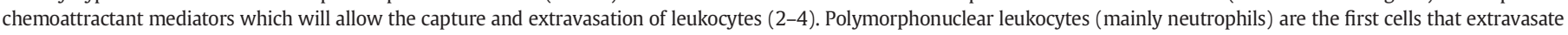

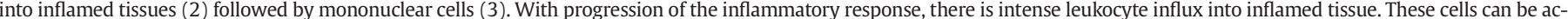

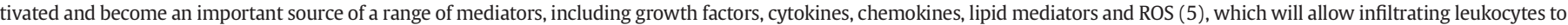

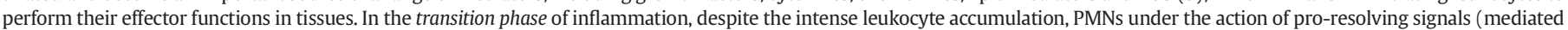

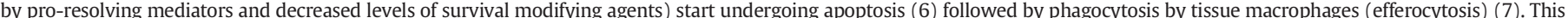

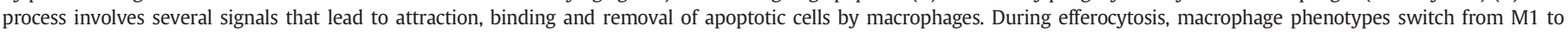

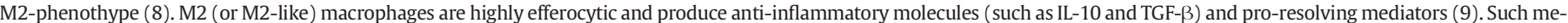

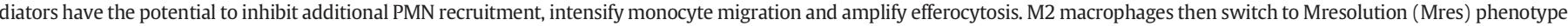

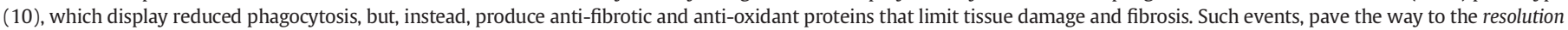

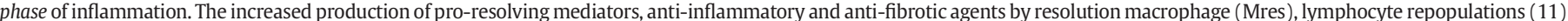
and lymph node drainage or apoptosis of macrophage (12) close the inflammatory process and restore tissue homeostasis.

Alessandri et al., 2011). Regulated clearance of apoptotic cells leads to shutdown of cellular activity and inhibition of inflammatory responses. Therefore, it is considered that granulocyte apoptosis followed by phagocytosis is the most desirable form of cell death for successful resolution (Savill, 1997; Gilroy et al., 2004; Rossi et al., 2007; Hallett et al., 2008).

Morphologically, apoptosis proceeds with chromatin condensation, nuclear fragmentation with rounding up and apoptotic body formation, organelle involution and cytoplasm shrinkage (Kroemer et al., 2009). Along with morphological evaluation performed by light and scanning electron microscopy (Rossi et al., 1993), apoptosis can be assessed by a number of techniques, including deoxyribonucleic acid (DNA) gel electrophoresis (Ward et al., 1999), western blotting (Duffin et al., 2009), TUNEL (terminal deoxy-nucleotidyl-transferase mediated dUTP nick end labeling; which detects DNA fragmentation) (Gorczyca et al., 1992) and flow cytometry (van et al., 1998; Duffin et al., 2009). Flow cytometric assessment of apoptosis is generally performed using labeled annexin- $\mathrm{V}$, which binds to phosphatidylserine (PS) exposed on the surface of apoptotic cells, and propidium iodide (PI), which marks necrotic cells.

There are much data supporting a critical role for caspases in the mechanism underlying leukocyte apoptosis (Weinmann et al., 1999; Daigle \& Simon, 2001; Duffin et al., 2009; Sousa et al., 2009, 2010; Yazdi et al., 2010; Alessandri et al., 2011; Vago et al., 2012). Caspases (cysteinyl aspartate proteases) are involved in both apoptosis pathways, namely the extrinsic and intrinsic pathways. The extrinsic pathway is triggered when an extrinsic ligand stimulates a death receptor (e.g. Fas/Fas ligand and TNF-TNFR) and activates pro-caspase 8 (Krammer, 2000; Geering et al., 2011). The clustering of procaspase-8 molecules initiates an autocatalytic caspase activation cascade with subsequent cleavage and activation of effector caspases (in particular caspase-3) which drive apoptosis. Caspase-8 can either directly cleave procaspase-3 to caspase- 3 which causes apoptosis without mitochondrial depolarization (Huang et al., 1999) or caspase-8 can cleave the 
pro-apoptotic B-cell lymphoma 2 (Bcl-2) homolog Bid (the Bcl-2 family proteins will be discussed later) to its truncated form (tBid) with activation of the intrinsic pathway and release of pro-apoptotic factors from mitochondria. Conversely, the intrinsic pathway is largely dependent on the relative balance of pro-apoptotic versus anti-apoptotic proteins from the Bcl-2 family. The intrinsic pathway controls apoptosis in response to stimuli such as cytotoxic agents, UV radiation or oxidative stress (Siegel, 2006). A relative abundance of pro-apoptotic Bcl-2 proteins (or relative decrease in anti-apoptotic proteins) results in mitochondrial outer-membrane permeabilization with release of proteins from the mitochondrial inner membrane space into the cytosol. These proteins include cytochrome $c$ which interacts with pro-caspase- 9 and the cytosolic protein apoptotic-protease-activating factor-1 (APAF1) to form the apoptosome complex which activates the effector caspase-3 driving extensive cleavage of substrates and irreversible cell death (Acehan et al., 2002). Other proteins such as second mitochondria-derived activator of caspases (SMAC/DIABLO) are also released from mitochondria, with SMAC/DIABLO inhibiting the inhibitors of apoptosis (IAP) proteins which further augments activation of the caspase cascade.

In addition to apoptotic death, several studies have described non-apoptotic forms of granulocyte death, particularly in neutrophils (von et al., 2005; Huang et al., 2009; Mitroulis et al., 2010; Mihalache et al., 2011; Prince et al., 2012). For example, there is evidence that autophagy occurs in human and mouse neutrophils in both a phagocytosis-independent and dependent manner (Huang et al., 2009; Mitroulis et al., 2010). Autophagic cell death is morphologically defined as cell death that occurs in the absence of chromatin condensation and it is accompanied by massive autophagic vacuolization of cytoplasm (Kroemer et al., 2009). It has been reported that induction of autophagy is associated with an adaptive response to cellular stressors, such as nutrient deprivation or growth factor withdrawal. Moreover, inflammation-related agents including pathogens, ROS and hypoxia also induce autophagy and autophagy-like neutrophils have been observed in vivo in septic shock, rheumatoid arthritis, cystic fibrosis and skin disorders (Moreau et al., 2010; Mihalache et al., 2011). Similarly, phagocytosis of Escherichia coli or Ig-G coated beads induces recruitment of the autophagy protein LC3 to phagosomes suggesting induction of autophagy (Huang et al., 2009; Mitroulis et al., 2011). Mitroulis et al. (2010) have shown that neutrophil exposure to rapamycin, toll-like receptor (TLR) agonists or phorbol myristate acetate (PMA) resulted in cytoplasmic vacuole accumulation, previously characterized as autophagy-like vacuoles, suggesting phagocytosis-independent autophagy. High levels of intracellular ROS generated by neutrophil nicotinamide adenine dinucleotide phosphate (NADPH) oxidases are suggested as essential for autophagy induction induced by PMA, TLR activation and phagocytosis (Huang et al., 2009). A role for ROS in CD44-induced neutrophil cell death in the presence of granulocyte-macrophage colonystimulating factor (GM-CSF) or formyl-Met-Leu-Phe (fMLP) has also been suggested (Mihalache et al., 2011).

The production of neutrophil extracellular traps (NETs) composed mainly of DNA and granule constituents leads to non-apoptotic neutrophil death termed NETosis (Brinkmann et al., 2004; Amulic \& Hayes, 2011). The primary function of NETs seems to be the binding and killing of bacteria and fungi. Nevertheless, NETs may also enhance inflammation, as suggested by NET production in neutrophils isolated from synovial fluid or peripheral blood of patients with acute gout. Inhibition of phagolysosomal fusion or IL-1 $\beta$ blockade prevents NET formation suggesting that NETosis is associated with IL-1 $\beta$ and autophagy-related signaling in vivo. Interestingly it has also been reported that DNA can be released from neutrophils which do not undergo cell death (Yousefi et al., 2009) and as such the role of NETosis on neutrophil death is not yet fully understood. Moreover, it has recently been demonstrated that infection may induce NETosis in neutrophils that are crawling in the microcirculation following infection. In this case, neutrophils do not undergo lysis and retain their ability to multitask in the context of infection (Yipp et al., 2012).

Finally, many agents have been reported to induce cell necrosis, morphologically characterized by a gain in cell volume, swelling of organelles, plasma membrane rupture and subsequent loss of intracellular contents (Kroemer et al., 2009). Necrosis can proceed either as a primary event (primary necrosis) or can occur following apoptosis when phagocytosis is delayed (secondary necrosis). Until recently, necrosis was considered a non-specific mode of cell death, but a body of evidence has demonstrated that certain types of necrosis are finely regulated by signal transduction pathways leading to the term necroptosis (programmed necrosis) (Degterev et al., 2005; Han et al., 2011). It has been reported that necroptosis contributes to physiological and pathological processes including maintaining homeostasis and inflammatory diseases (Han et al., 2011). In this context the protein serine/threonine kinase receptor interacting protein 1 (RIP1) family member RIP3 has been referred as a key important mediator of caspase-independent cell death (Cho et al., 2009; Zhang et al., 2009).

It has been demonstrated that isolated human neutrophils undergo necroptosis after infection with virulent Shigella flexneri requiring type III secretion, IpaB and IpaC invasins, and actin polymerization (François et al., 2000). In agreement with this, Kobayashi et al. (2010) have shown that neutrophils containing ingested Staphylococcus aureus undergo morphological changes leading to rapid lysis. Importantly, phagosome membranes remained intact until the point of cell destruction suggesting that $S$. aureus was inducing programmed necrosis rather than non-specific lysis caused by escape of the pathogen from phagosomes or by the cytolytic action of secreted pore-forming toxins. In fact, it has been demonstrated in monocyte-macrophages, neutrophils and eosinophils that pathogens can disrupt death pathways as a survival strategy impairing antimicrobial functions of immune cells (Dockrell \& Whyte, 2006; Feoktistova et al., 2011; Prince et al., 2012).

Although necrosis has been traditionally correlated with enhanced inflammation and tissue injury and is therefore considered unwanted cell death, few reports have conversely suggested that necrotic cells can inhibit inflammatory reactions (Hirt \& Leist, 2003; Casares et al., 2005). Of note, it has been recently shown that annexin A1 (AnxA1) externalization during secondary necrosis provides an important fail-safe mechanism counteracting inflammatory responses when the timely clearance of apoptotic cells has failed (Blume et al., 2012). This change of paradigm faces many challenges and there is no consensus on mechanisms driving necrosis and how this may be beneficially controlled. Table 1 summarizes the key modalities of cell death and their role in inflammation resolution.

\subsection{Recognition, response and removal of apoptotic cells by phagocytes}

An important consequence of the apoptotic process is induction of alterations on the expression of molecules on the cell surface of the dying cell. Such alterations lead to rapid recognition and phagocytosis of apoptotic cells (Fadok et al., 2001a; Gardai et al., 2006; Gregory \& Pound, 2010). Defective clearance of apoptotic bodies has been associated with autoimmunity and chronic inflammation (Munoz et al., 2005; Donnelly \& Barnes, 2012). As such, efficient phagocytosis of apoptotic cells is crucial for the resolution of inflammation (Savill, 1997; Hallett et al., 2008). Gregory and colleagues have rationalized three main phases and dynamic stages that connect apoptotic cells to the engulfing phagocyte, namely recognition, response and removal (Gregory \& Pound, 2010, 2011; Gregory et al., 2011).

The recognition phase involves migratory responses of mononuclear phagocytes in response to chemoattractants released from apoptotic cells signaling their location. Besides the classical chemokines CX3CL1 and CCL2 (Kobara et al., 2008; Truman et al., 2008), other chemoattractants include the lipid signals lysophosphatidylcholine and sphingosine-1-phosphate (S1P) and the nucleotides ATP and UTP (Lauber et al., 2003; Gude et al., 2008; Elliott et al., 2009; McDonald et 
Table 1

Types of cell death.

\begin{tabular}{|c|c|c|c|}
\hline Type of cell death & Key molecules & Major characteristics & Role in the resolution of inflammation \\
\hline Apoptosis & $\begin{array}{l}\text { Caspases- } 3,6,7,8,9 \\
\text { Bcl-2 family of proteins }\end{array}$ & $\begin{array}{l}\text { Chromatin condensation, nuclear fragmentation } \\
\text { with rounding up and apoptotic body formation, } \\
\text { organelle involution and cytoplasm shrinkage. }\end{array}$ & $\begin{array}{l}\text { It is considered the most desirable form of cell death for } \\
\text { successful resolution and is an important event in the } \\
\text { resolution of acute inflammation which limits tissue injury } \\
\text { caused by leukocytes at sites of inflammation. Furthermore, } \\
\text { regulated clearance of apoptotic cells leads to shutdown of } \\
\text { cellular activity and inhibition of inflammatory responses. }\end{array}$ \\
\hline Necroptosis & $\begin{array}{l}\text { RIP1 (also known as } \\
\text { RIPK1) and RIP3 }\end{array}$ & $\begin{array}{l}\text { It is considered programmed necrosis associated } \\
\text { with caspase-independent cell death. }\end{array}$ & $\begin{array}{l}\text { It has been reported that necroptosis contributes to } \\
\text { inflammatory diseases. }\end{array}$ \\
\hline
\end{tabular}

Autophagy $\quad \mathrm{Bcl}-2, \mathrm{Bcl}-\mathrm{XL}$, Beclin1, Auto-digestive process that promotes delivery of ATG5-ATG12, ATG8 intracellular components from the cytoplasm to (LC3) lysosomal or vacuolar compartments for terminal degradation and recycling.

Necrosis No signal determined It is characterized by a gain in cell volume, swelling of organelles, plasma membrane rupture and subsequent loss of intracellular contents

NET-osis Neutrophil Extracellular Traps (NETs)

It is a form of pathogen-induced cell death involving disintegration of the nuclear envelope, mixing of cytoplasmic and nuclear materials, and loss of internal membranes and cytoplasmic organelles

Pyroptosis Caspase-1-dependent Involves cellular lysis and release of the cytosolic contents to the extracellular space.

Not clearly determined.

It has been traditionally correlated with enhanced inflammation and tissue injury.

Not clearly understood

It is predicted to be inherently inflammatory and coincides

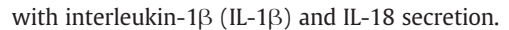

al., 2010; Marques et al., 2012). In addition, it has been reported that molecules such as covalent dimer of ribosomal protein S19, endothelial monocyte-activating polypeptide II (EMAP II), AnxA1, transforming growth factor- $\beta$ (TGF- $\beta$ ) and thrombospondin 1 direct mononuclear phagocytes towards apoptotic cells (Horino et al., 1998; Knies et al., 1998; Chen et al., 2001; Scannell et al., 2007; Peter et al., 2010).

Interestingly, it has been suggested that along with chemoattractant molecules, apoptotic cells also release agents such as lipoxins (LXs), lactoferrin and AnxA1 which inhibit granulocyte recruitment, contributing towards the predominant presence of mononuclear cells seen during the resolution phase (Schwab et al., 2007; Bournazou et al., 2009a; Vago et al., 2012). Bournazou et al. (2009a, 2009b) have shown in vitro and in vivo that lactoferrin, which is released by apoptotic cells, selectively inhibited migration of granulocytes but not mononuclear phagocytes. Lactoferrin concentration-dependently decreased the migration of neutrophils despite the presence of powerful neutrophil chemoattractants including fMLP, C5a, IL-8 and LTB 4 . The inhibitory ability of lactoferrin on neutrophil migration has also been confirmed in vivo using a murine peritonitis model induced by thioglycollate, whereas the migration of other types of leukocytes was not reduced (Bournazou et al., 2009a). Moreover, we have recently shown that an AnxA1 peptidomimetic, Ac2-26, was able to decrease neutrophil influx into the pleural cavity without alterations in mononuclear cell numbers (Vago et al., 2012).

Apoptotic cells signal the requirement to be removed by loss of 'don't-eat-me' signals, such as CD31 (Brown et al., 2002) and CD47 (Gardai et al., 2005), as well as release and display of various 'eat-me' signals, including phospholipids, nucleotides and by externalization of the molecule PS (Fadok et al., 2001b). Macrophages differentiated from recruited monocytes as well as tissue resident macrophages recognize these "eat-me" signals via receptors which include CD36, CD14, integrins $\alpha \nu \beta 3$ and $\alpha \nu \beta 5$, lectin, vitronectin and PS receptors (e.g. BAI1, TIM-4 and stabilin-2) (Savill et al., 1992; Devitt et al., 1998; Park et al., 2007; Gregory \& Pound, 2011). The interaction between "eat-me" signals on apoptotic cells with receptors on macrophages leads to firm tethering and subsequent activation of engulfment pathways. This ensures that apoptotic cells are efficiently removed from tissue prior to membrane rupture with release of cytotoxic mediators, minimizing tissue damage and perpetuation of the inflammatory response.

A body of in vitro and in vivo evidence shows that phagocytes that consume apoptotic granulocytes switch towards a pro-resolution phenotype that suppresses the inflammatory response. This helps to contribute to a non-phlogistic environment that paves the way towards successful resolution of inflammation. Macrophages are usually classified as either classically (M1) or alternatively (M2) activated. Classically activated (M1) are considered pro-inflammatory and are driven by interferon-gamma (IFN- $\gamma$ ) produced by Th1 cells or by recognition of pathogen-associated molecule patterns to promote pro-inflammatory responses. Alternatively activated (M2) are driven by IL-4 and/or IL-13 produced by Th2 cells and produce IL-10 and TGF- $\beta$, which have several anti-inflammatory actions. Early efferocytosis (non-phlogistic phagocytosis of apoptotic cells) leads to a mixed resolution-phase macrophage population with a more alternatively activated phenotype as well as enhanced phagocytosis/efferocytosis. Subsequently, macrophages convert to a resolution-promoting macrophage (Mres) profile which limits dysregulated tissue repair/fibrosis and migrate to the local draining lymph nodes promoting macrophage regulatory properties at remote sites (Bellingan et al., 1996; Bystrom et al., 2008; Schif-Zuck et al., 2011; Stables et al., 2011; Ariel \& Serhan, 2012).

Interestingly, Ramachandran et al. (2012) have recently identified and characterize the macrophage phenotype responsible for tissue remodeling following hepatic injury (restorative macrophage). Using a CCl4-induced model of reversible hepatic fibrosis, it has been reported that a $\mathrm{CD} 11 \mathrm{~B}^{\mathrm{hi}} \mathrm{F} 4 / 80^{\text {intermediate }}$ Ly- $6 \mathrm{C}^{\text {lo }}$ monocyte-derived macrophage subset was more abundant in livers observed during maximal fibrosis resolution and depletion of this population caused a failure of scar remodeling. Importantly these restorative macrophages derive from recruited Ly-6 $\mathrm{C}^{\text {hi }}$ monocytes (indicative of a phenotypic switch in vivo conferring pro-resolution properties) and presented features of being pos phagocytic. In vivo the administration of liposomes containing fluorescent microspheres, which enhance macrophage efferocytosis, caused increased restorative macrophage number and accelerated hepatic fibrosis resolution, suggesting a novel strategy for the treatment of tissue fibrosis.

Uptake of apoptotic cells by phagocytes leads to up-regulation of cell-surface expression of co-inhibitory molecules such as PD-L1 and ICOS-L; release of anti-inflammatory cytokines IL-10 and TGF- $\beta$, secretion of PAF, prostaglandin $\mathrm{E}_{2}\left(\mathrm{PGE}_{2}\right)$ and cAMP (Fadok et al., 1998a; McDonald et al., 1999; Huynh et al., 2005; Girkontaite et al., 2007; Bystrom et al., 2008; Gregory \& Pound, 2010). It has been also reported that macrophages which ingested apoptotic cells release pro-resolving lipid mediators such as $\mathrm{LXA}_{4}$, resolvin (Rv) E1, protectin D1 and maresins contributing to termination of the inflammatory 
process (Schwab et al., 2007; Yazid et al., 2011). Conversely, engulfment of apoptotic cells inhibits the release of pro-inflammatory cytokines, including TNF- $\alpha$, GM-CSF, IL-12, IL-1 $\beta$ and IL-18 (Fadok et al., 1998b; McDonald et al., 1999). The uptake of apoptotic cells also drives inhibition of inducible NO synthase (iNOS) expression and stimulates the expression of arginase- 1 in murine macrophages resulting in suppression of nitric oxide (NO) synthesis (Freire-de-Lima et al., 2006). Moreover, it has been shown in vitro that IL-10 and dexamethasone significantly increase uptake of apoptotic cells by human macrophages (Liu et al., 1999; Giles et al., 2001; Michlewska et al., 2009), whereas macrophages from IL-10-deficient mice have decreased phagocytosis in comparison to wild type mouse macrophages (Michlewska et al., 2009).

There is ongoing interest in delineating further mechanisms underlying the interactions between apoptotic cells and phagocytes, especially in vivo. Better understanding in this area may be potentially relevant to the treatment of chronic diseases such as systemic lupus erythematous where defective removal of apoptotic cells represents an important aspect in the pathogenesis of the disease.

\section{Evidence for natural and drug-induced resolution of inflammation}

Studies in vitro provide essential background information and understanding as to how resolution may occur in vivo but do not describe the complexity of in vivo phenomena. There has been much recent interest in the understanding of the signal transduction pathways governing leukocyte survival and apoptosis in vivo. Although a number of pathways have been evaluated, studies are difficult as many pathways become interrelated or co-dependent in vivo. On top of this complexity, it is not possible to extrapolate pathways governing cell death from one leukocyte type to another. For instance, although neutrophils and eosinophils are closely related granulocytes, glucocorticoids induce opposing effects on these two cell types. It has been shown that while these powerful anti-inflammatory drugs induce apoptosis in lymphocytes as well as eosinophils, they delay constitutive apoptosis of neutrophils, at least in vitro (Meagher et al., 1996). Several studies have described a number of key molecules and pathways involved in the maintenance of leukocyte survival and apoptotic death in vitro and in vivo and have highlighted the importance of the subsequent regulated clearance of apoptotic cells by inflammatory macrophages (Rossi et al., 1998; Liu et al., 1999; Ward et al., 1999; Rossi et al., 2006; Sousa et al., 2009, 2010; Alessandri et al., 2011; Lopes et al., 2011; Vago et al., 2012). It is believed that defined molecular pathways promote leukocyte survival (or prevent death) once these cells migrate into inflammatory tissue. Therefore, the use of animal models of inflammation together with knowledge of mechanisms regulating human leukocyte apoptosis in vitro is important in the quest to understand fully the molecular pathways relevant to human inflammatory diseases. Delineating these key pathways will likely reveal potential opportunities for pharmacological interventions (apoptosis-based) which treat inflammatory disorders by blocking the undesired effect of inappropriate leukocyte accumulation, activation or removal.

\subsection{Mediators of natural resolution with focus on pro-resolution mediators}

2.1.1. Pro-resolving lipid mediators (lipoxins, resolvins, protectins, maresins) Following investigations mainly by Serhan and colleagues, a number of lipid mediators derived from polyunsaturated fatty acids (PUFAs) have been discovered as anti-inflammatory and pro-resolution agents. These include lipoxins, E-series resolvins, D-series resolvins, protectins/ neuroprotectins and maresins (please see reviews by Serhan, 2007; Serhan \& Chiang, 2008; Serhan et al., 2008; Spite \& Serhan, 2010 for definition and chemical structures of the lipids). It has been demonstrated that lipid mediators have a modulatory role in various acute and chronic animal models of inflammatory conditions, including arthritis, peritonitis, ischemia-reperfusion injury, inflammatory pain and asthma (Levy et al., 2007; Souza et al., 2007; Conte et al., 2010; Xu et al., 2010; Serhan et al., 2012).

Lipoxin $\mathrm{A}_{4}\left(\mathrm{LXA}_{4}\right)$, lipoxin $\mathrm{B}_{4}\left(\mathrm{LXB}_{4}\right)$ and aspirin-triggered lipoxins (ATLs) were the first mediators biosynthesized from arachidonic acid (AA) to be recognized as anti-inflammatory, pro-resolving lipid mediators (Chiang et al., 2005). LXs and ATLs stimulate the formyl-peptide receptor 2/lipoxin $\mathrm{A}_{4}$ receptor (FPR2/ALXR) inhibiting cellular recruitment as well as enhancing non-phlogistic phagocytosis of apoptotic cells by macrophages (Godson et al., 2000; Fierro et al., 2003; Maderna \& Godson, 2005). Moreover a number of investigations have provided strong evidence that LXs are relevant for resolution in animal models (Souza et al., 2007; Conte et al., 2010 and reviewed by Ryan \& Godson, 2010). For instance, aspirin-triggered 15-epi-LXA enhances $_{4}$ resolution of acute lung inflammation by overriding the anti-apoptotic signal from myeloperoxidase (MPO) to induce neutrophil apoptosis (El Kebir et al., 2009). Conversely, Prieto et al. (2010) have shown that $\mathrm{LXA}_{4}$ protects human and murine macrophages from apoptosis through the activation of PI3K/Akt and extracellular-signal-regulated kinase (ERK) pathway suggesting that pro-resolution molecules may act differently dependent on the cell type under investigation.

Additionally, the association between LXs and IL-10 production has been studied by Souza et al. (2007) who evaluated the role of $\mathrm{LXA}_{4}$ and AnxA1 in germ free mice. These mice, which have no detectable bacteria in their intestines, generate little evidence of local or systemic injury following intestinal ischemia and reperfusion dependent upon high levels of $\mathrm{LXA}_{4}$, AnxA1 and IL-10. The treatment of conventional mice with the 15-epi-LXA 4 analog or an AnxA1-derived peptide markedly inhibited the reperfusion-associated inflammatory response and improved survival. This was associated with reduced TNF- $\alpha$ production in the intestine, lung and serum whereas IL-10 production was increased. The ability of $\mathrm{LXA}_{4}$ and AnxA1 to prevent reperfusion injury was lost in IL-10 deficient-mice. In order to further investigate the role of these mediators on the production of IL-10 in vivo, the effect of $\mathrm{LXA}_{4}$ was inhibited using either an inhibitor of 5-LO (ZM230487) or a non-specific antagonist of ALXR receptor (BOC-1) following reperfusion injury. Treatment with ZM230487 or BOC-1 led to increased production of TNF- $\alpha$ and reduced survival. Similarly the treatment of germ-free mice with anti-AnxA1 antiserum enhanced tissue injury, TNF- $\alpha$ production and lethality similar to that found in conventional animals. Taken together these findings suggest that increased production of IL-10 may be an important action of $\mathrm{LXA}_{4}$ and AnxA1 in vivo. Furthermore, the presence of microbiota alters endogenous production of anti-inflammatory substances and modulates inflammatory responsiveness. Future studies are necessary to demonstrate whether IL-10 is also necessary in mediating actions of lipoxins in the context of the resolution of inflammation. Moreover, the impact of the microbiota in the context of resolution of inflammation needs to be defined in greater detail.

Besides producing AA derived mediators, PUFAs generate omega-3 fatty acids, in particular eicosapentaenoic acid (EPA) and docosahexaenoic acid (DHA). These, in turn, are enzymatically transformed to generate E series (RvE), D series (RvD) resolvins, protectins and maresins (Serhan \& Petasis, 2011). Rvs, also named specialized pro-resolving mediators (SPMs), share some of the actions of the LXs regarding resolution of the inflammatory process. Rvs decrease the recruitment of neutrophils in peritonitis and induce resolution in several animal models including peritonitis, ischemia/ reperfusion injury, inflammatory pain, and allergic airway inflammation (Hasturk et al., 2005; Duffield et al., 2006; Schwab et al., 2007; Xu et al., 2010; El Kebir et al., 2012; Rogerio et al., 2012). Moreover RvE1 enhances phagocytosis of zymosan A by human macrophages (Ohira et al., 2010). Interestingly RvE1 and RvD1 bind to receptors that until recently were orphan receptors named ChemR23 and GPR32, respectively (Arita et al., 2007; Krishnamoorthy et al., 2010; Oh et al., 
2011). Rvs have been shown to promote tear production, prevent loss of corneal epithelial cell barrier integrity, inhibit keratocyte transformation to myofibroblasts, decrease inflammation, modulate T-lymphocyte-cell responsiveness and reduce goblet cell apoptosis (Li et al., 2010; Zhang et al., 2010b; Dartt et al., 2011). These effects have encouraged and guided current phase I and phase II clinical trials for dry eye syndrome (keratoconjunctivitis sicca) where individuals suffer from insufficient tears and/or have tears with incorrect osmolarity and evaporate rapidly resulting in irritation, inflammation and pain (www.clinicaltrial.gov).

Protectins (and the isoforms biosynthesized in neural tissues termed neuroprotectins) have a key role in controlling inflammatory processes with effects seen in animal models of peritonitis, kidney ischemia/reperfusion, asthma and stroke (Marcheselli et al., 2003; Bannenberg et al., 2005; Duffield et al., 2006; Levy et al., 2007).

Maresins, originally isolated from exudates of murine macrophages, play pro-resolving actions during murine peritonitis in vivo with potency similar to RvE1 and protectin D1 (Serhan et al., 2009). Recently, the anti-inflammatory and pro-resolving effects of maresins have been confirmed with a synthetic compound (MaR1) based on maresin 1 produced by human macrophages (Serhan et al., 2012). MaR1 limited neutrophil infiltration in murine peritonitis and enhanced uptake of apoptotic neutrophils by human macrophages. Furthermore, MaR1and RvE1 enhanced the rate of tissue regeneration in planaria. MaR1 also dose-dependently blocks transient receptor potential cation channel subfamily $\mathrm{V}$ member 1 (TRPV1) currents in primary sensory neurons and reduced both inflammation- and chemotherapy-induced neuropathic pain in mice suggesting that maresins modulate different aspects of the inflammatory process including resolution, tissue regeneration, and pain resolution (Serhan et al., 2012). Taken together the aforementioned studies, including clinical trials, highlight how understanding the endogenous control of resolving inflammation by pro-resolving lipid mediators can help develop novel therapeutics for clinical use.

\subsubsection{Glucocorticoid induced proteins (AnxA-1, GILZ and MKP-1)}

Glucocorticoids (GCs) are potent anti-inflammatory and immunosuppressive drugs that are used therapeutically for the treatment of many inflammatory conditions (Clark, 2007; Perretti \& D'Acquisto, 2009; Beaulieu \& Morand, 2011; Clark \& Belvisi, 2012). During inflammation, endogenous GCs are produced by the adrenal glands and play a critical role during the resolution of inflammation. The broad-spectrum anti-inflammatory and immunosuppressive effects of GCs depend on their effects on signaling pathways, such as NF- $\kappa B$ and activating protein 1 (AP-1) pathways, and their capacity to induce anti-inflammatory regulatory proteins. However, it has been thought that the metabolic side effects of GCs are also dependent on GC-induced gene expression (Clark, 2007; Perretti \& D'Acquisto, 2009; Beaulieu \& Morand, 2011). These aspects of the mechanism of action and side effects of glucocorticoid therapy have been recently discussed by Clark and Belvisi (2012).

There is growing interest in three GC-induced proteins, namely AnxA1, glucocorticoid-induced leucine zipper (GILZ) and mitogenactivated protein kinase phosphatase/dual specificity phosphatase (MKP-1/DUSP-1). In fact, GILZ and MKP-1/DUSP-1 have presented significant anti-inflammatory in vivo and AnxA1 has shown antiinflammatory and pro-resolving properties in several experimental models of inflammation (Ayroldi \& Riccardi, 2009; Li et al., 2009; Perretti \& D'Acquisto, 2009; Beaulieu \& Morand, 2011; Vago et al., 2012). Knowledge of such proteins may allow dissociation of antiinflammatory effects of GC from their adverse metabolic effects and the main effects of these proteins during inflammatory conditions. AnxA1 (also known as lipocortin-1) is a 37-kDa calcium-dependent phospholipid-binding protein from the annexin superfamily that binds to and activates FPR2/ALXR, a receptor also shared with LXs (Perretti \& D'Acquisto, 2009). AnxA1 is a known anti-inflammatory molecule, with its activities studied predominantly in the context of inhibition of pro-inflammatory PGs and leukocyte recruitment in various models of inflammation (Getting et al., 1997; Bandeira-Melo et al., 2005; Souza et al., 2007; Babbin et al., 2008). AnxA1 knockout mice show exacerbated inflammatory responses and are resistant to some of the antiinflammatory effects of GCs (Hannon et al., 2002; Yang et al., 2004). Exogenous and endogenous AnxA1 exerts exquisite control on leukocyte recruitment to inflammatory sites by modulating both proinflammatory mediators (including those derived from activation of phospholipase A2, COX-2 and iNOS synthase) as well as the antiinflammatory cytokine IL-10. In addition to the anti-inflammatory activities of AnxA1, some in vitro and in vivo proprieties of this protein show that it promotes resolution of inflammation mainly by inducing neutrophil apoptosis and increasing efferocytosis by macrophages (reviewed by Perretti, 2012). It is known that apoptotic neutrophils release AnxA1, which then act on macrophages to promote efferocytosis (Scannell et al., 2007). Macrophages treated with GCs also secrete AnxA1, which contributes to the augmented phagocytosis of apoptotic neutrophils (Maderna et al., 2005). Microglial-derived AnxA1 targets apoptotic neurons, serving as both an "eat me" signal and a bridge between phosphatidylserine on the dying cell and FPR2 on the phagocytosing microglia (McArthur et al., 2010). AnxA1 released from apoptotic cells acts through FPR to dampen inflammatory monocyte activation, contributing to immunomodulatory effect of apoptotic cells on inflammation (Pupjalis et al., 2011). In addition, AnxA1 exposure during secondary necrosis provides an important failsafe mechanism counteracting inflammatory responses, even when the timely clearance of apoptotic cells has failed (Blume et al., 2009). The follow-up study of these authors demonstrated that the AnxA1 released peptide and culture supernatants of secondary necrotic-AnxA1-externalizing cells induced chemoattraction of monocytes (Blume et al., 2012). Thus, AnxA1 is conveying the well-known pro-resolution proprieties of apoptotic cells and seems to be part of the apoptotic cell-associated molecular patterns (ACAMPs) that interact with PRRs to convey a switch towards an anti-inflammatory response (Pupjalis et al., 2011). A recent paper using AnxA1 knockout mice has demonstrated that expression of AnxA1 by resident bone marrow macrophages is required for the efficient phagocytosis of apoptotic neutrophils under homeostatic conditions in vivo (Dalli et al., 2012). In the context of neutrophil apoptosis, it has been shown that AnxA1 regulates leukocyte apoptosis not only in vitro (Solito et al., 2003; Parente \& Solito, 2004) but also in vivo under inflammatory settings (Vago et al., 2012). Collectively, we can propose that during ongoing inflammation, endogenous and exogenous AnxA1 can exert exquisite modulation on the fate of recruited neutrophils by promoting their death by apoptosis, as well as their safe removal by phagocytes (efferocytosis), dampens inflammatory mediators and promotes monocyte subendothelial space locomotion. Both apoptosis and efferocytosis have been shown to be modulated by AnxA1 in vivo and are crucial for resolution of inflammation (Vago et al, 2012).

Our group has demonstrated the relevance and dynamics of AnxA1 in driving natural and dexamethasone induced resolution of inflammation by its ability to induce neutrophil apoptosis in vivo (Vago et al., 2012). AnxA1 is up-regulated during natural and drug-induced resolution of acute inflammation, and such increase is associated with increased Bax and caspase- 3 cleavage and appearance of apoptotic neutrophils at the site of inflammation. Neutralization of AnxA1, by use of a specific antiserum or by blocking its receptor, prevented natural and GC-induced resolution. Importantly, use of the AnxA1 peptidomimetic Ac2-26 promoted caspase-dependent resolution of neutrophilic inflammation in the pleural cavity associated with the induction of neutrophil apoptosis. Therefore, this provides strong evidence that AnxA1 is a mediator of natural and GC-induced resolution of inflammation by promoting apoptosis of neutrophils in vivo (Vago et al., 2012). Importantly, AnxA1 cleavage was maximal at times of neutrophil recruitment and treatment of inflamed mice with anti-inflammatory drugs prevented AnxA1 cleavage. This is in accordance with recent data showing that AnxA1 cleavage resistant protein is effective in ameliorating several aspects of inflammation 
(Pederzoli-Ribeil et al., 2010; Patel et al., 2012), reinforcing the idea that AnxA1 cleavage resistant mutant or its peptido-mimetic may represent a powerful anti-inflammatory strategy for the treatment of diseases, in which neutrophil accumulation plays a relevant role.

GILZ was first identified in 1997 in a study which identified GC-induced genes involved with apoptosis (D'Adamio et al., 1997). GILZ has since been shown as a novel GC-induced protein in several cell types which mediates many anti-inflammatory effects of GCs in leukocytes (Ayroldi \& Riccardi, 2009; Beaulieu \& Morand, 2011). GILZ binds and inhibits several main pathways involved in inflammation, including the transcription factors NF- $\kappa \mathrm{B}$ and AP-1 and the mitogen-activated protein kinase (MAPK) pathway. Inhibition of these pathways is believed to be central to the ability of GILZ to inhibit inflammation (Ayroldi \& Riccardi, 2009). In addition, GILZ binds to Ras/Raf and reduces Akt phosphorylation, suggesting that GILZ may also affect the Akt survival pathway (Ayroldi et al., 2001, 2002, 2007).

GILZ has been mostly studied in T cells, where it has been shown to have both pro- and anti-apoptotic properties (D'Adamio et al., 1997; Asselin-Labat et al., 2004; Delfino et al., 2004). The involvement of GILZ in the context of apoptosis has been shown in GILZ transgenic mice, which overexpress GILZ in the T cell lineage. Thymocytes from these mice undergo apoptosis, activate caspase- 8 and down-regulate $\mathrm{Bcl}-\mathrm{xL}$, suggesting that GILZ has a similar effect to GCs. In contrast, GILZ does not induce apoptosis in mature mouse T-cell lymphocytes (Delfino et al., 2004; Ayroldi \& Riccardi, 2009). Inhibition of the PI3K/Akt pathway resulted in up-regulation of GILZ and increased apoptosis of multiple myeloma cells (Grugan et al., 2008). From our in vivo studies using a model of lipopolysaccharide (LPS) induced pleural inflammation, we have found that GILZ expression paralleled spontaneous resolution of inflammation and was associated with neutrophil apoptosis. In addition, there was increased GILZ expression in inflammatory exudates of mice after treatment with anti-inflammatory drugs (Sousa and Teixeira, unpublished observations).

Interestingly, GILZ is a target of the inhibitory effects of AnxA1 (Yang et al., 2009), supporting our findings that the kinetics of GILZ expression is remarkably similar to the kinetics of AnxA1 expression. Strategies that inhibit AnxA1, such as use of a specific antiserum or by blocking its receptor also cause GILZ inhibition (Sousa and Teixeira, unpublished observations), suggesting that GILZ could be an AnxA1 target in vivo. However, at present the mechanism governing AnxA1 regulation of GILZ expression remains unknown. Like AnxA1, GILZ has been shown to mediate several effects of GC, including modulation of T-lymphocyte activation, apoptosis and proliferation, and is up-regulated by IL-10 and TGF- $\beta$ in several cell types (D'Adamio et al., 1997; Ayroldi \& Riccardi, 2009). GILZ appears to have a physiological role in the regulation of inflammation, however there are few reports exploring the role of GILZ in inflammatory diseases (Cannarile et al., 2009; Beaulieu et al., 2010; Srinivasan \& Janardhanam, 2011; Esposito et al., 2012). Cannarile et al (2009) have shown that mice that overexpress GILZ in T-cells are less prone to dinitrobenzene sulfonic acid-induced colitis with reductions in intestinal damage associated with inhibition of nuclear translocation of NF- $\kappa$ B and inhibition of TNF- $\alpha$, IFN- $\alpha$ and IL- 1 production in $\mathrm{CD} 4+\mathrm{T}$ lymphocytes of the lamina propria. Another study showed that endogenous GILZ controls the inflammatory response in a mouse model of collagen induced arthritis, and was able to modulate the expression of pro-inflammatory cytokines. In this study the inhibition of endogenous GILZ by small interfering ribonucleic acid (siRNA) increased the severity of disease with enhanced production of TNF- $\alpha$ and IL-1 $\beta$ (Beaulieu et al., 2010). GILZ over-expression in T lymphocytes inhibited inflammation and tissue damage in spinal cord injury (Esposito et al., 2012), while treatment of mice with a GILZ peptide was beneficial in experimental autoimmune encephalomyelitis (Srinivasan \& Janardhanam, 2011). Taken together, these recent studies suggest that a GILZ-based strategy could be an emerging therapeutic tool to treat inflammatory conditions without the metabolic effects of GCs. Future research with recently generated GILZ deficient mice
(Bruscoli et al., 2012; Suarez et al., 2012) will help shed light on the role of GILZ on resolution of inflammation.

MKP-1 was the first described member of a large family of phosphatases that catalyze removal of phosphate from serine, threonine or tyrosine residues and has been shown as an important negative regulator of inflammatory responses (Clark, 2007). MKP-1 is also known as DUSP-1 since it dephosphorylates and inactivates members of the MAPK family, a key signaling pathway activated by pro-inflammatory agonists. It has been reported that certain anti-inflammatory effects of dexamethasone are partially mediated by MKP-1 (Abraham \& Clark, 2006; Abraham et al., 2006). King et al. (2009) have observed that dexamethasone induces expression of MKP-1 in human bronchial epithelial and pulmonary cells that mirrored reduced TNF $\alpha$-stimulated p38 MAPK phosphorylation, induction of IL-8 expression and NF-kB-dependent transcription. Several studies have appreciated that MKP-1 may interfere with the inflammatory process by targeting MAPK such as c-Jun N-terminal kinase (JNK), p38 and ERK1/2 (Franklin \& Kraft, 1997; Chen et al., 2002; Abraham \& Clark, 2006; Salojin et al., 2006). For instance, Salojin et al. (2006) have reported a pivotal role of MKP-1 in the negative control of innate immune responses in vivo. Specifically MKP-1 $1^{-1-}$ mice were given low-dose LPS challenge and exhibited significantly increased serum TNF- $\alpha$, IL-6, IL-12, monocyte chemotactic protein-1 (MCP-1), IFN- $\gamma$ and IL-10. Furthermore, the absence of MKP-1 increased systemic levels of pro-inflammatory cytokines and enhanced the incidence and severity of autoimmune arthritis. Bone marrow-derived MKP-1 ${ }^{-/-}$ macrophages enhanced constitutive and TLR-induced activation of p38 and ERK1/2 MAPK pathways. Similarly, the disease-modifying anti-rheumatic drug aurothiomalate, which drives anti-inflammatory and anti-erosive actions through increased expression of MKP-1, in turn reduces activation of p38 MAPK and suppresses expression of COX-2, matrix metalloproteinase-3 (MMP-3) and IL-6 (Nieminen et al., 2010). A very recent study showed that knockout of MKP-1 exacerbated colitis in IL-10-deficient mice and proposed a pivotal role of MKP-1 as a negative regulator of mucosal immune responses (Matta et al., 2012). Another role for MKP-1 has been proposed by Perdiguero et al. (2012). They found that the pro- to anti-inflammatory macrophage polarization switch is controlled by the balance of p38 MAPK and MKP-1 during the process of muscle healing. The studies mentioned above do show the correlation between expression of MKP-1, actions of steroids and decrease of inflammation. In agreement we also observed that MKP-1 expression is associated with natural resolution of acute inflammation and decreased phosphorylation of p38 e JNK MAPKs (unpublished). However, it remains to be determined whether MKP-1 does indeed contribute to resolution of inflammation in vivo and whether it is a useful target for the development of pro-resolving therapies.

\subsubsection{Reactive oxygen species (ROS)}

Reactive oxygen species (ROS), including superoxide anion $\left(\mathrm{O}_{2}^{-}\right)$, hydrogen peroxide $\left(\mathrm{H}_{2} \mathrm{O}_{2}\right)$, and hydroxyl radical $(\bullet \mathrm{OH})$ are normally produced during cellular energy production in aerobic cells and are removed by antioxidant enzymes, such as superoxide dismutase (SOD), catalase, glutathione peroxidase (GPx), and peroxiredoxins (Prxs). ROS can be generated either by the mitochondrial electron transport chain or by the NADPH oxidase (NOX) complex in the plasma membrane and cytosol (Forman \& Torres, 2002). Stimulation of ROS was first reported in neutrophils and macrophages and named "the respiratory burst" due to the brief necessity of oxygen. ROS influence many physiological processes including hormone biosynthesis, intracellular signaling and host defense against different pathogens (Bogdan et al., 2000; Dröge, 2002).

Besides the relevance of ROS for an adequate anti-microbial response, ROS may also damage host DNA, lipids, and proteins and therefore lead to cellular injury and death (Prütz, 1996; Shacter, 2000; Niethammer et al. 2009). It has been suggested that ROS may have a role in the development of many inflammatory diseases, including cancer, atherosclerosis, 
arthritis, diabetes and degenerative diseases (Quinlan et al., 1994; Dröge, 2002; Riedl \& Nel, 2008; Phillips et al., 2010).

Several transcription factors and signaling pathways important for pro-inflammatory processes, such as NF-kB, AP-1, MAPKs and PI3K, are activated by ROS (Li et al., 2002; Chen et al., 2004; Carreras \& Poderoso, 2007; Groeger et al., 2009; Lopes et al., 2011). In fact, oxidative stress promotes changes in nuclear histones by acetylation, methylation, and phosphorylation leading to chromatin remodeling, recruitment of basal transcription factors and activation of RNA polymerase II. These, in turn, increase gene expression of pro-inflammatory mediators (Sanlioglu et al., 2001; Forman \& Torres, 2002; Wang et al., 2002). Furthermore, the release of ROS from damaged tissue can form a concentration gradient that directs leukocyte recruitment towards the site of tissue injury, demonstrating that ROS can act as damage-associated molecular patterns (DAMPS) and thus modulate inflammatory responses in tissue (Niethammer et al., 2009). Based on these findings it has been suggested that anti-oxidative agents may be a useful strategy to decrease ROS levels and act as anti-inflammatory therapies (Yasui \& Baba, 2006; Impellizzeri et al., 2011).

Conversely several studies suggest that ROS production may regulate negatively inflammation. For example, Lee et al. (2011) have reported that NOX2-deficient mice spontaneously develop severe arthritis with increased inflammatory cytokines such as TNF- $\alpha$ and IL-1 $\beta$. It was observed that NOX2 deficiency or ROS depletion significantly affected the development of CD11b + myeloid cells and Th17/Treg cells, promoting inflammatory cytokine production and inflammatory arthritis development. In agreement with the latter findings, Deng et al. (2012) have argued that generation of ROS regulated acute lung inflammation. Deficiency of the $\mathrm{p} 47^{\text {phox }}$ component of NADPH oxidase in macrophages was associated with increased inflammation in a model of systemic endotoxin. ROS deficiency was associated with decreased activation of the Akt/GSK3- $\beta$ pathway that resulted in deficiency of IL-10 production. These findings highlight a complex role of ROS in the context of inflammation and suggest that temporal control of ROS production may determine whether ROS act as pro- or anti-inflammatory agents.

Recent studies have also demonstrated a role for ROS in the regulation of leukocyte survival in vitro and in vivo (Kankaanranta et al., 2002; Lee \& Shin, 2009; Lopes et al., 2011; Honda et al., 2012). Neutrophils from patients with SAPHO syndrome (synovitis, acne, pustulosis, hyperostosis and osteitis) have a specific defect in ROS production, indicating that decreased production of these molecules is involved in the development and maintenance of this inflammatory disease (Ferguson et al., 2008). Moreover patients with chronic granulomatous disease, characterized by a genetic defect in superoxide anion production and consequently hydrogen peroxide, have decreased ability to resolve inflammation (Coxon et al., 1996). Interestingly, in patients with Down's syndrome in which the gene for SOD is over-expressed, spontaneous apoptosis as well as that induced by anti-Fas is accelerated making these patients more susceptible to infectious diseases (Yasui et al., 2005). Investigating the molecular mechanisms underlying the involvement of ROS induced leukocyte apoptosis, Honda et al. (2012) have implicated the kinase Btk. Btk-deficient neutrophils had enhanced ROS production after TNF- $\alpha$ or TLR stimulation. This was associated with accelerated human neutrophil apoptosis which was reversed by transduction of wild-type Btk.

Hydrogen peroxide has also been described as an important mediator of cell death, as shown by studies that $\mathrm{H}_{2} \mathrm{O}_{2}$ induced apoptosis in neutrophils (Lopes et al., 2011), eosinophils (Lee \& Shin, 2009), epithelial cells (Hussain et al., 2010), endothelial cells (Fang et al., 2010), human hepatoma cells (Kim et al., 2010) and lymphoma cells (Klamt et al., 2009). Moreover, it has been shown that gp91phox - / - mice, which lack the ability to assemble NADPH oxidase and are therefore incapable of generating ROS, manifest an increased susceptibility to infection and prolonged inflammatory reactions that may result in granulomatous lesions (Pollock et al., 1995; Rajakariar et al., 2009). Similarly, experiments using transgenic mice that have high levels of superoxide dismutase demonstrate reduced number of neutrophils in bronchoalveolar lavage after intratracheal administration of particulate pollutants (Yasui et al., 2005). Although the mechanisms of cell apoptosis induced by $\mathrm{H}_{2} \mathrm{O}_{2}$ are not fully elucidated, Aikawa et al (2010) have demonstrated that $\mathrm{H}_{2} \mathrm{O}_{2}$-induced apoptotic death of Jurkat cells is inhibited by overexpression of human $\mathrm{Bcl}-2$ or by ablation of Bax/Bak, suggesting that $\mathrm{H}_{2} \mathrm{O}_{2}$-induced apoptosis is mediated by the intrinsic apoptotic pathway.

Our group has also investigated the effects of $\mathrm{H}_{2} \mathrm{O}_{2}$ on the resolution of inflammation. Lopes et al. (2011) have shown by both genetic and pharmacological approaches a role for $\mathrm{H}_{2} \mathrm{O}_{2}$ in resolving neutrophilic inflammation in a murine model of antigen-induced arthritis. In this model, challenge with antigen induces neutrophil recruitment which is sustained for 12-24 h prior to subsequent resolution by $48 \mathrm{~h} . \mathrm{H}_{2} \mathrm{O}_{2}$ production peaked at $24 \mathrm{~h}$, prior to induction of resolution. In gp91phox $-/-$ mice the neutrophil recruitment was similar to wild mice. However, there was delayed resolution in gp91phox-/- mice or after administration of catalase to wild-type animal, suggesting that $\mathrm{H}_{2} \mathrm{O}_{2}$ contributes to natural neutrophil clearance (Lopes et al., 2011). Animals which were treated with either low dose $\mathrm{H}_{2} \mathrm{O}_{2}$ or SOD at the peak of the inflammatory process (thereby increasing the local levels of $\mathrm{H}_{2} \mathrm{O}_{2}$ ) had enhanced resolution of inflammation concurrent with an increased number of apoptotic neutrophils and accumulation of the pro-apoptotic protein Bax and activated caspase-3. Importantly, macrophage counts were unaffected, indicating relative specificity for neutrophils. Inhibition of Akt phosphorylation and decreased NF- $\kappa B$ p65 translocation to the nucleus appeared to be the major mechanisms by which $\mathrm{H}_{2} \mathrm{O}_{2}$ affected neutrophil survival in murine antigen-induced arthritis (Lopes et al., 2011). Administration of intravenous immunoglobulin preparations, which are beneficial therapeutic agents in the treatment of autoimmune systemic inflammatory diseases, may also increase the production of intracellular $\mathrm{H}_{2} \mathrm{O}_{2}$ and induce apoptosis of LPS-stimulated neutrophils in vitro (Takeshita et al., 2005). As such pharmacological modulation of $\mathrm{H}_{2} \mathrm{O}_{2}$ production may represent a novel therapeutic target to modulate neutrophilic inflammation.

\subsubsection{COX2-derived cyclopentenone prostaglandins}

Evidence suggests that it may be possible to exploit the antiinflammatory and pro-resolution effects of $\mathrm{PGD}_{2}$ and its cyclopentenone PG (CyPG) metabolites (Ward et al., 2002; Gilroy et al., 2003; Rajakariar et al., 2007; Gilroy, 2010; Surh et al., 2011). Cells can metabolize AA into $\mathrm{PGH}_{2}$ which is further metabolized to thromboxane (TX) $\mathrm{A}_{2}, \mathrm{PGE}_{2}$, $\mathrm{PGD}_{2}, \mathrm{PGF}_{2} \alpha$ and $\mathrm{PGI}_{2}$ depending on the enzymes present in the cell. $\mathrm{PGD}_{2}$, in turn, can be further metabolized to $\mathrm{PGJ}_{2}, \Delta^{12-14} \mathrm{PGJ}_{2}$ and 15-deoxy- $\Delta^{12,14}$ (15d-PGJ $)$ (Straus \& Glass, 2001; Gilroy, 2010). CyPG metabolites may play an important role in both homeostatic and inflammatory processes including inhibition of cell cycle progression, platelet aggregation and cytokine production in immune cells (Straus \& Glass, 2001; Cuzzocrea et al., 2002; Rajakariar et al., 2007). Furthermore, endogenous CyPGs, especially $15 \mathrm{~d}-\mathrm{PGJ}_{2}$, are produced during inflammatory responses and exert potent immunomodulatory and anti-inflammatory effects (Lawrence et al., 2002; Gilroy et al., 2003; Scher \& Pillinger, 2005; Surh et al., 2011). In addition to activating intracellular peroxisome proliferator-activated receptors $\gamma$ (PPAR $\gamma$ ) and inhibiting tumor growth (Ishihara et al., 2004), it has been reported that $15 d-P G J_{2}$ regulates redox-sensitive transcription (Kim \& Surh, 2006) and apoptosis of granulocyte, macrophage and myofibroblast cells (Li et al., 2001; Ward et al., 2002; Castrillo et al., 2003; Gilroy et al., 2003).

PPAR $\gamma$ is a member of a nuclear receptor family which regulates transcription of several adipocyte-specific genes involved in lipid synthesis and storage (Lehrke \& Lazar, 2005). PPAR $\gamma$ also regulates inflammatory signaling pathways with stimulation leading to inhibition of pro-inflammatory cytokine expression, suppression of iNOS and regulation of ROS (Jiang et al., 1998; Ricote et al., 1998; Li et al., 2000; von et al., 2007; Schmidt et al., 2010; Bystrom et al., 2011). Several synthetic PPAR $\gamma$ ligands have been shown to effectively induce inflammatory 
cell apoptosis (Kim et al., 2007; Kang et al., 2008; Zaytseva et al., 2008), with 15d-PGJ 2 being a natural ligand of PPARy (Forman et al., 1995). Despite the involvement of PPAR $\gamma$ in mediating various effects induced by $\mathrm{PGD}_{2}$ metabolites, it has been observed that $\Delta^{12} \mathrm{PGJ}_{2}$ and $15 \mathrm{~d}-\mathrm{PGJ} 2$ can inhibit the activation of NF-KB. Indeed LPS and TNF- $\alpha$ induce $\mathrm{I} \kappa \mathrm{B}-\alpha$ degradation in granulocytes in a PPAR $\gamma$ independent manner (Rossi et al., 2000; Ward et al., 2002). In accordance with this finding, it has been recently described that $15 \mathrm{~d}-\mathrm{PGJ} 2$ induces apoptosis in human non-small cell lung carcinoma (A549 cells) via ROS production with subsequent Akt down-regulation and caspase activation in a PPAR $\gamma$-independent fashion (Wang \& Mak, 2011).

Cuzzocrea et al. (2003) have shown that $15 d-\mathrm{PGJ}_{2}$ treatment is protective in experimental colitis in the rat. Moreover, treatment with 15d-PGJ2 is effective in other in vivo models including adjuvantinduced arthritis, autoimmune encephalomyelitis (Diab et al., 2002) and ischemia/reperfusion kidney injury (Chatterjee et al., 2004). Rajakariar et al. (2007) have also shown that endogenous $15 d-P G J_{2}$ controls the levels of pro- and anti-inflammatory cytokines and subsequent leukocyte accumulation in peritonitis. Furthermore, it was observed that the resolution phase was characterized by macrophage and lymphocyte influx. This is in keeping with previous findings reporting a role for 15d-PGJ2 on induction of macrophage apoptosis, therefore limiting an acute inflammatory episode and preventing development of chronic inflammation (Gilroy et al., 2003). Although some reports describe a detrimental effect of CyPGs on the resolution of the inflammatory response (Matsuoka et al., 2000), most evidence suggests that CyPGs accelerate resolution of the inflammatory phase by preventing cell recruitment and inducing apoptosis (Gilroy et al., 2003; Rajakariar et al., 2007; Napimoga et al., 2008) via both PPAR $\gamma$-dependent and independent mechanisms. Further studies to clarify the exact role of CyPGs metabolites on the inflammatory process are necessary prior to their application as potential pro-resolutive agents.

\subsubsection{Interleukin 10 (IL-10)}

IL-10 belongs to the class II family of $\alpha$-helical cytokines and regulates innate and adaptive immunity (Moore et al., 2001). This cytokine is secreted by several cell types including macrophages, monocytes, dendritic cells, granulocytes, epithelial cells, keratinocytes, mast cells, B lymphocytes and regulatory T cells (Moore et al., 2001; Fontenot et al., 2003; O'Garra et al., 2004; Chung et al., 2007; Saraiva \& O'Garra, 2010). Upon binding of IL-10 to the tetrameric IL-10 receptor (IL-10R), Jak1 and Tyk2 are stimulated which in turn stimulate the transcription factor STAT3 which is responsible for the majority of IL-10 mediated immune responses (Moore et al., 2001; Glocker et al., 2011). Other mechanisms have also been implicated in the biological effects of IL-10 such as inhibition of NFKB, up-regulated expression of the suppressor of cytokine signaling 3 (SOCS3) protein, down-regulation of TLR4 and activation of PI3K (Schottelius et al., 1999; Muzio et al., 2000; Saraiva \& O'Garra, 2010). IL-10 modulates inflammatory mediator production by neutrophils, monocytes, and macrophages, limiting the secretion of pro-inflammatory cytokines such as TNF- $\alpha$, IL-1, IL-6, IL-8 and IL-12. Additionally IL-10 reduces co-stimulatory and MHC class II molecule expression (Cassatella et al., 1993; Voll et al., 1997; Saraiva \& O'Garra, 2010; Zhang et al., 2010a). Besides its actions on innate immunity, IL-10 plays an immune regulatory role on the processing of antigens and differentiation and proliferation of $\mathrm{T}$ cells, and $\mathrm{B}$ cells. Furthermore, it has been reported that IL-10 is a potent stimulator of natural killer (NK) cells and CD8 + cytotoxic T cells (Fiorentino et al., 1991; Saraiva \& O'Garra, 2010; Zhang et al., 2010a).

In vivo studies have confirmed the ability of IL-10 to restrict the inflammatory process in diverse settings including respiratory virus infection, acute myocarditis, endotoxic shock, colitis and ischemia and reperfusion (Fuss et al., 2002; Souza et al., 2004, 2007; Loebbermann et al., 2012; Roffê et al., 2012). Specifically, Souza et al. (2004) have argued that the high levels of IL- 10 found in germ-free mice are correlated to the hyporesponsiveness to inflammatory response since the inhibition of this cytokine is accompanied by an increase of TNF- $\alpha$-production, neutrophil recruitment and reperfusion-induced tissue injury and lethality.

Mice deficient in IL-10 (IL-10-/-) or the IL-10R $\beta$-chain (IL-10rb-/-) develop severe spontaneous enterocolitis (Kühn et al., 1993). Interestingly it has been reported that tumor-associated macrophages (TAM) release high levels of IL-10 (Ley et al., 2012). Moreover, patients with diffuse large B-cell lymphoma have elevated IL-10 levels and JAK/STAT activation suggesting that IL-10 contributes to tumor proliferation and longevity by dampening the inflammatory reaction directed against the tumor (Gupta et al., 2012).

Owing to these anti-inflammatory and immunosuppressive abilities, we investigated whether IL-10 could induce neutrophil apoptosis or regulate efferocytosis. IL-10 did not directly induce neutrophil apoptosis, but inhibited neutrophil survival induced by LPS by modifying ERK signaling. IL-10 did not override the effect of other pro-survival agents, including GM-CSF, dexamethasone, cAMP and TNF- $\alpha$ (Ward et al., 2005). We have also shown that IL-10 markedly increased the ability of macrophages to phagocytose apoptotic cells (Michlewska et al., 2009), with phagocytosis in turn leading to greater release of IL-10.

Taken together, these findings suggest that the IL-10 (produced either by phagocytes from the engulfment of apoptotic cell or other sources) may contribute to the resolution of the inflammatory process by prevention of longevity induced by bacterial products, decreased pro-inflammatory and increased anti-inflammatory cytokine production and enhanced macrophage ability to phagocytose apoptotic cells. However, formal demonstration of the role of IL-10 in either natural or drug-induced resolution of inflammation is still lacking.

\subsubsection{Melanocortin system}

The melanocortin (MC) peptides, which include adrenocorticotropic hormone (ACTH), $\alpha$-melanocyte-stimulating hormone ( $\alpha$-MSH), $\beta-\mathrm{MSH}$, and $\gamma$-MSH are derived from a larger precursor molecule called the pro-opiomelanocortin (POMC) gene (Catania, 2007). One of the main peptides of the MC system is $\alpha$-MSH which exerts neuro-immunomodulatory effects via activation of the G-protein coupled MC receptors (MCRs). So far, 5 MCRs have been cloned (Wikberg et al., 2000). In vitro, it has been shown that binding of $\alpha$-MSH to MCRs leads to down-regulation of various proinflammatory cytokines, such as IL-1, IL-6, TNF- $\alpha$, IL-2, IFN- $\gamma$, IL-4, and IL-13 (Delgado et al., 1998; Mandrika et al., 2001; Catania, 2007). At the molecular level, $\alpha$-MSH activates cAMP-dependent pathways and may mediate its anti-inflammatory effects by modulation of NF-KB activation (Haycock et al., 1999; Catania et al., 2010).

MC peptides and their receptors have been appreciated as anti-inflammatory agents in many experimental models of acute and chronic inflammation including atopic dermatitis, arthritis, allergic inflammation, inflammatory bowel diseases and ischemia-reperfusion injury (Raap et al., 2003; Getting et al., 2008; Kannengiesser et al., 2008; Leoni et al., 2008; Catania et al., 2010; Patel et al., 2010; Montero-Melendez et al., 2011a; Etori et al., 2012). Evidence shows that ACTH, $\alpha-\mathrm{MSH}$, and other MC agonists can activate MC1 and MC3 on macrophages through cAMP and/or NF-kB-dependent mechanisms to abrogate pro-inflammatory cytokines, chemokines, and NO and enhance anti-inflammatory mediator levels such as IL-10 and HO-1 (revised in Patel et al., 2011).

Getting et al. (2008) investigated the potential of MC peptides in murine models of allergic and non-allergic inflammation. In an allergic model of inflammation, MC peptides inhibited leukocyte accumulation in wild type-mice. The pan-agonist $\alpha$-MSH markedly decreased eosinophil accumulation in mutant MCR1 mice (which receptor is unable to couple to adenylate cyclase and activate cAMP synthesis) but not in MC3R-null mice, suggesting a preferential role for MC3R in mediating the anti-inflammatory effects of $\mathrm{MC}$ in this model. In vitro analysis identified the presence of two receptors (MC1R and MC3R) on alveolar macrophages. Alveolar macrophage incubation with the selective MC3R 
agonist [D-TRP8]-g-MSH and pan-agonist $\alpha$-MSH increased levels of cAMP. Similarly in a model of LPS-induced lung inflammation, MC peptides displayed significant attenuation of neutrophil accumulation and inhibition of TNF- $\alpha$ release, highlighting the beneficial potential of MC peptides in inflammatory lung disorders (Getting et al., 2008). In agreement with these findings, Montero-Melendez et al. (2011b) have reported that a promising analog of $\alpha$-MSH (AP214, which has high binding affinity for MCRs) inhibited cell infiltration and cytokine release in zymosan-induced peritonitis. Furthermore, AP214 augmented the uptake of zymosan particles and human apoptotic neutrophils by wild-type macrophages. In experimental arthritis, AP214 caused significant reductions in clinical score by acting on the endogenous MCR3 receptor. Importantly mice treated with AP214 present increased efferocytosis of human apoptotic neutrophil, showing that this peptide also modulates a key step of resolution response.

AP214 has been tested in other preclinical studies including sepsis-induced acute kidney injury (Doi et al., 2008), ischemiainduced acute kidney injury (Simmons et al., 2010) and endotoxininduced systemic inflammatory response syndrome (Kristensen et al., 2011). Importantly, clinical evidence indicates that AP214 is effective in preventing post-surgical kidney injury being investigated with initial results suggesting good efficacy, safety and tolerability. (www. clinicaltrials.gov). Further development of $\alpha$-MSH-peptide analogs for long term anti-inflammatory treatment may include the development of MCR3 specific agonists. It must be pointed out, however, that the studies described above mainly focus on the anti-inflammatory effects of MC peptides and analogs and further demonstration of their effects in the context of resolution of inflammation needs to be shown.

In Table 2, we summarize the effects of several mediators for their ability to induce resolution of inflammation in vivo or to induce biological effects in vitro thought to be relevant for the resolution process.

\subsection{Receptors implicated in mediating resolution}

\subsubsection{GPR43 and GPR120}

Free fatty acids (FFAs) which bind G-protein-coupled receptors (GPCRs) including GRP119, GPR84, GPR120, GPR40 (FFAR1), GPR43 (FFAR2) and GPR41 elicit several biological effects including adipogenesis, regulation of appetite, release of regulatory peptides and potential anti-inflammatory effects (Hong et al., 2005; Karaki et al., 2006; Gotoh et al., 2007; Maslowski et al., 2009; Sina et al., 2009; Oh et al., 2010; Vinolo et al., 2011a). GPR120 and GPR40 are activated by medium- and long-chain FFAs, and GPR119 is activated by long-chain fatty acids; GPR84 is activated by medium-chain FFAs; GPR43 and GPR41 are activated by short-chain fatty acids (Milligan

Table 2

Selected mediators of inflammation and their known effects on key events associated with inhibition of inflammation or induction of resolution of inflammation.

\begin{tabular}{|c|c|c|c|c|}
\hline Mediator & $\begin{array}{l}\text { Evidence for } \\
\text { anti-inflammatory } \\
\text { effects in vivo }\end{array}$ & $\begin{array}{l}\text { Evidence for } \\
\text { pro-resolution } \\
\text { effects in vivo }\end{array}$ & $\begin{array}{l}\text { Evidence for } \\
\text { induction of } \\
\text { granulocyte } \\
\text { apoptosis } \\
\text { in vitro }\end{array}$ & $\begin{array}{l}\text { Evidence for } \\
\text { induction of } \\
\text { phagocytosis } \\
\text { in vitro }\end{array}$ \\
\hline LXs and ATLs & Yes & Yes & Yes & Yes \\
\hline Rvs & Yes & Yes & No & Yes \\
\hline Protectins & Yes & Yes & Yes & Yes \\
\hline Maresin & Yes & Yes & No & Yes \\
\hline AnxA1 & Yes & Yes & Yes & Yes \\
\hline GILZ & Yes & No & No & No \\
\hline MKP-1 & Yes & No & No & No \\
\hline $\mathrm{H}_{2} \mathrm{O}_{2}$ & No & Yes & Yes & Yes \\
\hline $\begin{array}{l}\text { PGD2 and } \\
15 \mathrm{~d}-\mathrm{PGJ}_{2}\end{array}$ & Yes & Yes & Yes & No \\
\hline IL-10 & Yes & No & No & Yes \\
\hline$\alpha-\mathrm{MSH}$ & Yes & Yes & No & Yes \\
\hline
\end{tabular}

et al., 2006). GPR43 and GPR120 (Brown et al., 2003; Le Poul et al., 2003) have received attention for their potential therapeutic application in the treatment of several inflammatory diseases, including obesity and type 2 diabetes mellitus (Hirasawa et al., 2005; Maslowski et al., 2009; Oh et al., 2010; Cornall et al., 2011; Talukdar et al., 2011). GPR43 is expressed in adipose tissue, gastrointestinal endocrine cells and leukocytes, with particularly high levels on monocytes and neutrophils (Le Poul et al., 2003; Nilsson et al., 2003; Karaki et al., 2006; Maslowski et al., 2009).

Binding of short chain fatty acids (SCFAs), such as acetate, propionate and butyrate or synthetic agonists (e.g. phenylacetamide-1), to GPR43 induces neutrophil chemotaxis in vitro (Vinolo et al., 2011b). SCFAs and phenylacetamide- 1 also promote GPR43-dependent activation of multiple pathways including PKB, protein kinase C, p38, ERK and the transcriptional factor activating transcriptional factor-2 (ATF-2) (Maslowski et al., 2009). In vivo, there have been conflicting reports on the effects of SCFAs and GPR43 on the inflammatory response (Maslowski et al., 2009; Sina et al., 2009). We have previously shown that GPR43 ${ }^{-/-}$mice showed greater unresolved inflammation in models of colitis, arthritis and asthma suggesting that stimulation of GPR43 was necessary for normal resolution of inflammation (Maslowski et al., 2009). Indeed, GPR43-1- mice had increased bronchoalveolar lavage inflammatory cells as well as enhanced levels of eosinophil peroxide in the lung tissue in ovalbumin (OVA)-induced allergic airway inflammation. Moreover, it has been reported that germ-free mice, which are devoid of bacteria and express little or no SCFAs, showed a similar dysregulation of certain inflammatory responses. Specifically, dextran sulfate sodium (DSS)-induced intestinal inflammation in germ-free mice caused enhanced colonic inflammation and the increased intake of fermentable dietary fiber or SCFAs improved clinical parameters, corroborating a body of evidence which has suggested that intestinal microbiota modulates host immune responses and protects against intestinal inflammatory diseases (Mazmanian et al., 2008; Wen et al., 2008). In contrast, Sina et al. (2009) found that GPR43-deficient mice had attenuated cell infiltration and higher mortality in chronic colitis. Death was associated with dissemination of Clostridium spp. It is difficult to reconcile the different findings between the studies of Sina and Malowski, which could be related to the nature of the models used (acute versus chronic colitis). However, it is clear that under certain conditions, GPR43 could be playing a role in limiting the intensity and duration of the inflammatory response. However, formal demonstration of the ability of GPR43 in modulating resolution of inflammation still needs to be shown.

GPR120 is broadly distributed and highly expressed in adipose tissue (Gotoh et al., 2007; Oh et al., 2010), macrophages (Oh et al., 2010), gastrointestinal tract, lung (Hirasawa et al., 2005; Gotoh et al., 2007) and pituitary (Gotoh et al., 2007). GPR120 shares effects with GPR43 being reported as a potent anti-inflammatory and insulin-sensitization mediator (Hirasawa et al., 2005; Maslowski et al., 2009; Oh et al., 2010; Cornall et al., 2011; Talukdar et al., 2011). It has been reported that GPR120 couples to Gq and $\beta$-arrestin 2 elevating intracellular calcium levels and activating the ERK cascade (Hirasawa et al., 2005). Oh et al. (2010) have shown that the stimulation of GPR120 with $\omega-3$ FAs (DHA or EPA) or a GPR120 agonist, GW9508, causes anti-inflammatory effects on RAW264.7 cells and monocytic peritoneal macrophages. For instance, DHA and GW9508 markedly inhibited LPS-induced phosphorylation of JNK and IKKb, IkB degradation, cytokine secretion and inflammatory gene expression. All effects were abolished by siRNA mediated knockdown of GPR120. Importantly GPR120-/- mice become insulin resistant, with hyperinsulinemia and decreased insulin stimulated glucose disposal. Taking the results together, it is suggested that GPR120 mediates potent insulin sensitizing and anti-diabetic effects in vivo by preventing macrophage-induced tissue inflammation. The aforementioned effects of GPR43 and GPR120 on the inflammatory process are encouraging and supportive for further studies to formally demonstrate their capacity to modify the resolution phase of inflammation. 


\subsubsection{ChemR23}

ChemR23 (also called chemokine-like receptor-1) is a GPCR expressed on monocytes/macrophages, immature dendritic cells (DCs), plasmacytoid DCs, NK cells and on chondrocytes (Samson et al., 1998; Parolini et al., 2007; Luangsay et al., 2009; Berg et al., 2010). Its natural agonist, chemerin, binds to ChemR23 at low concentration and acts as a chemoattractant for monocytes/macrophages and immature DCs (Wittamer et al., 2003; Vermi et al., 2005; Luangsay et al., 2009). In addition to chemerin, RvE1 also binds to ChemR23 to regulate inflammation (Arita et al., 2007; Oh et al., 2011). The role of ChemR23 in the context of inflammation has been studied recently in vitro and in vivo suggesting an important role for ChemR23 in mediating inflammation and, potentially, pro-resolution pathways (Cash et al., 2008, 2010; Bondue et al., 2011; Demoor et al., 2011; Iannone \& Lapadula, 2011). For example, Bondue et al (2011) studied the role of chemerin/ ChemR23 in cellular recruitment and resolution of viral-induced pulmonary inflammatory in wild type and ChemR23 knockout mice. ChemR23 $3^{-1-}$ mice displayed higher morbidity and mortality with enhanced respiratory dysfunction, delayed viral clearance and increased neutrophilic infiltration. Chemerin levels increased in bronchoalveolar lavage during viral infection in both groups but they were higher in ChemR23 $3^{-1-}$ mice. Furthermore these mice had impaired recruitment of plasmacytoid DCs and a reduction in type I interferon, key players of anti-viral immunity. However, plasmacytoid DC depletion and adoptive transfer experiments showed that increased morbidity/mortality in ChemR23 $3^{-1-}$ mice was not due to impaired plasmacytoid DC recruitment, but to a more severe inflammatory status involving ChemR23 expressed by non-leukocytic cells. Cash et al (2008) found that the administration of chemerin in zymosan-induced peritoneal inflammation promoted zymosan clearance and apoptotic neutrophil ingestion by macrophages in wild-type but not ChemR23-/- mice, suggesting an important role for chemerin/ChemR23 in promoting efferocytosis. Therefore, Chemerin/ChemR23 interaction seems to preferentially limit inflammation and has effects associated with greater resolution, albeit formal demonstration of the capacity of this ligand to induce resolution in vivo is lacking.

\subsection{Signaling pathways of survival and death}

The inflammatory response is characterized by coordinated activation of various signaling pathways that regulate expression of both pro- and anti-inflammatory mediators in resident tissue cells and leukocytes recruited from blood (Lawrence \& Fong, 2010). Granulocytes survive in the circulation for only a few hours but mediators released at the site of inflammation can extend the lifespan of recruited granulocytes. For instance neutrophils may only survive in the circulation for 7-10 h but their longevity is extended by cytokines (e.g. IL-6, IL-8 and GM-CSF), bacterial products (e.g. LPS) and local factors such as oxygen tension (Rossi et al., 2007). Likewise, eosinophil survival is augmented at sites of inflammation by cytokines such as IL-3, IL-5 and GM-CSF (Cara et al., 2000). Several signaling pathways have been implicated in leukocyte survival, including NF-кB, PI3K/Akt and MAPKs. Generally these signaling pathways lead to enhanced levels of pro-survival molecules and diminished level of pro-apoptotic molecules. In Fig. 2, we show an example of the crosstalk between signaling pathways and pro-resolution mediators in vivo. The interaction described between cAMP, $\mathrm{H}_{2} \mathrm{O}_{2}$ and AnxA1 and certain intracellular pathways is derived from our own studies evaluating natural and drug (steroid)-induced resolution in models of acute neutrophilic inflammation in mice. It is unlikely that this figure represents the interaction among various mediators and pathways in more complex models of acute and chronic inflammation, but it serves to describe the interaction of certain effectors in the regulation of resolution of inflammation by apoptosis.

The manipulation of key intracellular pathways could be of potential benefit in the control of inflammatory disease. However, it is noteworthy that these pathways participate in numerous physiological functions and, therefore, potential therapeutic use of blocking survival pathways should be considered with great care in clinical development.

\subsubsection{Nuclear factor kappa $B(N F-\kappa B)$}

$\mathrm{NF}-\kappa \mathrm{B}$ is a transcription factor recognized as a key regulator of innate and adaptive immune responses, cell survival and oncogenesis (Bonizzi

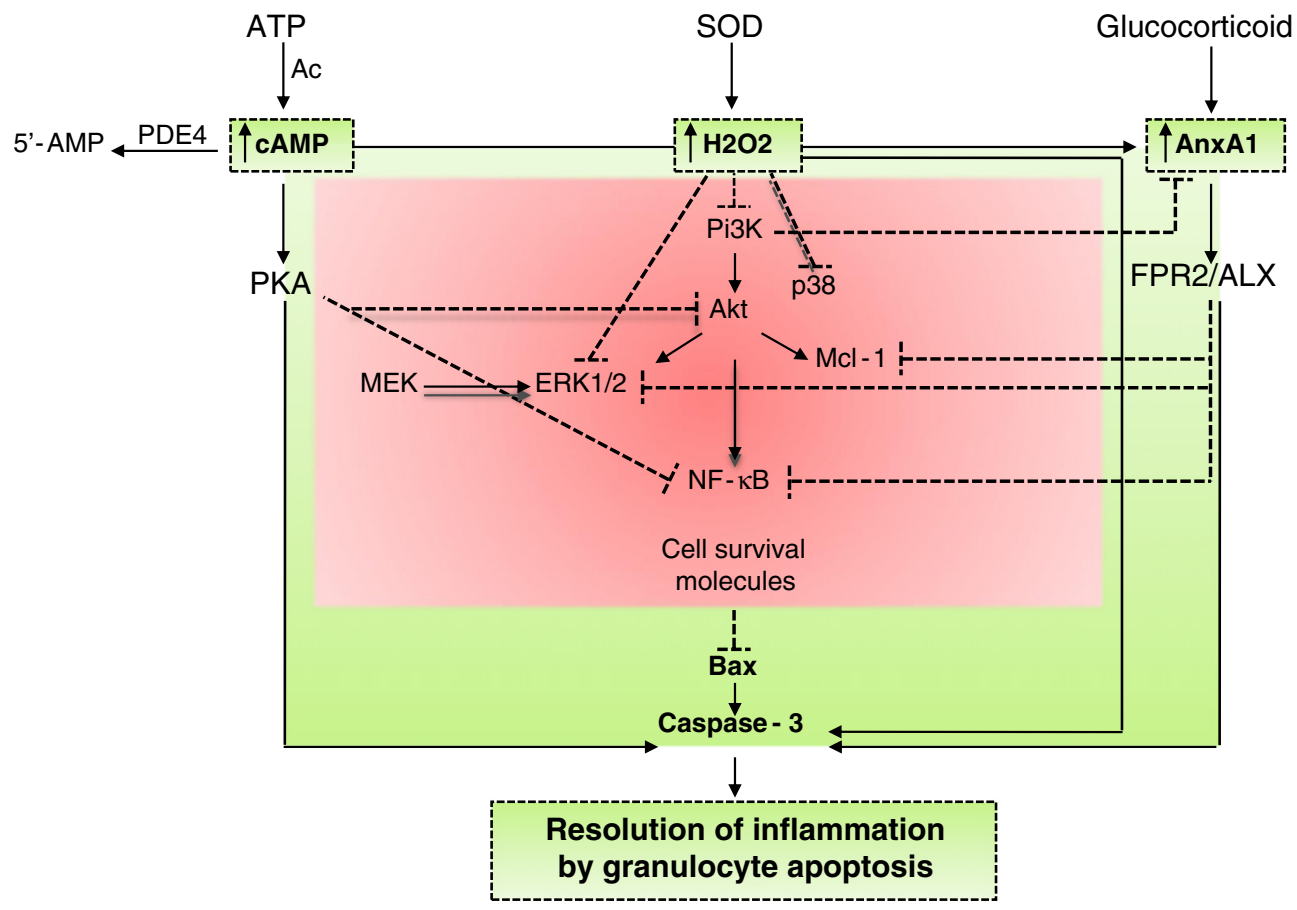

Fig. 2. Crosstalk between signaling pathways and pro-resolution mediators in the regulation of the resolution of inflammation by apoptosis 
\& Karin, 2004; Lawrence \& Fong, 2010). Although NF-кB had initially been thought of as only controlling pro-inflammatory signaling pathways, consistent evidence has now shown that NF- $\kappa \mathrm{B}$ controls genes involved in both the onset as well as the resolution phase of the inflammatory process (Lawrence et al., 2001; Greten et al., 2007; Lawrence \& Fong, 2010). NF- $\kappa$ B activation can drive at least two signaling pathways - canonical and alternative - which enable NF- $\kappa$ B to translocate towards the nucleus. There, it binds to consensus sites in the DNA of responsive genes, activating gene transcription (Bonizzi \& Karin, 2004). The canonical pathway is triggered by microbial products and pro-inflammatory cytokines (e.g. TNF- $\alpha$ and IL-1) and regulated by I $\mathrm{B}$ kinase (IKKß) inducing phosphorylation of I $\kappa$ Bs. Such phosphorylation targets $\mathrm{IkB}$ to proteosomal degradation allowing the release and nuclear translocation of p50/RelA heterodimers (Karin \& Ben-Neriah, 2000). Conversely, the alternative pathway is stimulated by TNF-family cytokines, including lymphotoxin $\beta$ (TNFSF3), CD40 ligand (CD40L and TNFSF5), B cell activating factor (BAFF and TNFSF13B) and receptor activator of NF-kB (RANKL and TNFSF11) (Senftleben et al., 2001; Novack et al., 2003; Bonizzi \& Karin, 2004). The latter pathway is characterized by the requirement of IKK $\alpha$ for activation through phosphorylation followed by proteosomal processing of $\mathrm{p} 100$ (the p52 precursor) and nuclear translocation of p52/RelB heterodimers (Bonizzi \& Karin, 2004). NF- $\kappa B$ activates the transcription of many pro-inflammatory mediators including cytokines (e.g. IL-6, TNF- $\alpha$, IL1- $\beta$ ), chemokines (e.g. CXCL8, MCP-1), enzymes that produce secondary inflammatory mediators (e.g. iNOS, COX-2) and adhesion molecules (e.g. VCAM-1, ICAM-1, E-selectin) contributing to the induction and perpetuation of inflammation (Elewaut et al., 1999; Maeda et al., 2005). As such IKK $\beta$ has been suggested as relevant for the development of new anti-inflammatory therapies (Karin et al., 2004; Lawrence \& Fong, 2010).

Activation of NF- $\kappa \mathrm{B}$ and IKK $\alpha$ influences granulocyte survival and apoptosis, therefore influencing the resolution phase of the inflammatory response (Ward et al., 1999; Lawrence et al., 2001; Fujihara et al., 2002; Ward et al., 2004; Greten et al., 2007; Sousa et al., 2009). NF-kB controls the expression of many intracellular pro-survival proteins, such as $\mathrm{Bcl}-2$ family members (e.g. Bcl-xL, XIAP), which appear relevant for their capacity to enhance survival of inflammatory cells (Ward et al., 2004). Several inhibitors of NF- $\kappa B$ have been developed and tested both in vitro and in vivo. For instance, the fungal metabolite gliotoxin inhibits NF- $\kappa B$ and increases the rate of constitutive apoptosis of human neutrophils and eosinophils (Ward et al., 1999) and increases the apoptotic effects of TNF- $\alpha$ (Ward et al., 1999; Fujihara et al., 2002).

Inhibition of NF-kB in vivo promotes resolution of established neutrophilic and eosinophilic inflammation (Sousa et al., 2009; Lopes et al., 2011). NF-kB inhibition in a mouse model of arthritis was associated with enhanced neutrophil apoptosis and resolution of inflammation (Lopes et al., 2011) while inhibition in a model of allergic pleurisy caused eosinophil apoptosis with consequent resolution of inflammation. However, the use of the NF- $\kappa B$ inhibitors PDTC and $\mathrm{SN}-50$ in a model of LPS-induced pleurisy failed to promote resolution of neutrophil inflammation despite LPS inducing significant NF- $\kappa$ B activation. Furthermore, inhibition of NF- $\kappa B$ in a model of carrageenan-induced neutrophilic inflammation prolonged the inflammatory response and prevented apoptosis (Lawrence et al., 2001). These apparently conflicting results may be explained by the timing of NF- $\kappa$ B inhibition, as RelA/p50 heterodimers are prevalent at the beginning of inflammation to drive pro-inflammatory mediator production and leukocyte recruitment and survival, whereas during times of resolution p50/p50 heterodimers predominate and are responsible for pro-inflammatory mediator suppression and induction of apoptotic genes (Lawrence et al., 2001; Gilroy et al., 2004). Therefore, in vivo manipulation of the NF- $\kappa B$ system likely requires either a timely inhibition or inhibition of specific NF- $\kappa B$ subunits to ensure an anti-inflammatory and pro-resolution outcome.

\subsubsection{PI3K/Akt}

Phosphoinositide 3-kinases (PI3Ks) are a family of lipid kinases that phosphorylate the 3 '-hydroxyl group of phosphatidylinositols (PtdIns) ${ }^{3}$ resulting in the formation of PtdIns(3)P, PtdIns(3,4)P2 and PtdIns(3,4,5)P3, collectively named 3'-PtdIns lipids. PI3Ks are subdivided into three different classes according to their substrate and sequence homology (Vanhaesebroeck \& Waterfield, 1999). PI3K is activated by several stimuli including antigen receptors, cytokine and chemokine receptors leading to the activation of signaling pathways including Ser/Thr kinases, Akt (or PKB), PDK1 and BTk (Toker \& Cantley, 1997; Fruman \& Cantley, 2002; Engelman et al., 2006). PI3Ks and their downstream signaling pathways have a central role in numerous processes including cell metabolism, cell cycle and survival, protein synthesis, cell polarity and motility, vesicle trafficking and immune function (Berwick et al., 2002; Burgering \& Medema, 2003; Nobukuni et al., 2005; Vanhaesebroeck et al., 2012). It has also been demonstrated that PI3K controls fundamental leukocyte functions such as growth, proliferation, recruitment, activation and survival (Sasaki et al., 2000; Yum et al., 2001; Yang et al., 2003; Puri et al., 2004; Pinho et al., 2005; Russo et al., 2011). For example, our group has demonstrated that there is a tissue- and stimulus-dependent role for different isoforms of PI3K in regulating neutrophil migration in vivo in response to different chemoattractants (Pinho et al., 2007). For instance, neutrophil recruitment into the alveolar space or in response to the exogenous administration of C5a or fMLP was dependent upon only PI3K $\gamma$, whereas CXCL1-induced neutrophil recruitment to the pleural cavity induced similar neutrophil influx in PI3K $\gamma$-deficient and wild-type animals.

With regard to the molecular mechanisms behind the ability of PI3K to influence cell survival, studies have indicated that the intracellular pro-apoptotic protein BAD (Bcl-2-associated death promoter) is an important downstream target of PI3K/Akt. Akt phosphorylates $\mathrm{BAD}$, thereby suppressing apoptosis and promoting cell survival (Datta et al., 1997; Song et al., 2005). Moreover, the PI3K/Akt pathway is relevant in mediating the anti-apoptotic and pro-inflammatory signals activated by LPS, GM-CSF and TNF- $\alpha$ in granulocytes (Yang et al., 2003; Cowburn et al., 2004).

Our group has shown that PI3K contributes to the resolution phase of inflammation by influencing granulocyte apoptosis (Pinho et al., 2005; Sousa et al., 2009; Rodrigues et al., 2010). In vivo, using OVA challenge as a model of eosinophilic inflammation (Klein et al., 2002; Alessandri et al., 2003; Pinho et al., 2003), we found that treatment with the PI3K inhibitors wortmannin or LY294002 at the peak of inflammation after the cells had migrated markedly reduced eosinophil numbers, an effect associated with inhibition of Akt phosphorylation and increased eosinophil apoptosis (Pinho et al., 2005; Sousa et al., 2009). Likewise, treatment with dexamethasone $24 \mathrm{~h}$ after antigen challenge of sensitized mice rapidly cleared eosinophils from the pleural cavity (Sousa et al., 2009) a feature already observed in vitro (Liu et al., 1999). Morphologically, apoptotic eosinophils could be observed inside macrophages as early as $6 \mathrm{~h}$ after the administration of dexamethasone. A major caveat of the studies discussed above is that they made use of non-selective PI3K inhibitors and the role of the various family members is yet to be determined.

One study from our group showed that in MOG-induced experimental autoimmune encephalomyelitis, PI3K $\gamma$-deficient animals developed milder clinical disease as well as decreased levels of the chemokines CCL2 and CCL5 in brain tissue (Rodrigues et al., 2010). However neither PI3K $\gamma$-deficiency nor use of the PI3K inhibitor AS-605240 affected leukocyte rolling or adhesion as assessed by intravital microscopy. On the other hand, there was a marked increase in the percentage of leukocytes undergoing apoptosis in PI3K $\gamma$-deficient mice suggesting that the role of PI3K $\gamma$ in this model appeared to be the mediation of leukocyte survival. Further demonstration of this pro-survival role of $\mathrm{PI} 3 \mathrm{~K} \gamma$ in models in vivo is necessary. 


\subsubsection{Cyclic AMP (cAMP)}

cAMP is a ubiquitous second messenger produced after adenylate cyclase activation in response to several stimuli. The two main cAMP effectors are heterodimeric cyclic AMP-dependent protein kinase PKA and EPAC (exchange protein directly activated by cAMP) but there are additional, less well-characterized effector proteins. Once activated by cAMP, PKA acts by causing dissociation of the catalytic subunit C, which phosphorylates several enzymes regulating a variety of cellular process. Cyclic AMP plays an important role in the immune system, usually promoting suppressive effects on the functions of inflammatory cells (Serezani et al., 2008). Intracellular levels of cyclic AMP levels depend on efflux from the cells or are controlled by phosphodiesterases (PDEs) (Soderling \& Beavo, 2000).

PDEs are enzymes that hydrolyze cyclic adenosine and guanosine $3^{\prime}, 5^{\prime}$-monophosphate enzymes (cAMP/cGMP) to their corresponding 5 -mononucleotides 5'-AMP and 5'-GMP, which do not activate cyclic nucleotide-dependent protein kinases. Inhibition of these enzymes enhances cAMP and cGMP levels in the cells (Schudt et al., 2011). There are different families of PDEs with important roles in different cells or tissues. For instance, $\mathrm{PDE}_{4}$ isozyme plays a particularly important role in the immune system and is the predominant PDE in inflammatory cells such as mast cells, eosinophils, neutrophils, T cells and macrophages (Page \& Spina, 2011). It has been well appreciated that selective inhibition of $\mathrm{PDE}_{4}$ has anti-inflammatory properties (Teixeira et al., 1997; Souza et al., 2001; Bopp et al., 2009; Sousa et al., 2009, 2010).

Recently, we described in an allergic pleurisy model that cAMP elevation promoted by administration of a $\mathrm{PDE}_{4}$ inhibitor or by cAMP mimetic drugs at the peak of inflammation induced a significant reduction of eosinophils, without a change in mononuclear cells (Sousa et al., 2009). This reduction of eosinophils was associated with an increase in the number of apoptotic cells in the pleural cavity and correlated to an increased expression of the pro-apoptotic protein Bax. Moreover, we showed that this resolution of eosinophilic inflammation by rolipram, a $\mathrm{PDE}_{4}$ inhibitor, was PKA-dependent and due to inhibition of Akt phosphorylation and NF- KB activation. An important role for cAMP during the resolution process is supported by studies which described that drugs that elevate the intracellular levels of cAMP regulate granulocyte apoptosis in vitro (Rossi et al., 1995; Martin et al., 2001; Parkkonen et al., 2008) and their subsequent recognition and uptake by macrophages (Rossi et al., 1998). Another agent that can elevate cAMP, $\mathrm{PGD}_{2}$, selectively induces caspase-dependent eosinophil apoptosis in a peroxisome-activated receptor- $\gamma$ (PPAR- $\gamma$ )-independent manner (Ward et al., 2002).

By using a model of LPS-induced pleurisy, Sousa et al. (2010) induced neutrophil accumulation by intrapleural administration of LPS and evaluated the effect and mechanisms of $\mathrm{PDE}_{4}$ inhibition and other cAMP-elevating agents or mimetics on the resolution of the neutrophilic inflammation. Treatment with rolipram $4 \mathrm{~h}$ after LPS challenge (when the cell influx was already established but had not peaked yet) dose-dependently reduced the number of neutrophils in the pleural cavity via PKA, the best known cAMP effector. Furthermore, the administration of forskolin (an adenylate cyclase activator) or db-cAMP (a cell-permeable cAMP analog) into the pleural cavity prevented neutrophil accumulation mirrored by an increased number of apoptotic cells in the cavity. Rolipram-induced neutrophil apoptosis was associated with decreased expression of Mcl-1, a key anti-apoptotic protein regulating neutrophil survival, and increased caspase-3 cleavage. Rolipraminduced resolution was caspase-dependent since treatment with the pan-caspase inhibitor zVAD-fmk inhibited inflammatory cell apoptosis and prevented resolution of neutrophil numbers. Since rolipraminduced resolution of neutrophilic inflammation was associated with Akt and NF- $\kappa$ B inhibition, we evaluated these pathways in greater detail using the LPS-induced pleurisy model. The use of a PI3K inhibitor (LY294002) and an Akt inhibitor (Akt inhibitor V) also enhanced apoptosis and promoted neutrophil clearance. Conversely NF-kB inhibitors failed to resolve neutrophil accumulation in our LPS-induced pleurisy model, showing that although rolipram promotes inhibition of NF- $\kappa \mathrm{B}$ activation, this pathway appears not to be critical for rolipram-induced resolution of neutrophilic inflammation (Sousa et al., 2010).

These in vivo findings using LPS-induced pleurisy are in contrast with in vitro studies using neutrophils, which have shown that $\mathrm{PDE}_{4}$ inhibition or an increase of cAMP levels can delay or inhibit spontaneous neutrophil apoptosis (Rossi et al., 1995; Conran et al., 2007; Parkkonen et al., 2008). However, it is noteworthy that these studies used mainly human peripheral blood neutrophils and therefore the complex in vivo inflammatory environment was not replicated. In addition it has also been reported that elevating cAMP induces a switch of the pro-inflammatory macrophages into resolution-phase macrophages (Bystrom et al., 2008) emphasizing that cAMP manipulation in vivo can act on multiple interacting cell types. As such cAMP elevating drugs may be a useful therapeutic strategy to induce resolution of inflammation.

\subsubsection{MAPK (mitogen-activated protein kinase) pathways}

The MAPK family of serine threonine kinases integrates and processes multiple cell surface signals (Kumar et al., 2003; Kaminska, 2005). There are three main groups of distinctly regulated MAP kinase cascades known in humans that lead to differential gene expression: extracellular-signal-regulated kinase ERK1/2, c-Jun N-terminal kinases (JNKs) and p38 MAP kinase (Pearson et al., 2001; Kaminska, 2005). MAPKs phosphorylate and activate transcription factors present in the cytoplasm or nucleus, driving the expression of genes and consequently biological responses (Pearson et al., 2001; Kumar et al., 2003; Saba-El-Leil et al., 2003). Commonly, ERKs are activated by mitogenic and proliferative stimuli, whereas JNKs and p38 MAPKs respond to environmental stress, including UV radiation, heat, osmotic shock and inflammatory cytokines (Stevenson et al., 1994; Lee \& Young, 1996; Pearson et al., 2001). However, in in vivo settings these patterns of activation are not straightforward and these proteins cooperate in response to various stimuli.

There is much evidence demonstrating that MAPKs contribute to the inflammatory process by regulating expression of cytokines, chemokine cell adhesion molecules and recruitment of leukocytes (Suzuki et al., 1999; Kumar et al., 2003; Sawatzky et al., 2006; Junttila et al., 2008). Moreover, it is clear that all MAPK subtypes play a role in modulating granulocyte apoptosis. The relevance of each family member varies according to cell type and experimental condition (Suzuki et al., 2001; Alvarado-Kristensson \& Andersson, 2005; Derouet et al., 2006; reviewed by Junttila et al., 2008). The relevance of MAPKs for the resolution of inflammation in vivo is less well known, making it very difficult to understand the precise relevance of these mediators in vivo and the potential of inhibitors of these enzymes for resolution of inflammation.

In vivo data using carrageenan-induced pleurisy have demonstrated that the ERK1/2 inhibitor PD98059 enhanced resolution of inflammation with reduced numbers of neutrophils and macrophages in the pleural cavity and increased neutrophil apoptosis (Sawatzky et al., 2006). Interestingly, PD98059 does not have a direct effect on constitutive neutrophil apoptosis in non-inflammatory conditions (Ward et al., 2005; Sawatzky et al., 2006), suggesting that its pro-apoptotic effect is a result of inhibition of survival factor-induced anti-apoptotic effects. The pro-resolving effect of endogenous and exogenous anxA1 was associated with ERK inhibition (Vago et al., 2012). Indeed AnxA1 knockout mice showed exacerbated MAPK activation and production of pro-inflammatory cytokines (Yang et al., 2006).

While ERK is best known for its role in the regulation of activation and survival of a plethora of cell types, including granulocytes (Pagès et al., 1993; Geest et al., 2009; Chapman \& Miner, 2011) the exact role of p38 in the control of granulocytes apoptosis/survival is controversial and both pro- and anti-apoptotic effects have been described (Junttila et al., 2008; Langereis et al., 2010; Lin et al., 2011). In the 
context of resolution of inflammation, there is a recent report showing that pro- to anti-inflammatory macrophage polarization switch is controlled by the balance of p38 MAPK and the MAPK phosphatase MKP-1 during muscle healing process (Perdiguero et al., 2012). Precise demonstration of pro-survival roles of p38 in vivo is necessary.

\subsubsection{B-cell lymphoma 2 (Bcl-2) family}

The Bcl-2 family comprises a series of intracellular proteins with a central regulatory role on mitochondrial integrity and caspase activation, thus controlling the intrinsic pathway of apoptosis (Cory \& Adams, 2002). Bcl-2 family members can be either pro-apoptotic or anti-apoptotic and are divided into three distinct groups on the basis of their possession of the four conserved $\mathrm{Bcl}-2$ homology domains (BH1-4). Pro-apoptotic Bcl-2 proteins share homology in either two or three BH domains. This group includes Bax and Bak which themselves induce mitochondrial outer membrane permeabilization (MOMP), causing the release of caspase-activating proteins and other cell death mediators. The pro-apoptotic BH3-only proteins (including Bad, Bid, Bim and Puma) possess homology only in the BH3 region and act to activate Bax and Bak, either directly or binding and down-regulating anti-apoptotic proteins. Finally, the anti-apoptotic group is composed of proteins, such as Bcl-2, Bcl- $\mathrm{X}_{\mathrm{L}}, \mathrm{Mcl}-1$ and $\mathrm{Bcl} 2 \mathrm{~A} 1$, which show sequence homology through $\mathrm{BH} 1$ to $\mathrm{BH} 4$. These members inhibit apoptosis mainly by sequestering $\mathrm{BH} 3$-only proteins and thereby preventing activation of Bax or Bak (Cory \& Adams, 2002).

Owing to their modulatory role in apoptosis, $\mathrm{Bcl}-2$ family proteins are potential therapeutic targets for conditions where cellular apoptosis/survival is dysregulated such as inflammatory diseases (Adams \& Cory, 2007). In fact it has been observed that in sputum of patients with severe asthma, there is increased expression of the anti-apoptotic protein Bcl-2 (Jang et al., 2000; El-Gamal et al., 2004). Moreover, a significant inverse correlation was found between eosinophils that expressed $\mathrm{Bcl}-2$ and peak expiratory flow rate (El-Gamal et al., 2004).

There is a substantial body of evidence supporting the notion that neutrophils and eosinophils express Bcl-2 family proteins and the balance between the expression of the pro-apoptotic and anti-apoptotic members represents a relevant factor determining the lifespan of granulocytes (Simon, 2001; Bianchi et al., 2006). For instance some members of the Bcl-2 family are involved in eosinophil survival. Specifically, increased expression of Bcl-X $\mathrm{X}_{\mathrm{L}}$ (Dibbert et al., 1998), maintained Bid cleavage (Segal et al., 2007), inhibition of Bax translocation to the mitochondria (Dewson et al., 2001), and delayed Bax cleavage (Conus et al., 2005) result in maintained mitochondrial integrity and inhibition of caspase activation (Dewson et al., 2001; Conus et al., 2005). Likewise, neutrophils express anti-apoptotic members (Bcl- $\mathrm{X}_{\mathrm{L}}, \mathrm{Bcl} 2 \mathrm{~A} 1$ and Mcl-1) as well as pro-apoptotic proteins (Bax, Bak, Bid, Bim and Puma) and those proteins regulate constitutive as well as inducible apoptosis/survival pathways (Weinmann et al., 1999; Moulding et al., 2001; Guo et al., 2006; Cowburn et al., 2011).

Experiments in vivo using carrageenan induced pleurisy demonstrated that inflammatory cells from the onset of the inflammatory express $\mathrm{Bcl}-\mathrm{X}_{\mathrm{L}}$ and defective levels of Bax. However, during resolution the profile is inverted with increased expression of Bax and low levels of $\mathrm{Bcl}-\mathrm{X}_{\mathrm{L}}$. Furthermore the Bax inhibitor (peptide V5) given at the peak of inflammation enhanced the number of macrophages/monocytes and neutrophils in the pleural cavity associated with a decrease in the amount of neutrophil apoptosis preventing resolution (Sawatzky et al., 2006). In agreement with the ability of Bax to accelerate inflammation resolution by shifting the balance towards a pro-apoptotic direction, our group has shown that strategies which enhance resolution of inflammation - i.e. treatment with rolipram, SOD, dexamethasone, wortmannin and AnxA1 peptidomimetics - were able to increase Bax expression which was associated with granulocyte apoptosis and resolution of inflammation (Sousa et al., 2009, 2010; Lopes et al., 2011; Vago et al., 2012).
Recently, Iwata et al. (2010) have reported that administration of the anti-apoptotic recombinant human (rh) Bcl-2 or rhBcl-2A1 protein reduced apoptosis and tissue damage in murine models of hind limb and myocardial ischemia-reperfusion injury. Moreover, the same group also evaluated the effect of $\mathrm{rhBcl}-2$ or rhBcl-2A1 on a murine model of sepsis induced by cecal ligation and puncture (CLP) (Iwata et al., 2011). The administration of anti-apoptotic proteins markedly improved animal survival. Protection was accompanied by decreased number of apoptotic cells and reduced cleaved caspase- 3 expression in the intestine and heart. Guo et al (2006) using the same CLP model also showed increased levels of $\mathrm{Bcl}-\mathrm{X}_{\mathrm{L}}$ and decreased expression of Bim in neutrophils isolated from blood of septic animals.

A few studies have highlighted an important role of Mcl-1 on eosinophil and neutrophil survival and apoptosis (Dzhagalov et al., 2007; Sivertson et al., 2007; Duffin et al., 2009; Leitch et al., 2010; Sousa et al., 2010; Milot \& Filep, 2011; Lucas et al., 2012; Vago et al., 2012). In fact the anti-apoptotic protein Mcl-1 plays a major role in controlling the rate at which neutrophils undergo apoptosis. Mcl-1 transcripts are particularly unstable with rapid turnover and a half-life of $\sim 3 \mathrm{~h}$ (Moulding et al., 2001; Edwards et al., 2004). Additionally it has been shown that either Mcl-1 expression or turnover is regulated by several agents such as GM-CSF, TNF- $\alpha$ (Moulding et al., 2001; Derouet et al., 2004), sodium salicylate (Derouet et al., 2006), cAMP and PI3K/Akt (Sousa et al., 2010), cyclin-dependent-kinase inhibitors (CDKi) (Rossi et al., 2006; Duffin et al., 2009; Leitch et al., 2010, 2012) and more recently AnxA1 peptide, Ac2-26 (Vago et al., 2012). Cross et al. (2008) have reported that in human neutrophils, TNF- $\alpha$ at high concentrations was able to increase the rate of Mcl-1 degradation via activation of caspases whereas low concentrations induced anti-apoptotic Bfl-1 expression. These concentration-dependent responses might help explain the discrepant effects of TNF on neutrophil survival/death (Salamone et al., 2001; van den Berg et al., 2001) and understand the complicated scenario in vivo. Another study reported that the opposing effects of dexamethasone on granulocytes relied on the ability of glucocorticoids to stabilize Mcl-1 in neutrophils but not in eosinophils (Sivertson et al., 2007). This might be one of the mechanisms underlying the induction of eosinophil apoptosis by glucocorticoids and its success as a therapy for eosinophil dominant inflammation such as asthma, while explaining the reduced efficacy of glucocorticoids on neutrophil dominant diseases such as chronic obstructive pulmonary disease (COPD). From our findings, we demonstrated that eosinophils and neutrophils underwent apoptosis in vitro following treatment with the CDK inhibitor R-roscovitine preceded by down-regulation of the protein Mcl-1 (discussed below). Additionally we have shown that the proapoptotic effects of rolipram, PI3K inhibitors and Ac2-26 in LPSinduced pleurisy (as discussed) were associated with decreased cellular levels of Mcl-1 suggesting that the down-regulation of this protein contributes to the resolution proprieties of these agents (Sousa et al., 2010; Vago et al., 2012). Importantly, Wardle et al. (2011) have recently shown in vitro that decreased levels of Mcl-1 may be the signal for apoptosis leading to caspase activity in neutrophils. Altogether, the findings mentioned above provide strong evidence for a role of $\mathrm{Bcl}-2$ members in driving inflammatory persistence or resolution of inflammation in vivo, suggesting that these molecules could potentially be pharmacological targets for novel anti-inflammatory therapies.

\subsubsection{Cyclin-dependent-kinases (CDK)}

CDK inhibitor drugs (CDKi) are a class of potential therapeutic agents that have shown much potential as novel anti-inflammatory and pro-resolution drugs (Rossi et al., 2006; Duffin et al., 2009; Koedel et al., 2009; Leitch et al., 2010; Alessandri et al., 2011; Leitch et al., 2012). CDKs are protein kinases that bind to cyclin partners to mediate phosphorylation reactions within cells. CDKs have been associated with transcription, neural functions and apoptosis (Knockaert et al., 2002; Alarcón et al., 2009; Koedel et al., 2009; Lange et al., 2009; Leitch et al., 2009; Menn et al., 2010; Wang et al., 2012). CDKi 
insert into the ATP-binding pocket of CDKs resulting inhibition of CDK activity (Leitch et al., 2009). CDKi are under clinical trials for oesophageal, lung, prostate and non-small-cell lung cancers (Senderowicz, 2003).

Rossi et al. (2006) have established that the CDKi, R-roscovitine, can induce human neutrophil apoptosis in a time-, concentrationand caspase-dependent manner and override delayed neutrophil apoptosis induced by pro-survival factors such as GM-CSF, LPS and GCS (Leitch et al., 2010). Importantly, it was reported that R-roscovitine enhanced the resolution of established neutrophil-dependent inflammation in vivo using several models of inflammation, including carrageenan-induced pleurisy, arthritis and bleomycin-induced lung injury (Rossi et al., 2006). Further investigating the molecular mechanisms associated with the resolution-inducing effects of $\mathrm{CDKi}$, we have demonstrated recently that the phosphorylation of RNA polymerase II (RNA pol II) by CDKs 7 and 9 is inhibited by R-roscovitine and that specific effects on neutrophil transcriptional capacity are responsible for neutrophil apoptosis (Leitch et al., 2012). Specifically, RNA pol II is present in neutrophils and is phosphorylated by CDKs 7 and 9 in order to enhance transcriptional capacity. When neutrophils were incubated with the R-roscovitine there was a significant time-dependent loss of RNApolII phosphorylation suggesting that CDKi down-regulates gene transcription. Moreover, LPS treatment increased neutrophil CDK7 gene transcription and this process was down-regulated by R-roscovitine. Importantly, R-roscovitine drove neutrophil apoptosis by Mcl-1 down-regulation whereas other pro-survival $\mathrm{Bcl}-2$ homologs were unaffected at gene expression level. Confirming the in vitro findings, a CDK7/9 specific pharmacological agent (DRB) and R-roscovitine drove resolution of inflammation in a bleomycin-induced lung injury model. A similar important role for CDK9 has been demonstrated by Wang et al. (2012).

R-roscovitine also drives rapid human eosinophil apoptosis in a caspase-dependent fashion by loss of mitochondrial membrane potential as well as down-regulation of the survival protein Mcl-1 (Duffin et al., 2009; Alessandri et al., 2011; Farahi et al., 2011). AT7519 is another CDKi which has an attractive biological profile including water solubility (Squires et al., 2009; Santo et al., 2010; Squires et al., 2010), which is also currently in clinical trials as an anti-cancer therapy (Mahadevan et al., 2011). Recently, we have shown that AT7519 and $\mathrm{R}$-roscovitine were able to induce apoptosis of human eosinophils in a concentration-dependent manner (Alessandri et al., 2011). However, AT7519 appeared to be roughly 50 times more potent than R-roscovitine. Having shown that AT7519 promoted direct eosinophil apoptosis in vitro we evaluated the ability of this agent to resolve eosinophil-dominant inflammation in vivo. By utilizing a murine model of allergic pleurisy induced by OVA, we have found that systemic administration of AT7519 at the peak of the inflammatory process (24 h) dramatically reduced the number of total leukocytes, eosinophils and mononuclear cells in the pleural cavity at $48 \mathrm{~h}$ after challenge, consistent with enhanced resolution of established eosinophilic inflammation. Moreover, the pro-resolution action of AT7519 was due to its ability to drive eosinophil apoptosis prior to subsequent clearance of apoptotic cells by macrophages, as administration of the caspase inhibitor zVAD-fmk prevented AT7519-induced resolution of inflammation. This highlights the importance of phagocytic clearance of inflammatory cells to the resolution process.

The effect of the CDKi, R-roscovitine, has also been investigated in a zebrafish model of sterile inflammation following tail transection (Loynes et al., 2010). This in vivo model enables the monitoring and tracking of all stages of the inflammatory process at the single organism level. Renshaw et al. (2006) have shown that the natural resolution of inflammation occurring between 6 and $24 \mathrm{~h}$ post tail transection was significantly reduced by treatment with zVD-fmk whereas treatment with R-roscovitine enhanced the resolution. Moreover, Koedel et al (2009) have shown that R-roscovitine, in combination with antibiotic therapy, enhanced resolution of experimental pneumococcal meningitis in mice by promoting neutrophil apoptosis.
Recently, we have reported that CDK inhibition overrides neutrophil survival mediated by a major gram positive bacterial cell wall component, lipoteichoic acid (Tait et al., 2012) and in agreement with our own data (unpublished) it has also been reported that R-Roscovitine-driven neutrophil apoptosis reduces lung inflammation in vivo induced by lipoteichoic acid and Streptococcus pneumoniae (Hoogendijk et al., 2012a) as well as lung damage induced by mechanical ventilation (Hoogendijk et al., 2012b).

Taken together these findings suggest CDK as a promising pharmacological target for treatment of inflammatory conditions. Further studies using novel inhibitors that are more selective will help clarify the mechanisms underlying the effects on transcription activity and apoptosis induction. This knowledge will be useful for the development of more apoptosis-oriented therapeutics and hopefully minimize any deleterious side effects.

\section{Concluding remarks}

Timely resolution of inflammation is essential to maintain tissue health after stimuli that cause tissue dysfunction or damage. Resolution of inflammation is an active process which involves key events including leukocyte apoptosis, recognition and phagocytosis of dying cells (efferocytosis). There are now several studies clearly showing that induction of resolution is possible in vivo and may be useful to control inflammatory responses. Therefore, it is possible that induction of resolution may be used to develop new therapies to treat chronic inflammatory diseases.

Herein, we have reviewed the role of several mediators, receptors and signaling pathways which have been shown to modulate the inflammation in vivo interfering in crucial events for the resolution of inflammation. For many of these mediators and pathways, however, formal demonstration of their role in the resolution of inflammation in vivo is lacking. It is crucial that we are able to differentiate mediators or pathways which are necessary for the resolution process from those necessary for the onset of inflammation. Knowledge of the exact role of these mediators will help in defining the therapeutic potential in blocking or mimicking their activity.

Another important point to be made is that the capacity to induce apoptosis and efferocytosis in vitro will not necessarily translate into capacity to induce resolution in vivo. The in vivo scenario is certainly much more complicated than an isolated cell exposed to high concentrations of mediators without relevant matrices. Conversely, there are several examples of molecules which induce resolution in vivo but not necessarily via direct effects on apoptosis or efferocytosis in vitro. Therefore, there is much need for in vivo experimentation in the field and the forthcoming years will define roles and potential mechanisms of action of molecular pathways in vivo.

Another challenge in this promising and exciting field is to translate the current findings to human clinical trials in order to determine the real usefulness of resolution-based strategies to treat patients over current therapies. Indeed, new avenues have been opened in this area with $\alpha$-MSH analogs and resolvins. $\alpha$-MSH analogs are being evaluated for post-surgical kidney injury after major thoracic surgery and resolvins are being studied in the context of dry eye syndrome (www.clinicaltrial.gov). These interesting studies open new avenues for tests in other pro-resolution scenarios.

Additionally to the aforementioned points and equally important is the belief that an ideal approach to treat chronic inflammatory disease aims to inhibit persistent inflammation and restore tissue function. Current pharmacological strategies are based upon inhibition of endogenous factors that participate in normal physiology and therefore, they may trigger imbalance of the homeostasis and undesirable side effects. For instance, glucocorticoids may induce osteoporosis and NSAIDs can trigger gastric ulceration. As regards to resolution-based therapies, it is potentially concerning whether side effects may include inappropriately early termination of inflammation thus preventing control and 
elimination of the inciting insult. However, as resolution-based strategies mimic the actions of mediators which are crucial for the natural response towards successful termination of inflammation this may help limit side effects. In addition resolution based strategies may also enhance innate immune responses to bacterial infections by enhancing the ability of macrophages to recognize and phagocytose those agents.

Finally, how will molecules which induce resolution of inflammation interact with molecules which prevent induction of inflammation in the clinical setting? Will they potentiate the activity of one another and will this not increase the risk of immunosuppression? Will drugs which induce resolution of inflammation be better used to induce remission of disease followed by drugs which then prevent flares (productive phase)? Is this a valid therapeutic promise? Before all of this is tested, we do need to take into the clinic molecules which are proven to be pro-resolving in vivo in pre-clinical models. The years to come will hopefully see exceptional developments in the field.

\section{Conflict of interest statement}

The authors declare that there are no conflicts of interest.

\section{Acknowledgment}

The authors would like to acknowledge funding from Conselho Nacional de Desenvolvimento Científico e Tecnológico (CNPq, Brazil), Comissão de Aperfeiçoamento de Pessoal do Ensino Superior (CAPES, Brazil), Pró-reitoria de Pesquisa (PRPq/UFMG, Brazil), Fundação do Amparo a Pesquisa de Minas Gerais (FAPEMIG, Brazil) the Instituto Nacional de Ciência e Tecnologia (INCT in Dengue) and the European Community's Seventh Framework Programme [FP7-2007-2013] under grant agreement HEALTH-F4-2011-281608. ALA is currently funded through a Chief Scientist Office (Scotland) awarded research grant: ETM/86. CDL is funded by a Wellcome Trust grant: WT094415. AGR is funded by Medical Research Council grant: G0601481.

\section{References}

Abraham, S. M., \& Clark, A. R. (2006). Dual-specificity phosphatase 1: a critical regulator of innate immune responses. Biochem Soc Trans 34, 1018-1023.

Abraham, S. M., Lawrence, T., Kleiman, A., Warden, P., Medghalchi, M., Tuckermann, J. et al. (2006). Antiinflammatory effects of dexamethasone are partly dependent on induction of dual specificity phosphatase 1.J Exp Med 203, 1883-1889.

Acehan, D., Jiang, X., Morgan, D. G., Heuser, J. E., Wang, X., \& Akey, C. W. (2002) Three-dimensional structure of the apoptosome: implications for assembly, procaspase-9 binding, and activation. Mol Cell 9, 423-432.

Adams, J. M., \& Cory, S. (2007). Bcl-2-regulated apoptosis: mechanism and therapeutic potential. Curr Opin Immunol 19, 488-496.

Aikawa, T., Shinzawa, K., Tanaka, N., \& Tsujimoto, Y. (2010). Noxa is necessary for hydrogen peroxide-induced caspase-dependent cell death. FEBS Lett 584, 681-688.

Alarcón, C., Zaromytidou, A. I., Xi, Q., Gao, S., Yu, J., Fujisawa, S., et al. (2009). Nuclear CDKs drive Smad transcriptional activation and turnover in BMP and TGF-beta pathways. Cell 139, 757-769.

Alessandri, A. L., Duffin, R., Leitch, A. E., Lucas, C. D., Sheldrake, T. A., Dorward, D. A. et al. (2011). Induction of eosinophil apoptosis by the cyclin-dependent kinase inhibitor AT7519 promotes the resolution of eosinophil-dominant allergic inflammation. PLoS One 6, e25683.

Alessandri, A. L., Pinho, V., Souza, D. G., Castro, M. S., Klein, A., \& Teixeira, M. M. (2003) Mechanisms underlying the inhibitory effects of tachykinin receptor antagonists on eosinophil recruitment in an allergic pleurisy model in mice. $\mathrm{Br} J$ Pharmaco $140,847-854$

Alvarado-Kristensson, M., \& Andersson, T. (2005). Protein phosphatase 2A regulates apoptosis in neutrophils by dephosphorylating both p38 MAPK and its substrate caspase 3.J Biol Chem 280, 6238-6244.

Amulic, B., \& Hayes, G. (2011). Neutrophil extracellular traps. Curr Biol 21, R297-R298.

Ariel, A., \& Serhan, C. N. (2012). New lives given by cell death: macrophage differentiation following their encounter with apoptotic leukocytes during the resolution of inflammation. Front Immunol 3, 4.

Arita, M., Ohira, T., Sun, Y. P., Elangovan, S., Chiang, N., \& Serhan, C. N. (2007). Resolvin E1 selectively interacts with leukotriene B4 receptor BLT1 and ChemR23 to regulate inflammation. J Immunol 178, 3912-3917.

Asselin-Labat, M. L., David, M., Biola-Vidamment, A., Lecoeuche, D., Zennaro, M. C., Bertoglio, J., et al. (2004). GILZ, a new target for the transcription factor FoxO3, protects T lymphocytes from interleukin-2 withdrawal induced apoptosis. Blood 104, 215-223.
Ayroldi, E., Migliorati, G., Bruscoli, S., Marchetti, C., Zollo, O., Cannarile, L., et al. (2001). Modulation of T-cell activation by the glucocorticoid-induced leucine zipper factor via inhibition of nuclear factor B. Blood 98, 743-753.

Ayroldi, E., \& Riccardi, C. (2009). Glucocorticoid-induced leucine zipper (GILZ): a new important mediator of glucocorticoid action. FASEB J 23, 3649-3658.

Ayroldi, E., Zollo, O., Bastianelli, A., Marchetti, C., Agostini, M., Di Virgilio, R., et al. (2007). GILZ mediates the antiproliferative activity of glucocorticoids by negative regulation of Ras signaling. J Clin Invest 117, 1605-1615.

Ayroldi, E., Zollo, O., Macchiarulo, A., Di, M. B., Marchetti, C., \& Riccardi, C. (2002). Glucocorticoid-induced leucine zipper inhibits the Raf-extracellular signalregulated kinase pathway by binding to Raf-1. Mol Cell Biol 22, 7929-7941.

Babbin, B. A., Laukoetter, M. G., Nava, P., Koch, S., Lee, W. Y., Capaldo, C. T., et al. (2008). Annexin A1 regulates intestinal mucosal injury, inflammation, and repair. J Immunol $181,5035-5044$.

Baggiolini, M. (1998). Chemokines and leukocyte traffic. Nature 392, 565-568.

Baggiolini, M., \& Loetscher, P. (2000). Chemokines in inflammation and immunity. Immunol Today 21, 418-420.

Bandeira-Melo, C., Bonavita, A. G., Diaz, B. L., Silva, P. M. R., Carvalho, V. F., Jose, P. J., et al. (2005). A novel effect for annexin 1-derived peptide Ac2-26: reduction of allergic inflammation in the rat. J Pharmacol Exp Ther 313, 1416-1422.

Bannenberg, G. L., Chiang, N., Ariel, A., Arita, M., Tjonahen, E., Gotlinger, K. H., et al. (2005). Molecular circuits of resolution: formation and actions of resolvins and protectins. J Immunol 174, 4345-4355.

Beaulieu, E., \& Morand, E. F. (2011). Role of GILZ in immune regulation, glucocorticoid actions and rheumatoid arthritis. Nat Rev Rheumatol 7, 340-348.

Beaulieu, E., Ngo, D., Santos, L., Yang, Y. H., Smith, M., Jorgensen, C., et al. (2010). Glucocorticoid-induced leucine zipper is an endogenous antiinflammatory mediator in arthritis. Arthritis Rheum 62, 2651-2661.

Bellingan, G. J., Caldwell, H., Howie, S. E., Dransfield, I., \& Haslett, C. (1996). In vivo fate of the inflammatory macrophage during the resolution of inflammation: inflammatory macrophages do not die locally, but emigrate to the draining lymph nodes. J Immunol 157, 2577-2585.

Berg, V., Sveinbjornsson, B., Bendiksen, S., Brox, J., Meknas, K., \& Figenschau, Y. (2010). Human articular chondrocytes express ChemR23 and chemerin; ChemR23 promotes inflammatory signalling upon binding the ligand chemerin21-157. Arthritis Res Ther 12, R228.

Berwick, D. C., Hers, I., Heesom, K. J., Moule, S. K., \& Tavares, J. M. (2002). The identification of ATP-citrate lyase as a protein kinase B (Akt) substrate in primary adipocytes. J Biol Chem 277, 33895-33900.

Bianchi, S. M., Dockrell, D. H., Renshaw, S. A., Sabroe, I., \& Whyte, M. K. B. (2006). Granulocyte apoptosis in the pathogenesis and resolution of lung disease. Clin Sci 110, 293-304.

Blume, K. E., Soeroes, S., Keppeler, H., Stevanovic, S., Kretschmer, D., Rautenberg, M., et al. (2012). Cleavage of annexin A1 by ADAM10 during secondary necrosis generates a monocytic "find-me" signal. J Immunol 188, 135-145.

Blume, K. E., Soeroes, S., Waibel, M., Keppeler, H., Wesselborg, S., Herrmann, M., et al. (2009). Cell surface externalization of annexin A1 as a failsafe mechanism preventing inflammatory responses during secondary necrosis. J Immunol 183, 8138-8147.

Bogdan, C., Röllinghoff, M., \& Diefenbach, A. (2000). Reactive oxygen and reactive nitrogen intermediates in innate and specific immunity. Curr Opin Immunol 12, 64-76.

Bondue, B., Vosters, O., de Nadai, P., Glineur, S., De Henau, O., Luangsay, S., et al. (2011). ChemR23 dampens lung inflammation and enhances anti-viral immunity in a mouse model of acute viral pneumonia. PLoS Pathog 7, e1002358.

Bonizzi, G., \& Karin, M. (2004). The two NF-kB activation pathways and their role in innate and adaptive immunity. Trends Immunol 25, 280-288.

Bopp, T., Dehzad, N., Reuter, S., Klein, M., Ullrich, N., Stassen, M., et al. (2009). Inhibition of cAMP degradation improves regulatory T cell-mediated suppression. J Immunol 182, 4017-4024.

Bournazou, I., Mackenzie, K. J., Duffin, R., Rossi, A. G., \& Gregory, C. D. (2009a). Inhibition of eosinophil migration by lactoferrin. Immunol Cell Biol 88, 220-223.

Bournazou, I., Pound, J. D., Duffin, R., Bournazos, S., Melville, L. A., Brown, S. B., et al. (2009b). Apoptotic human cells inhibit migration of granulocytes via release of lactoferrin. J Clin Invest 119, 20-32.

Brinkmann, V., Reichard, U., Goosmann, C., Fauler, B., Uhlemann, Y., Weiss, D. S., et al. (2004). Neutrophil extracellular traps kill bacteria. Science 303, 1532-1535.

Brown, A. J., Goldsworthy, S. M., Barnes, A. A., Eilert, M. M., Tcheang, L., Daniels, D., et al. (2003). The orphan G protein-coupled receptors GPR41 and GPR43 are activated by propionate and other short chain carboxylic acids. J Biol Chem 278, 11312-11319.

Brown, S., Heinisch, I., Ross, E., Shaw, K., Buckley, C. D., \& Savill, J. (2002). Apoptosis disables CD31-mediated cell detachment from phagocytes promoting binding and engulfment. Nature 418, 200-203.

Bruscoli, S., Velardi, E., Di Sante, M. Bereshchenko, O., Venanzi, A., Coppo, M., et al. (2012). Long glucocorticoid-induced leucine zipper (L-GILZ) protein interacts with Ras protein pathway and contributes to spermatogenesis control. J Biol Chem 287, 1242-1251.

Burgering, B. M. T., \& Medema, R. H. (2003). Decisions on life and death: FOXO Forkhead transcription factors are in command when PKB/Akt is off duty. J Leukoc Biol 73, 689-701.

Bystrom, J., Evans, I., Newson, J., Stables, M., Toor, I., van Rooijen, N., et al. (2008). Resolution-phase macrophages possess a unique inflammatory phenotype that is controlled by cAMP. Blood 112, 4117-4127.

Bystrom, J., Wray, J. A., Sugden, M. C., Holness, M. J., Swales, K. E., Warner, T. D., et al. (2011). Endogenous epoxygenases are modulators of monocyte/macrophage activity. PLoS One 6, e26591.

Cannarile, L., Cuzzocrea, S., Santucci, L., Agostini, M., Mazzon, E., \& Esposito, E. (2009). Glucocorticoid-induced leucine zipper is protective in Th1-mediated models of colitis. Gastroenterology 136, 530-541. 
Cara, D. C., Negrao-Correa, D., \& Teixeira, M. M. (2000). Mechanisms underlying eosinophil trafficking and their relevance in vivo. Histol Histopathol 15, 899-920.

Carreras, M. C., \& Poderoso, J. J. (2007). Mitochondrial nitric oxide in the signaling of cell integrated responses. Am J Physiol Cell Physiol 292, C1569-C1580.

Casares, N., Pequignot, M. O., Tesniere, A., Ghiringhelli, F., Roux, S., Chaput, N., et al. (2005). Caspase-dependent immunogenicity of doxorubicin-induced tumor cell death. J Exp Med 202, 1691-1701.

Cash, J. L., Christian, A. R., \& Greaves, D. R. (2010). Chemerin peptides promote phagocytosis in a ChemR23- and Syk-dependent manner. J Immunol 184, 5315-5324.

Cash, J. L., Hart, R., Russ, A., Dixon, J. P. C., Colledge, W. H., Doran, J., et al. (2008). Synthetic chemerin-derived peptides suppress inflammation through ChemR23. J Exp Med 205, 767-775.

Cassatella, M. A., Meda, L., Bonora, S., Ceska, M., \& Constantin, G. (1993). Interleukin 10 (IL-10) inhibits the release of proinflammatory cytokines from human polymorphonuclear leukocytes. Evidence for an autocrine role of tumor necrosis factor and IL- 1 beta in mediating the production of IL- 8 triggered by lipopolysaccharide. J Exp Med 178, 2207-2211.

Castrillo, A., Través, P. G., Martín-Sanz, P., Parkinson, S., Parker, P. J., \& Boscá, L. (2003). Potentiation of protein kinase $C$ zeta activity by 15 -deoxy-delta(12,14)-prostaglandin $\mathrm{J}(2)$ induces an imbalance between mitogen-activated protein kinases and NF-kappa B that promotes apoptosis in macrophages. Mol Cell Biol 23, 1196-1208.

Catania, A. (2007). The melanocortin system in leukocyte biology. J Leukoc Biol 81, 383-392.

Catania, A., Lonati, C., Sordi, A., Carlin, A., Leonardi, P., \& Gatti, S. (2010). The melanocortin system in control of inflammation. Scientific World Journal 10(1840-53), 1840-1853.

Chapman, M. S., \& Miner, J. N. (2011). Novel mitogen-activated protein kinase kinase inhibitors. Expert Opin Investig Drugs 20, 209-220.

Chatterjee, P. K., Patel, N. S. A., Cuzzocrea, S., Brown, P. A. J., Stewart, K. N., Mota-Filipe, H., et al. (2004). The cyclopentenone prostaglandin 15-deoxy-delta(12,14)-prostaglandin J2 ameliorates ischemic acute renal failure. Cardiovasc Res 61, 630-643.

Chen, C. C., Chow, M. P., Huang, W. C., Lin, Y. C., \& Chang, Y. J. (2004). Flavonoids inhibit tumor necrosis factor-alpha-induced up-regulation of intercellular adhesion molecule-1 (ICAM-1) in respiratory epithelial cells through activator protein-1 and nuclear factor-kappaB: structure-activity relationships. Mol Pharmacol 66, 683-693.

Chen, W., Frank, M. E., Jin, W., \& Wahl, S. M. (2001). TGF-beta released by apoptotic T cells contributes to an immunosuppressive milieu. Immunity 14, 715-725.

Chen, P., Li, J., Barnes, J., Kokkonen, G. C., Lee, J. C., \& Liu, Y. (2002). Restraint of proinflammatory cytokine biosynthesis by mitogen-activated protein kinase phosphatase-1 in lipopolysaccharide-stimulated macrophages. J Immunol 169, 6408-6416.

Chiang, N., Arita, M., \& Serhan, C. N. (2005). Anti-inflammatory circuitry: lipoxin, aspirin-triggered lipoxins and their receptor ALX. Prostaglandins Leukot Essent Fatty Acids 73, 163-177.

Cho, Y., Challa, S., Moquin, D., Genga, R., Ray, T. D., Guildford, M., et al. (2009). Phosphorylation-driven assembly of the RIP1-RIP3 complex regulates programmed necrosis and virus-induced inflammation. Cell 137, 1112-1123.

Chung, K. F. (2012). Inflammatory biomarkers in severe asthma. Curr Opin Pulm Med $18,35-41$

Chung, E. Y., Liu, J., Homma, Y., Zhang, Y., Brendolan, A., Saggese, M., et al. (2007). Interleukin-10 expression in macrophages during phagocytosis of apoptotic cells is mediated by homeodomain proteins Pbx1 and Prep-1. Immunity 27, 952-964.

Clark, A. R. (2007). Anti-inflammatory functions of glucocorticoid-induced genes. Mol Cell Endocrinol 275, 79-97.

Clark, A. R., \& Belvisi, M. G. (2012). Maps and legends: the quest for dissociated ligands of the glucocorticoid receptor. Pharmacol Ther 134, 54-67.

Conran, N., Almeida, C. B., Lanaro, C., Ferreira, R. P., Traina, F., Saad, S. T. O., et al. (2007). Inhibition of caspase-dependent spontaneous apoptosis via a cAMP-protein kinase A dependent pathway in neutrophils from sickle cell disease patients. Br J Haematol $139,148-158$

Conte, F. P., Menezes-de-Lima, O., Verri, W. A., Cunha, F. Q., Penido, C., \& Henriques, M. G. (2010). Lipoxin A4 attenuates zymosan-induced arthritis by modulating endothelin-1 and its effects. Br J Pharmacol 161, 911-924.

Conus, S., Bruno, A., \& Simon, H. U. (2005). Leptin is an eosinophil survival factor.J Allergy Clin Immunol 116, 1228-1234.

Cornall, L. M., Mathai, M. L., Hryciw, D. H., \& McAinch, A. J. (2011). Diet-induced obesity up-regulates the abundance of GPR43 and GPR120 in a tissue specific manner. Cell Physiol Biochem 28, 949-958.

Cory, S., \& Adams, J. M. (2002). The Bcl2 family: regulators of the cellular life-or-death switch. Nat Rev Cancer 2, 647-656.

Cotran, R. S., Kumar, V., \& Collins, T. (Eds.). (1999). Robbins Pathologic Basis of Disease (6th ed.). Philadelphia: WB Saunders Co.

Cowburn, A., Deighton, J., Walmsley, S., \& Chilvers, E. (2004). The survival effect of TNF-alpha in human neutrophils is mediated via NF-kappa B-dependent IL-8 release. Eur J Immunol 34, 1733-1743.

Cowburn, A. S., Summers, C., Dunmore, B. J., Farahi, N., Hayhoe, R. P., Print, C. G., et al. (2011). Granulocyte/macrophage colony-stimulating factor causes a paradoxical increase in the BH3-only pro-apoptotic protein Bim in human neutrophils. Am J Respir Cell Mol Biol 44, 879-887.

Coxon, A., Rieu, P., Barkalow, F. J., Askari, S., Sharpe, A. H., von Andrian, U. H., et al. (1996). A novel role for the beta 2 integrin CD11b/CD18 in neutrophil apoptosis: a homeostatic mechanism in inflammation. Immunity 5, 653-666.

Cross, A., Moots, R. J., \& Edwards, S. W. (2008). The dual effects of TNF on neutrophil apoptosis are mediated via differential effects on expression of Mcl-1 and Bfl-1. Blood 111, 878-884.

Cuzzocrea, S., Ianaro, A., Wayman, N. S., Mazzon, E., Pisano, B., Dugo, L., et al. (2003). The cyclopentenone prostaglandin 15-deoxy-delta(12,14)- PGJ2 attenuates the development of colon injury caused by dinitrobenzene sulphonic acid in the rat. Br J Pharmacol 138, 678-688.

Cuzzocrea, S., Wayman, N. S., Mazzon, E., Dugo, L., Di Paola, R., Serraino, I., et al. (2002) The cyclopentenone prostaglandin 15-deoxy-delta(12,14)-prostaglandin J(2) attenuates the development of acute and chronic inflammation. Mol Pharmacol 61, 997-1007.

D'Adamio, F., Zollo, O., Moraca, R., Ayroldi, E., Bruscoli, S., Bartoli, A., et al. (1997). A new dexamethasone-induced gene of the leucine zipper family protects $\mathrm{T}$ lymphocytes from TCR/CD3-activated cell death. Immunity 7, 803-812.

Daigle, I., \& Simon, H. U. (2001). Critical role for caspases 3 and 8 in neutrophil but not eosinophil apoptosis. Int Arch Allergy Immunol 126, 147-156.

Dalli, J., Jones, C. P., Cavalcanti, D. M., Farsky, S. H., Perretti, M., \& Rankin, S. M. (2012). Annexin A1 regulates neutrophil clearance by macrophages in the mouse bone marrow. FASEB J 26, 387-396.

Dartt, D. A., Hodges, R. R., Li, D., Shatos, M. A., Lashkari, K., \& Serhan, C. N. (2011). Conjunctival goblet cell secretion stimulated by leukotrienes is reduced by resolvins $\mathrm{D} 1$ and $\mathrm{E} 1$ to promote resolution of inflammation. J Immunol 186, 4455-4466.

Datta, S. R., Dudek, H., Tao, X., Masters, S., Fu, H., Gotoh, Y., et al. (1997). Akt phosphorylation of BAD couples survival signals to the cell-intrinsic death machinery. Cell 91, 231-241.

Degterev, A., Huang, Z., Boyce, M., Li, Y., Jagtap, P., Mizushima, N., et al. (2005). Chemical inhibitor of nonapoptotic cell death with therapeutic potential for ischemic brain injury. Nat Chem Biol 1, 112-119.

Delfino, D. V., Agostini, M., Spinicelli, S., Vito, P., \& Riccardi, C. (2004). Decrease of Bcl-xL and augmentation of thymocyte apoptosis in GILZ overexpressing transgenic mice. Blood 104, 4134-4141.

Delgado, R., Carlin, A., Airaghi, L., Demitri, M. T., Meda, L., Galimberti, D., et al. (1998). Melanocortin peptides inhibit production of proinflammatory cytokines and nitric oxide by activated microglia. J Leukoc Biol 63, 740-745.

Demoor, T., Bracke, K. R., Dupont, L. L., Plantinga, M., Bondue, B., Roy, M. O., et al (2011). The role of ChemR23 in the induction and resolution of cigarette smoke-induced inflammation. J Immunol 186, 5457-5467.

Deng, J., Wang, X., Qian, F., Vogel, S., Xiao, L., Ranjan, R., et al. (2012). Protective role of reactive oxygen species in endotoxin-induced lung inflammation through modulation of IL-10 expression. J Immunol 188, 5734-5740.

Derouet, M., Thomas, L., Cross, A., Moots, R. J., \& Edwards, S. W. (2004). Granulocyte macrophage colony-stimulating factor signaling and proteasome inhibition delay neutrophil apoptosis by increasing the stability of Mcl-1.J Biol Chem 279, 26915-26921.

Derouet, M., Thomas, L., Moulding, D. A., Akgul, C., Cross, A., Moots, R. J., et al. (2006). Sodium salicylate promotes neutrophil apoptosis by stimulating caspase-dependent turnover of Mcl-1. J Immunol 176, 957-965.

Devitt, A., Moffatt, O. D., Raykundalia, C., Capra, J. D., Simmons, D. L., \& Gregory, C. D. (1998). Human CD14 mediates recognition and phagocytosis of apoptotic cells. Nature 392, 505-509.

Dewson, G., Cohen, G. M., \& Wardlaw, A. J. (2001). Interleukin-5 inhibits translocation of Bax to the mitochondria, cytochrome c release, and activation of caspases in human eosinophils. Blood 98, 2239-2247.

Diab, A., Deng, C., Smith, J. D., Hussain, R. Z., Phanavanh, B., Lovett-Racke, A. E., et al. (2002). Peroxisome proliferator-activated receptor-gamma agonist 15-deoxydelta(12,14)-prostaglandin $\mathrm{J}(2)$ ameliorates experimental autoimmune encephalomyelitis. J Immunol 168, 2508-2515.

Dibbert, B., Daigle, I., Braun, D., Schranz, C., Weber, M., Blaser, K., et al. (1998). Role for $\mathrm{Bcl}-\mathrm{xL}$ in delayed eosinophil apoptosis mediated by granulocyte-macrophage colony-stimulating factor and interleukin-5. Blood 92, 778-783.

Dockrell, D. H., \& Whyte, M. K. B. (2006). Regulation of phagocyte lifespan in the lung during bacterial infection. J Leukoc Biol 79, 904-908.

Doi, K., Hu, X., Yuen, P. S. T., Leelahavanichkul, A., Yasuda, H., Kim, S. M., et al. (2008). AP214, an analogue of alpha-melanocyte-stimulating hormone, ameliorates sepsis-induced acute kidney injury and mortality. Kidney Int 73, 1266-1274.

Donnelly, L. E., \& Barnes, P. J. (2012). Defective phagocytosis in airways disease. Chest $141,1055-1062$

Dröge, W. (2002). Free radicals in the physiological control of cell function. Physiol Rev $82,47-95$.

Duffield, J. S., Hong, S., Vaidya, V. S., Lu, Y., Fredman, G., Serhan, C. N., et al. (2006). Resolvin D series and protectin D1 mitigate acute kidney injury. J Immunol 177, 5902-5911.

Duffin, R., Leitch, A. E., Fox, S., Haslett, C., \& Rossi, A. G. (2010). Targeting granulocyte apoptosis: mechanisms, models, and therapies. Immunol Rev 236, 28-40.

Duffin, R., Leitch, A. E., Sheldrake, T. A., Hallett, J. M., Meyer, C., Fox, S., et al. (2009). The CDK inhibitor, R-roscovitine, promotes eosinophil apoptosis by down-regulation of Mcl-1. FEBS Lett 583, 2540-2546.

Dzhagalov, I., St. John, A., \& He, Y. W. (2007). The antiapoptotic protein Mcl-1 is essential for the survival of neutrophils but not macrophages. Blood 109, 1620-1626.

Edwards, S. W., Derouet, M., Howse, M., \& Moots, R. J. (2004). Regulation of neutrophil apoptosis by Mcl-1. Biochem Soc Trans 32, 489-492.

El Kebir, D., Gjorstrup, P., \& Filep, J. G. (2012). Resolvin E1 promotes phagocytosisinduced neutrophil apoptosis and accelerates resolution of pulmonary inflammation. Proc Natl Acad Sci U S A 109, 14983-14988.

El Kebir, D., József, L., Pan, W., Wang, L., Petasis, N. A., Serhan, C. N., et al. (2009) 15-Epi-lipoxin A4 inhibits myeloperoxidase signaling and enhances resolution of acute lung injury. Am J Respir Crit Care Med 180, 311-319.

Elewaut, D., DiDonato, J. A., Mogg Kim, J., Truong, F., Eckmann, L., \& Kagnoff, M. F. (1999). NF-kappa B is a central regulator of the intestinal epithelial cell innate immune response induced by infection with enteroinvasive bacteria. I Immunol $163,1457-1466$

El-Gamal, Y., Heshmat, N., Mahran, M., \& El-Gabbas, Z. (2004). Expression of the apoptosis inhibitor Bcl-2 in sputum eosinophils from children with acute asthma. Clin Exp Allergy 34, 1701-1706. 
Elliott, M. R., Chekeni, F. B., Trampont, P. C., Lazarowski, E. R., Kadl, A., Walk, S. F., et al. (2009). Nucleotides released by apoptotic cells act as a find-me signal to promote phagocytic clearance. Nature 461, 282-286.

Eltzschig, H. K., \& Eckle, T. (2011). Ischemia and reperfusion from mechanism to translation. Nat Med 17, 1391-1401.

Engelman, J. A., Luo, J., \& Cantley, L. C. (2006). The evolution of phosphatidylinosito 3-kinases as regulators of growth and metabolism. Nat Rev Genet 7, 606-619.

Esposito, E., Bruscoli, S., Mazzon, E., Paterniti, I., Coppo, M., Velardi, E., et al. (2012) Glucocorticoid-induced leucine zipper (GILZ) over-expression in T lymphocytes inhibits inflammation and tissue damage in spinal cord injury. Neurotherapeutics 9, 210-225.

Etori, M., Yonekubo, K., Sato, E., Mizukami, K., Hirahara, K., Karasuyama, H., et al. (2012). Melanocortin receptors 1 and 5 might mediate inhibitory effects of alpha-melanocyte-stimulating hormone on antigen-induced chronic allergic skin inflammation in IgE transgenic mice. J Invest Dermatol 132, 1925-1927.

Fadok, V. A., Bratton, D. L., \& Henson, P. M. (2001a). Phagocyte receptors for apoptotic cells: recognition, uptake, and consequences. J Clin Invest 108, 957-962.

Fadok, V. A., Bratton, D. L., Konowal, A., Freed, P. W., Westcott, J. Y., \& Henson, P. M. (1998a). Macrophages that have ingested apoptotic cells in vitro inhibit proinflammatory cytokine production through autocrine/paracrine mechanisms involving TGF-beta, PGE2, and PAF. J Clin Invest 101, 890-898.

Fadok, V. A., de Cathelineau, A., Daleke, D. L., Henson, P. M., \& Bratton, D. L. (2001b) Loss of phospholipid asymmetry and surface exposure of phosphatidylserine is required for phagocytosis of apoptotic cells by macrophages and fibroblasts. J Biol Chem 276, 1071-1077.

Fadok, V. A., McDonald, P. P., Bratton, D. L., \& Henson, P. M. (1998b). Regulation of macrophage cytokine production by phagocytosis of apoptotic and post-apoptotic cells. Biochem Soc Trans 26, 653-656.

Fang, W. T., Li, H. J., \& Zhou, L. S. (2010). Protective effects of prostaglandin E1 on human umbilical vein endothelial cell injury induced by hydrogen peroxide. Acto Pharmacol Sin 31, 485-492.

Farahi, N., Uller, L., Juss, J. K., Langton, A. J., Cowburn, A. S., Gibson, A., et al. (2011). Effects of the cyclin-dependent kinase inhibitor R-roscovitine on eosinophil survival and clearance. Clin Exp Allergy 41, 673-687.

Feoktistova, M., Geserick, P., Kellert, B., Dimitrova, D., Langlais, C., Hupe, M., et al. (2011) cIAPs block ripoptosome formation, a RIP1/caspase-8 containing intracellular cell death complex differentially regulated by cFLIP isoforms. Mol Cell 43, 449-463.

Ferguson, P. J., Lokuta, M. A., El-Shanti, H. I., Muhle, L., Bing, X., \& Huttenlocher, A. (2008). Neutrophil dysfunction in a family with a SAPHO syndrome-like phenotype. Arthritis Rheum 58, 3264-3269.

Fierro, I. M., Colgan, S. P., Bernasconi, G., Petasis, N. A., Clish, C. B., Arita, M., et al. (2003) Lipoxin A4 and aspirin-triggered 15-epi-lipoxin A4 inhibit human neutrophil migration: comparisons between synthetic 15 epimers in chemotaxis and transmigration with microvessel endothelial cells and epithelial cells. J Immunol 170, 2688-2694.

Fiorentino, D. F., Zlotnik, A., Vieira, P., Mosmann, T. R., Howard, M., Moore, K. W., et al. (1991). IL-10 acts on the antigen-presenting cell to inhibit cytokine production by Th1 cells. J Immunol 146, 3444-3451.

Fontenot, J. D., Gavin, M. A., \& Rudensky, A. Y. (2003). Foxp3 programs the development and function of CD4+CD25 + regulatory T cells. Nat Immunol 4, 330-336.

Forman, B. M., Tontonoz, P., Chen, J., Brun, R. P., Spiegelman, B. M., et al. (1995). 15-Deoxy-delta 12,14-prostaglandin $\mathrm{J} 2$ is a ligand for the adipocyte determination factor PPAR gamma. Cell 83, 803-812.

Forman, H. J., \& Torres, M. (2002). Reactive oxygen species and cell signaling: respiratory burst in macrophage signaling. Am J Respir Crit Care Med 166, S4-S8.

Francois, M., Le Cabec, V., Dupont, M. A., Sansonetti, P. J., \& Maridonneau-Parini, I. (2000). Induction of necrosis in human neutrophils by Shigella flexneri requires type III secretion, IpaB and IpaC invasins, and actin polymerization. Infect Immun 68, 1289-1296.

Franklin, C. C., \& Kraft, A. S. (1997). Conditional expression of the mitogen-activated protein kinase (MAPK) phosphatase MKP-1 preferentially inhibits p38 MAPK and stress-activated protein kinase in U937 cells. J Biol Chem 272, 16917-16923.

Freire-de-Lima, C. G., Xiao, Y. Q., Gardai, S. J., Bratton, D. L., Schiemann, W. P., \& Henson, P. M. (2006). Apoptotic cells, through transforming growth factor-beta, coordinately induce anti-inflammatory and suppress pro-inflammatory eicosanoid and NO synthesis in murine macrophages. J Biol Chem 281, 38376-38384.

Fruman, D. A., \& Cantley, L. C. (2002). Phosphoinositide 3-kinase in immunological systems. Semin Immunol 14, 7-18.

Fujihara, S., Ward, C., Dransfield, I., Hay, R., Uings, I., Hayes, B., et al. (2002). Inhibition of nuclear factorB activation un-masks the ability of TNF-alpha to induce human eosinophil apoptosis. Eur I Immunol 32, 457-466.

Fuss, I. J., Boirivant, M., Lacy, B., \& Strober, W. (2002). The interrelated roles of TGF-alpha and IL-10 in the regulation of experimental colitis. J Immunol 168, 900-908.

Gardai, S. J., Bratton, D. L., Ogden, C. A., \& Henson, P. M. (2006). Recognition ligands on apoptotic cells: a perspective. J Leukoc Biol 79, 896-903.

Gardai, S. J., McPhillips, K. A., Frasch, S. C., Janssen, W. J., Starefeldt, A., Murphy-Ullrich, J. E., et al. (2005). Cell-surface calreticulin initiates clearance of viable or apoptotic cells through trans-activation of LRP on the phagocyte. Cell 123, 321-334.

Geering, B., Gurzeler, U., Federzoni, E., Kaufmann, T., \& Simon, H. U. (2011). A nove TNFR1-triggered apoptosis pathway mediated by class IA PI3Ks in neutrophils. Blood 117, 5953-5962.

Geering, B., \& Simon, H. U. (2011). Peculiarities of cell death mechanisms in neutrophils. Cell Death Differ 18, 1457-1469.

Geest, C. R., Buitenhuis, M., Groot Koerkamp, M. J. A., Holstege, F. C. P., Vellenga, E., et al (2009). Tight control of MEK-ERK activation is essential in regulating proliferation, survival, and cytokine production of $\mathrm{CD} 34+$-derived neutrophil progenitors. Blood 114, 3402-3412.

Getting, S. J., Flower, R. J., \& Perretti, M. (1997). Inhibition of neutrophil and monocyte recruitment by endogenous and exogenous lipocortin 1. Br J Pharmacol 120, 1075-1082.
Getting, S. J., Riffo-Vasquez, Y., Pitchford, S., Kaneva, M., Grieco, P., Page, C. P., et al. (2008). A role for MC3R in modulating lung inflammation. Pulm Pharmacol Ther $21,866-873$.

Giles, K. M., Ross, K., Rossi, A. G., Hotchin, N. A., Haslett, C., \& Dransfield, I. (2001). Glucocorticoid augmentation of macrophage capacity for phagocytosis of apoptotic cells is associated with reduced p130Cas expression, loss of paxillin/pyk2 phosphorylation, and high levels of active Rac. J Immunol 167, 976-986.

Gilroy, D. W. (2010). Eicosanoids and the endogenous control of acute inflammatory resolution. Int J Biochem Cell Biol 42, 524-528.

Gilroy, D. W., Colville-Nash, P. R., McMaster, S., Sawatzky, D. A., Willoughby, D. A., \& Lawrence, T. (2003). Inducible cyclooxygenase-derived 15-deoxy(delta)12-14PGJ2 brings about acute inflammatory resolution in rat pleurisy by inducing neutrophil and macrophage apoptosis. FASEB J 17, 2269-2271.

Gilroy, D. W., Lawrence, T., Perretti, M., \& Rossi, A. G. (2004). Inflammatory resolution: new opportunities for drug discovery. Nat Rev Drug Discov 3, 401-416.

Girkontaite, I., Urbonaviciute, V., Maseda, D., Neubert, K., Herrmann, M., \& Voll, R. E. (2007). Apoptotic cells selectively suppress the Th1 cytokine interferon gamma in stimulated human peripheral blood mononuclear cells and shift the Th1/Th2 balance towards Th2. Autoimmunity 40, 327-330.

Glocker, E. O., Kotlarz, D., Klein, C., Shah, N., \& Grimbacher, B. (2011). IL-10 and IL-10 receptor defects in humans. Ann N Y Acad Sci 1246, 102-107.

Godson, C., Mitchell, S., Harvey, K., Petasis, N. A., Hogg, N., \& Brady, H. R. (2000). Cutting edge: lipoxins rapidly stimulate nonphlogistic phagocytosis of apoptotic neutrophils by monocyte-derived macrophages. J Immunol 164, 1663-1667.

Gorczyca, W., Bruno, S., Darzynkiewicz, R., Gong, J., \& Darzynkiewicz, Z. (1992). DNA strand breaks occurring during apoptosis - their early in situ detection by the terminal deoxynucleotidyl transferase and nick translation assays and prevention by serine protease inhibitors. Int J Oncol 1, 639-648.

Gotoh, C., Hong, Y. H., Iga, T., Hishikawa, D., Suzuki, Y., Song, S., et al. (2007). The regulation of adipogenesis through GPR120. Biochem Biophys Res Commun 354, 591-597.

Gregory, C., \& Pound, J. (2010). Microenvironmental influences of apoptosis in-vivo and in-vitro. Apoptosis 15, 1029-1049.

Gregory, C. D., \& Pound, J. D. (2011). Cell death in the neighbourhood: direct microenvironmental effects of apoptosis in normal and neoplastic tissues.J Pathol 223, 178-195.

Gregory, C. D., Rossi, A. G., Bournazou, I., Zhang, L., \& Willems, J. J. (2011). Leukocyte migratory responses to apoptosis: the attraction and the distraction. Cell Adh Migr 5, 293-297.

Greten, F. R., Arkan, M. C., Bollrath, J., Hsu, L. C., Goode, J., Miething, C., et al. (2007). NF-kappaB is a negative regulator of IL-1beta secretion as revealed by genetic and pharmacological inhibition of IKKbeta. Cell 130, 918-931.

Groeger, G., Quiney, C., \& Cotter, T. G. (2009). Hydrogen peroxide as a cell-survival signaling molecule. Antioxid Redox Signal 11, 2655-2671.

Grugan, K. D., Ma, C., Singhal, S., Krett, N. L., \& Rosen, S. T. (2008). Dual regulation of glucocorticoid-induced leucine zipper (GILZ) by the glucocorticoid receptor and the PI3-kinase/AKT pathways in multiple myeloma. J Steroid Biochem Mol Biol $110,244-254$.

Gude, D. R., Alvarez, S. E., Paugh, S. W., Mitra, P., Yu, J., Griffiths, R., et al. (2008). Apoptosis induces expression of sphingosine kinase 1 to release sphingosine-1-phosphate as a "come-and-get-me" signal. FASEB J 22, 2629-2638.

Guo, R. F., Sun, L., Gao, H., Shi, K. X., Rittirsch, D., Sarma, V. J., et al. (2006). In vivo regulation of neutrophil apoptosis by C5a during sepsis. J Leukoc Biol 80, 1575-1583.

Gupta, M., Han, J. J., Stenson, M., Maurer, M., Wellik, L., Hu, G., et al. (2012). Elevated serum IL-10 levels in diffuse large B-cell lymphoma: a mechanism of aberrant JAK2 activation. Blood 119, 2844-2853.

Hallett, J. M., Leitch, A. E., Riley, N. A., Duffin, R., Haslett, C., \& Rossi, A. G. (2008). Novel pharmacological strategies for driving inflammatory cell apoptosis and enhancing the resolution of inflammation. Trends Pharmacol Sci 29, 250-257.

Han, J., Zhong, C. Q., \& Zhang, D. W. (2011). Programmed necrosis: backup to and competitor with apoptosis in the immune system. Nat Immunol 12, 1143-1149.

Hannon, R., Croxtall, J. D., Getting, S. J., Roviezzo, F., Yona, S., Paul-Clark, M. J., et al. (2002). Aberrant inflammation and resistance to glucocorticoids in Annexin 1-/- mouse. FASEB J 17, 253-255.

Hasturk, H., Kantarci, A., Ohira, T., Arita, M., Ebrahimi, N., Chiang, N., et al. (2005). RvE1 protects from local inflammation and osteoclast-mediated bone destruction in periodontitis. FASEB J 20, 401-403.

Haycock, J. W., Wagner, M., Morandini, R., Ghanem, G., Rennie, I. G., \& Neil, S. (1999). Alpha-melanocyte-stimulating hormone inhibits NF-kappaB activation in human melanocytes and melanoma cells. J Invest Dermatol 113, 560-566.

Hirasawa, A., Tsumaya, K., Awaji, T., Katsuma, S., Adachi, T., Yamada, M., et al. (2005). Free fatty acids regulate gut incretin glucagon-like peptide-1 secretion through GPR120. Nat Med 11, 90-94.

Hirt, U. A., \& Leist, M. (2003). Rapid, noninflammatory and PS-dependent phagocytic clearance of necrotic cells. Cell Death Differ 10, 1156-1164.

Honda, F., Kano, H., Kanegane, H., Nonoyama, S., Kim, E. S., Lee, S. K., et al. (2012). The kinase Btk negatively regulates the production of reactive oxygen species and stimulation-induced apoptosis in human neutrophils. Nat Immunol 13, 369-378.

Hong, Y. H., Nishimura, Y., Hishikawa, D., Tsuzuki, H., Miyahara, H., Gotoh, C., et al. (2005). Acetate and propionate short chain fatty acids stimulate adipogenesis via GPCR43. Endocrinology 146, 5092-5099.

Hoogendijk, A. J., Kuipers, M. T., van der Poll, T., Schultz, M. J., \& Wieland, C. W. (2012a). Cyclin-dependent kinase inhibition reduces lung damage in a mouse model of ventilator-induced lung injury. Shock 38, 375-380.

Hoogendijk, A. J., Roelofs, J. J., Duitman, J., van Lieshout, M. H., Blok, D. C., van der Poll, T. et al. (2012b). R-roscovitine reduces lung inflammation induced by lipoteichoic acid and Streptococcus pneumoniae. Mol Med 18, 1086-1095. 
Horino, K., Nishiura, H., Ohsako, T., Shibuya, Y., Hiraoka, T., Kitamura, N., et al. (1998). A monocyte chemotactic factor, S19 ribosomal protein dimer, in phagocytic clearance of apoptotic cells. Lab Invest 78, 603-617.

Huang, J., Canadien, V., Lam, G. Y., Steinberg, B. E., Dinauer, M. C., Magalhaes, M. A. O., et al. (2009). Activation of antibacterial autophagy by NADPH oxidases. Proc Nat Acad Sci U S A 106, 6226-6231.

Huang, D. C., Hahne, M., Schroeter, M., Frei, K., Fontana, A., Villunger, A., et al. (1999). Activation of Fas by FasL induces apoptosis by a mechanism that cannot be blocked by Bcl-2 or Bcl-x(L). Proc Natl Acad Sci U S A 96, 14871-14876.

Hussain, S., Thomassen, L., Ferecatu, I., Borot, M. C., Andreau, K., Martens, J., et al. (2010). Carbon black and titanium dioxide nanoparticles elicit distinct apoptotic pathways in bronchial epithelial cells. Part Fibre Toxicol 7, 10.

Huynh, M. L., Malcolm, K. C., Kotaru, C., Tilstra, J. A., Westcott, J. Y., Fadok, V. A., et al. (2005). Defective apoptotic cell phagocytosis attenuates prostaglandin E2 and 15-hydroxyeicosatetraenoic acid in severe asthma alveolar macrophages. Am J Respir Crit Care Med 172, 972-979.

Iannone, F., \& Lapadula, G. (2011). Chemerin/ChemR23 pathway: a system beyond chemokines. Arthritis Res Ther 13, 104.

Impellizzeri, D., Esposito, E., Mazzon, E., Paterniti, I., Di Paola, R., Bramanti, P., et al. (2011). Effect of apocynin, a NADPH oxidase inhibitor, on acute lung inflammation. Biochem Pharmacol 81, 636-648.

Ishihara, S., Rumi, M. A., Okuyama, T., \& Kinoshita, Y. (2004). Effect of prostaglandins on the regulation of tumor growth. Curr Med Chem Anticancer Agents 4, 379-387.

Iwata, A., de Claro, R. A., Morgan-Stevenson, V. L., Tupper, J. C., Schwartz, B. R., Liu, L., et al. (2011). Extracellular administration of BCL2 protein reduces apoptosis and improves survival in a murine model of sepsis. PLoS One 6, e14729.

Iwata, A., Morgan-Stevenson, V., Schwartz, B., Liu, L., Tupper, J., Zhu, X., et al. (2010). Extracellular BCL2 proteins are danger-associated molecular patterns that reduce tissue damage in murine models of ischemia-reperfusion injury. PLoS One 5, e9103.

Jang, A. S., Choi, I. S., Lee, S., Seo, J. P., Yang, S. W., \& Park, C. S. (2000). Bcl-2 expression in sputum eosinophils in patients with acute asthma. Thorax 55, 370-374.

Jiang, C., Ting, A. T., \& Seed, B. (1998). PPAR-gamma agonists inhibit production of monocyte inflammatory cytokines. Nature 391, 82-86.

Junttila, M. R., Li, S. P., \& Westermarck, J. (2008). Phosphatase-mediated crosstalk between MAPK signaling pathways in the regulation of cell survival. FASEB J 22, 954-965

Kaminska, B. (2005). MAPK signalling pathways as molecular targets for anti-inflammatory therapy-from molecular mechanisms to therapeutic benefits. Biochim Biophys Acta 1754, 253-262.

Kang, D., Choi, C., Park, J., Kang, S., \& Kim, Y. (2008). Ciglitazone induces caspase-independent apoptosis through down-regulation of XIAP and survivin in human glioma cells. Neurochem Res 33, 551-561.

Kankaanranta, H., Giembycz, M. A., Barnes, P. J., Haddad, E., Saarelainen, S., Zhang, X., et al. (2002). Hydrogen peroxide reverses IL-5 afforded eosinophil survival and promotes constitutive human eosinophil apoptosis. Int Arch Allergy Immunol 127, 73-78.

Kannengiesser, K., Maaser, C., Heidemann, J., Luegering, A., Ross, M., Brzoska, T., et al. (2008). Melanocortin-derived tripeptide KPV has anti-inflammatory potential in murine models of inflammatory bowel disease. Inflamm Bowel Dis 14, 324-331.

Karaki, S. I., Mitsui, R., Hayashi, H., Kato, I., Sugiya, H., Iwanaga, T., et al. (2006). Short-chain fatty acid receptor, GPR43, is expressed by enteroendocrine cells and mucosal mast cells in rat intestine. Cell Tissue Res 324, 353-360.

Karin, M., \& Ben-Neriah, Y. (2000). Phosphorylation meets ubiquitination: the control of NF-kappaB activity. Annu Rev Immunol 18l, 621-663.

Karin, M., Yamamoto, Y., \& Wang, Q. M. (2004). The IKK NF-kappaB system: a treasure trove for drug development. Nat Rev Drug Discov 3, 17-26.

Kim, K. Y., Ahn, J. H., \& Cheon, H. G. (2007). Apoptotic action of peroxisome proliferator-activated receptor-gamma. Activation in human non-small-cell lung cancer is mediated via proline oxidase-induced reactive oxygen species formation. Mol Pharmacol 72, 674-685.

Kim, S. J., Jung, H. J., Hyun, D. H., Park, E. H., Kim, Y. M., \& Lim, C. J. (2010). Glutathione reductase plays an anti-apoptotic role against oxidative stress in human hepatoma cells. Biochimie 92, 927-932.

Kim, E. H., \& Surh, Y. J. (2006). 15-Deoxy-delta12,14-prostaglandin J2 as a potential endogenous regulator of redox-sensitive transcription factors. Biochem Pharmacol 72, 1516-1528.

King, E. M., Holden, N. S., Gong, W., Rider, C. F., \& Newton, R. (2009). Inhibition of NF-kappaB-dependent transcription by MKP-1: transcriptional repression by glucocorticoids occurring via p38 MAPK. J Biol Chem 284, 26803-26815.

Klamt, F., Zdanov, S., Levine, R. L., Pariser, A., Zhang, Y., Zhang, B., et al. (2009). Oxidant-induced apoptosis is mediated by oxidation of the actin-regulatory protein cofilin. Nat Cell Biol 11, 1241-1246.

Klein, A., Pinho, V., Alessandrini, A. L., Shimizu, T., Ishii, S., \& Teixeira, M. M. (2002). Platelet-activating factor drives eotaxin production in an allergic pleurisy in mice. Br J Pharmacol 135, 1213-1218.

Knies, U. E., Behrensdorf, H. A., Mitchell, C. A., Deutsch, U., Risau, W., Drexler, H. C. A., et al. (1998). Regulation of endothelial monocyte-activating polypeptide II release by apoptosis. Proc Natl Acad Sci U S A 95, 12322-12327.

Knockaert, M., Greengard, P., \& Meijer, L. (2002). Pharmacological inhibitors of cyclin-dependent kinases. Trends Pharmacol Sci 23, 417-425.

Kobara, M., Sunagawa, N., Abe, M., Tanaka, N., Toba, H., Hayashi, H., et al. (2008). Apoptotic myocytes generate monocyte chemoattractant protein- 1 and mediate macrophage recruitment. J Appl Physiol 104, 601-609.

Kobayashi, S. D., Braughton, K. R., Palazzolo-Ballance, A. M., Kennedy, A. D., Sampaio, E., Kristosturyan, E., et al. (2010). Rapid neutrophil destruction following phagocytosis of Staphylococcus aureus. J Innate Immun 2, 560-575.
Koedel, U., Frankenberg, T., Kirschnek, S., Obermaier, B., Hacker, H., Paul, R., et al. (2009). Apoptosis is essential for neutrophil functional shutdown and determines tissue damage in experimental pneumococcal meningitis. PLoS Pathog 5, e1000461.

Krammer, P. H. (2000). CD95's deadly mission in the immune system. Nature 407, 789-795.

Krishnamoorthy, S., Recchiuti, A., Chiang, N., Yacoubian, S., Lee, C. H., Yang, R., et al. (2010). Resolvin D1 binds human phagocytes with evidence for proresolving receptors. Proc Natl Acad Sci U S A 107, 1660-1665.

Kristensen, J., Jonassen, T. E., Rehling, M., Tønnesen, E., Sloth, E., Nielsen, S., et al. (2011). The $\alpha$-MSH analogue AP214 attenuates rise in pulmonary pressure and fall in ejection fraction in lipopolysaccharide-induced systemic inflammatory response syndrome in pigs. Clin Physiol Funct Imaging 31, 54-60.

Kroemer, G., Galluzzi, L., Vandenabeele, P., Abrams, J., Alnemri, E. S., Baehrecke, E. H., et al. (2009). Classification of cell death: recommendations of the Nomenclature Committee on Cell Death 2009. Cell Death Differ 16, 3-11.

Kubes, P. (2002). Introduction: the complexities of leukocyte recruitment. Semin Immunol 14, 65-72.

Kühn, R., Löhler, J., Rennick, D., Rajewsky, K., \& Müller, W. (1993). Interleukin-10-deficient mice develop chronic enterocolitis. Cell 75, 263-274.

Kumar, S., Boehm, J., \& Lee, J. C. (2003). p38 MAP kinases: key signalling molecules as therapeutic targets for inflammatory diseases. Nat Rev Drug Discov 2, 717-726.

Lange, C., Huttner, W. B., \& Calegari, F. (2009). Cdk4/CyclinD1 overexpression in neura stem cells shortens G1, delays neurogenesis, and promotes the generation and expansion of basal progenitors. Cell Stem Cell 5, 320-331.

Langereis, J. D., Raaijmakers, H. A., Ulfman, L. H., \& Koenderman, L. (2010). Abrogation of NF-KB signaling in human neutrophils induces neutrophil survival through sustained p38-MAPK activation. J Leukoc Biol 88, 655-664.

Lauber, K., Bohn, E., Kröber, S. M., Xiao, Y. J., Blumenthal, S. G., \& Lindemann, R. K. (2003). Apoptotic cells induce migration of phagocytes via caspase-3-mediated release of a lipid attraction signal. Cell 113, 717-730.

Lawrence, T., \& Fong, C. (2010). The resolution of inflammation: anti-inflammatory roles for NF-B. Int J Biochem Cell Biol 42, 519-523.

Lawrence, T., Gilroy, D. W., Colville-Nash, P. R., \& Willoughby, D. A. (2001). Possible new role for NF-kappaB in the resolution of inflammation. Nat Med 7, 1291-1297.

Lawrence, T., Willoughby, D. A., \& Gilroy, D. W. (2002). Anti-inflammatory lipid mediators and insights into the resolution of inflammation. Nat Rev Immunol 2 787-795.

Le Poul, E., Loison, C., Struyf, S., Springael, J. Y., Lannoy, V., Decobecq, M. E., et al. (2003) Functional characterization of human receptors for short chain fatty acids and their role in polymorphonuclear cell activation. J Biol Chem 278, 25481-25489.

Lee, Y. A., \& Shin, M. H. (2009). Mitochondrial respiration is required for activation of ERK1/2 and caspase-3 in human eosinophils stimulated with hydrogen peroxide. J Investig Allergol Clin Immunol 19, 188-194.

Lee, K., Won, H. Y., Bae, M. A., Hong, J. H., \& Hwang, E. S. (2011). Spontaneous and aging-dependent development of arthritis in NADPH oxidase 2 deficiency through altered differentiation of CD11b+ and Th/Treg cells. Proc Natl Acad Sci U S A 108, 9548-9553.

Lee, J. C., \& Young, P. R. (1996). Role of CSB/p38/RK stress response kinase in LPS and cytokine signaling mechanisms. J Leukoc Biol 59, 152-157.

Lehrke, M., \& Lazar, M. A. (2005). The many faces of PPARgamma. Cell 123, 993-999.

Leitch, A. E., Haslett, C., \& Rossi, A. G. (2009). Cyclin-dependent kinase inhibitor drugs as potential novel anti-inflammatory and pro-resolution agents. Br J Pharmaco 158, 1004-1016.

Leitch, A. E., Lucas, C. D., Marwick, J. A., Duffin, R., Haslett, C., \& Rossi, A. G. (2012, Jun 29). Cyclin-dependent kinases 7 and 9 specifically regulate neutrophil transcription and their inhibition drives apoptosis to promote resolution of inflammation. Cell Death Differ.

Leitch, A. E., Riley, N. A., Sheldrake, A., Festa, M., Fox, S., Duffin, R., et al. (2010). The cyclin-dependent kinase inhibitor R-roscovitine down-regulates Mcl-1 to override pro-inflammatory signalling and drive neutrophil apoptosis. Eur J Immunol 40, 1127-1138.

Leoni, G., Patel, H. B., Sampaio, A. L. F., Gavins, F. N. E., Murray, J. F., Grieco, P., et al (2008). Inflamed phenotype of the mesenteric microcirculation of melanocortin type 3 receptor-null mice after ischemia-reperfusion. FASEB J 22, 4228-4238.

Levy, B. D., Kohli, P., Gotlinger, K., Haworth, O., Hong, S., Kazani, S., et al. (2007) Protectin D1 is generated in asthma and dampens airway inflammation and hyperresponsiveness. J Immunol 178, 496-502.

Ley, S., Weigert, A., Weichand, B., Henke, N., Mille-Baker, B., Janssen, R. A. J., et al. (2012, Mar 12). The role of TRKA signaling in IL-10 production by apoptotic tumor cell-activated macrophages. Oncogene.

Li, L., Chen, S. F., \& Liu, Y. (2009). MAP kinase phosphatase-1, a critical negative regulator of the innate immune response. Int J Clin Exp Med 2, 48-67.

Li, J. M., Gall, N. P., Grieve, D. J., Chen, M., \& Shah, A. M. (2002). Activation of NADPH oxidase during progression of cardiac hypertrophy to failure. Hypertension 40, 477-484.

Li, N., He, J., Schwartz, C. E., Gjorstrup, P., \& Bazan, H. E. (2010). Resolvin E1 improves tear production and decreases inflammation in a dry eye mouse model. $J$ Ocul Pharmacol Ther 26, 431-439.

Li, M., Pascual, G., \& Glass, C. K. (2000). Peroxisome proliferator-activated receptor gamma-dependent repression of the inducible nitric oxide synthase gene. Mol Cell Biol 20, 4699-4707.

Li, L., Tao, J., Davaille, J., Feral, C., Mallat, A., Rieusset, J., et al. (2001). 15-Deoxy-delta 12,14-prostaglandin J2 induces apoptosis of human hepatic myofibroblasts. A pathway involving oxidative stress independently of peroxisome-proliferator-activated receptors. J Biol Chem 276, 38152-38158.

Lin, W. C., Lin, C. F., Chen, C. L., Chen, C. W., \& Lin, Y. S. (2011). Inhibition of neutrophil apoptosis via sphingolipid signaling in acute lung injury. J Pharmacol Exp Ther 339, 45-53. 
Liu, Y., Cousin, J. M., Hughes, J., Van Damme, J., Seckl, J. R., Haslett, C., et al. (1999). Glucocorticoids promote nonphlogistic phagocytosis of apoptotic leukocytes. J Immunol 162, 3639-3646.

Loebbermann, J., Schnoeller, C., Thornton, H., Durant, L., Sweeney, N. P., Schuijs, M. et al. (2012). IL-10 regulates viral lung immunopathology during acute respiratory syncytial virus infection in mice. PLoS One 7, e32371.

Lopes, F., Coelho, F. M., Costa, V. V., Vieira, L. M., Sousa, L. P., Silva, T. A., et al. (2011) Resolution of neutrophilic inflammation by $\mathrm{H}_{2} \mathrm{O}_{2}$ in antigen-induced arthritis. Arthritis Rheum 63, 2651-2660.

Loynes, C. A., Martin, J. S., Robertson, A., Trushell, D. M. I., Ingham, P. W., Whyte, M. K. B. et al. (2010). Pivotal advance: pharmacological manipulation of inflammation resolution during spontaneously resolving tissue neutrophilia in the zebrafish. J Leukoc Bio 87, 203-212.

Luangsay, S., Wittamer, V., Bondue, B., De Henau, O., Rouger, L., Brait, M., et al. (2009). Mouse ChemR23 is expressed in dendritic cell subsets and macrophages, and mediates an anti-inflammatory activity of chemerin in a lung disease model. $J$ Immunol $183,6489-6499$

Lucas, C. D., Allen, K. C., Dorward, D. A., Hoodless, L. J., Melrose, L. A., Marwick, J. A., et al. (2012, Nov 29). Flavones induce neutrophil apoptosis by down-regulation of Mcl-1 via a proteasomal-dependent pathway. FASEB J (Epub ahead of print).

Maderna, P., \& Godson, C. (2005). Taking insult from injury: lipoxins and lipoxin receptor agonists and phagocytosis of apoptotic cells. Prostaglandins Leukot Essent Fatty Acids 73, 179-187.

Maderna, P., Yona, S., Perretti, M., \& Godson, C. (2005). Modulation of phagocytosis of apoptotic neutrophils by supernatant from dexamethasone-treated macrophages and annexin-derived peptide Ac(2-26). J Immunol 174, 3727-3733.

Maeda, S., Kamata, H., Luo, J. L., Leffert, H., \& Karin, M. (2005). IKKbeta couples hepatocyte death to cytokine-driven compensatory proliferation that promotes chemical hepatocarcinogenesis. Cell 121, 977-990.

Mahadevan, D., Plummer, R., Squires, M. S., Rensvold, D., Kurtin, S., Pretzinger, C., et al. (2011). A phase I pharmacokinetic and pharmacodynamic study of AT7519, a cyclin-dependent kinase inhibitor in patients with refractory solid tumors. Ann Oncol 22, 2137-2143.

Mandhane, S. N., Shah, J. H., \& Thennati, R. (2011). Allergic rhinitis: an update on disease, present treatments and future prospects. Int Immunopharmacol 11, 1646-1662.

Mandrika, I., Muceniece, R., \& Wikberg, J. E. S. (2001). Effects of melanocortin peptides on lipopolysaccharide/interferon-gamma-induced NF-kappaB DNA binding and nitric oxide production in macrophage-like RAW 264.7 cells: evidence for dual mechanisms of action. Biochem Pharmacol 61, 613-621.

Marcheselli, V. L., Hong, S., Lukiw, W. J., Tian, X. H., Gronert, K., Musto, A., et al. (2003). Novel docosanoids inhibit brain ischemia-reperfusion-mediated leukocyte infiltration and pro-inflammatory gene expression. J Biol Chem 278, 43807-43817.

Marques, P. E., Amaral, S. S., Pires, D. A., Nogueira, L. L., Soriani, F. M., Lima, B. H., et al. (2012, Apr 24). Chemokines and mitochondrial products activate neutrophils to amplify organ injury during mouse acute liver failure. Hepatology.

Martin, M. C., Dransfield, I., Haslett, C., \& Rossi, A. G. (2001). Cyclic AMP regulation of neutrophil apoptosis occurs via a novel protein kinase A-independent signaling pathway. J Biol Chem 276, 45041-45050.

Maslowski, K. M., Vieira, A. T., Ng, A., Kranich, J., Sierro, F., Di, Y., et al. (2009). Regulation of inflammatory responses by gut microbiota and chemoattractant receptor GPR43. Nature 461, 1282-1286.

Matsuoka, T., Hirata, M., Tanaka, H., Takahashi, Y., Murata, T., \& Kabashima, K. (2000). Prostaglandin D2 as a mediator of allergic asthma. Science 287, 2013-2017.

Matta, R., Barnard, J. A., Wancket, L. M., Yan, J., Xue, J., Grieves, J., et al. (2012). Knockout of Mkp-1 exacerbates colitis in Il-10-deficient mice. Am J Physiol Gastrointest Liver Physiol 302, G1322-G1335.

Mazmanian, S. K., Round, J. L., \& Kasper, D. L. (2008). A microbial symbiosis factor prevents intestinal inflammatory disease. Nature 453, 620-625.

McArthur, S., Cristante, E., Paterno, M., Christian, H., Roncaroli, F., Gillies, G. E., et al (2010). Annexin A1: a central player in the anti-inflammatory and neuroprotective role of microglia. J Immunol 185(10), 6317-6328.

McDonald, P. P., Fadok, V. A., Bratton, D., \& Henson, P. M. (1999). Transcriptional and translational regulation of inflammatory mediator production by endogenous TGF-beta in macrophages that have ingested apoptotic cells. J Immunol 163, 6164-6172.

McDonald, B., Pittman, K., Menezes, G. B., Hirota, S. A., Slaba, I., Waterhouse, C. C., et al. (2010). Intravascular danger signals guide neutrophils to sites of sterile inflammation. Science 330, 362-366.

McFarland, H. F., \& Martin, R. (2007). Multiple sclerosis: a complicated picture of autoimmunity. Nat Immunol 8, 913-919.

Meagher, L. C., Cousin, J. M., Seckl, J. R., \& Haslett, C. (1996). Opposing effects of glucocorticoids on the rate of apoptosis in neutrophilic and eosinophilic granulocytes. J Immunol 156, 4422-4428.

Medzhitov, R. (2010). Inflammation 2010: new adventures of an old flame. Cell 140 771-776.

Menn, B., Bach, S., Blevins, T. L., Campbell, M., Meijer, L., \& Timsit, S. (2010). Delayed treatment with systemic (S)-roscovitine provides neuroprotection and inhibits in vivo CDK5 activity increase in animal stroke models. PLoS One 5, e12117.

Michlewska, S., Dransfield, I., Megson, I. L., \& Rossi, A. G. (2009). Macrophage phagocytosis of apoptotic neutrophils is critically regulated by the opposing actions of pro-inflammatory and anti-inflammatory agents: key role for TNF-beta. FASEB J $23,844-854$.

Mihalache, C. C., Yousefi, S., Conus, S., Villiger, P. M., Schneider, E. M., \& Simon, H. U. (2011). Inflammation-associated autophagy-related programmed necrotic death of human neutrophils characterized by organelle fusion events. J Immunol 186, 6532-6542.

Milligan, G., Stoddart, L. A., \& Brown, A. J. (2006). G protein-coupled receptors for free fatty acids. Cell Signal 18, 1360-1365.
Milot, E., \& Filep, J. G. (2011). Regulation of neutrophil survival/apoptosis by Mcl-1. Scientific World Journal 11, 1948-1962.

Mitroulis, I., Kambas, K., Chrysanthopoulou, A., Skendros, P., Apostolidou, E., Kourtzelis, I., et al. (2011). Neutrophil extracellular trap formation is associated with IL-1beta and autophagy-related signaling in gout. PLoS One 6, e29318.

Mitroulis, I., Kourtzelis, I., Kambas, K., Rafail, S., Chrysanthopoulou, A., Speletas, M., et al. (2010). Regulation of the autophagic machinery in human neutrophils. Eur J Immunol 40, 1461-1472.

Montero-Melendez, T., Patel, H. B., \& Perretti, M. (2011a). Role of melanocortin receptors in the regulation of gouty inflammation. Curr Rheumatol Rep 13, 138-145.

Montero-Melendez, T., Patel, H. B., Seed, M., Nielsen, S., Jonassen, T. E. N., \& Perretti, M. (2011b). The melanocortin agonist AP214 exerts anti-inflammatory and proresolving properties. Am J Pathol 179, 259-269.

Moore, K. W., de Waal Malefyt, R., Coffman, R. L., \& O'Garra, A. (2001). Interleukin-10 and the interleukin-10 receptor. Annu Rev Immunol 19, 683-765.

Moreau, K., Luo, S., \& Rubinsztein, D. C. (2010). Cytoprotective roles for autophagy. Curr Opin Cell Biol 22, 206-211.

Moulding, D. A., Akgul, C., Derouet, M., White, M. R. H., \& Edwards, S. W. (2001). BCL-2 family expression in human neutrophils during delayed and accelerated apoptosis. J Leukoc Biol 70, 783-792.

Munoz, L. E., Gaipl, U. S., Franz, S., Sheriff, A., Voll, R. E., Kalden, J. R., et al. (2005). SLEa disease of clearance deficiency? Rheumatology 44, 1101-1107.

Muzio, M., Bosisio, D., Polentarutti, N., D'amico, G., Stoppacciaro, A., Mancinelli, R., et al. (2000). Differential expression and regulation of toll-like receptors (TLR) in human leukocytes: selective expression of TLR3 in dendritic cells. J Immunol 164, 5998-6004.

Napimoga, M. H., Vieira, S. M., Dal-Secco, D., Freitas, A., Souto, F. O., Mestriner, F. L., et al. (2008). Peroxisome proliferator-activated receptor-gamma ligand, 15-deoxydelta12,14-prostaglandin J2, reduces neutrophil migration via a nitric oxide pathway. I Immunol 180, 609-617.

Nathan, C. \& Ding, A. (2010). Nonresolving inflammation. Cell 140, 871-882.

Nieminen, R., Korhonen, R., Moilanen, T., Clark, A. R., \& Moilanen, E. (2010). Aurothiomalate inhibits cyclooxygenase 2, matrix metalloproteinase 3 , and interleukin-6 expression in chondrocytes by increasing MAPK phosphatase 1 expression and decreasing p38 phosphorylation: MAPK phosphatase 1 as a novel target for antirheumatic drugs. Arthritis Rheum 62, 1650-1659.

Niethammer, P., Grabher, C., Look, A. T., \& Mitchison, T. J. (2009). A tissue-scale gradient of hydrogen peroxide mediates rapid wound detection in zebrafish. Nature 459, 996-999.

Nilsson, N. E., Kotarsky, K., Owman, C., \& Olde, B. (2003). Identification of a free fatty acid receptor, FFA2R, expressed on leukocytes and activated by short-chain fatty acids. Biochem Biophys Res Commun 303, 1047-1052.

Nobukuni, T., Joaquin, M., Roccio, M., Dann, S. G., Kim, S. Y., Gulati, P., et al. (2005). Amino acids mediate mTOR/raptor signaling through activation of class 3 phosphatidylinositol 30H-kinase. Proc Natl Acad Sci U S A 102, 14238-14243.

Novack, D. V., Yin, L., Hagen-Stapleton, A., Schreiber, R. D., Goeddel, D. V., Ross, F. P., et al. (2003). The IkappaB function of NF-kappaB2 p100 controls stimulated osteoclastogenesis. J Exp Med 198, 771-781.

O'Garra, A., Vieira, P. L., Vieira, P., \& Goldfeld, A. E. (2004). IL-10 producing and naturally occurring CD4+ Tregs: limiting collateral damage. J Clin Invest 114 , 1372-1378.

Oh, S. F., Pillai, P. S., Recchiuti, A., Yang, R., \& Serhan, C. N. (2011). Pro-resolving actions and stereoselective biosynthesis of $18 \mathrm{~S}$ E-series resolvins in human leukocytes and murine inflammation. J Clin Invest 121, 569-581.

Oh, D. Y., Talukdar, S., Bae, E. J., Imamura, T., Morinaga, H., Fan, W., et al. (2010). GPR120 is an omega-3 fatty acid receptor mediating potent anti-inflammatory and insulin-sensitizing effects. Cell 142, 687-698.

Ohira, T., Arita, M., Omori, K., Recchiuti, A., Van Dyke, T. E., \& Serhan, C. N. (2010). Resolvin E1 receptor activation signals phosphorylation and phagocytosis. J Biol Chem 285, 3451-3461.

Page, C. P., \& Spina, D. (2011). Phosphodiesterase inhibitors in the treatment of inflammatory diseases. Handb Exp Pharmacol 204, 391-414.

Pagès, G., Lenormand, P., L'Allemain, G., Chambard, J. C., Meloche, S., \& Pouysségur, J. (1993). Mitogen-activated protein kinases p42mapk and p44mapk are required for fibroblast proliferation. Proc Natl Acad Sci U S A 90, 8319-8323.

Parente, L., \& Solito, E. (2004). Annexin 1: more than an anti-phospholipase protein. Inflamm Res 53, 125-132.

Park, D., Tosello-Trampont, A. C., Elliott, M. R., Lu, M., Haney, L. B., Ma, Z., et al. (2007). BAI1 is an engulfment receptor for apoptotic cells upstream of the ELMO/Dock180/Rac module. Nature 450, 430-434.

Parkkonen, J., Hasala, H., Moilanen, E., Giembycz, M. A., \& Kankaanranta, H. (2008). Phosphodiesterase 4 inhibitors delay human eosinophil and neutrophil apoptosis in the absence and presence of salbutamol. Pulm Pharmacol Ther 21, 499-506.

Parolini, S., Santoro, A., Marcenaro, E., Luini, W., Massardi, L., Facchetti, F., et al. (2007). The role of chemerin in the colocalization of NK and dendritic cell subsets into inflamed tissues. Blood 109, 3625-3632.

Patel, H. B., Bombardieri, M., Sampaio, A. L. F., D'Acquisto, F., Gray, M., Grieco, P., et al. (2010). Anti-inflammatory and antiosteoclastogenesis properties of endogenous melanocortin receptor type 3 in experimental arthritis. FASEB J 24, 4835-4843.

Patel, H. B., Kornerup, K. N., Sampaio, A. L., D'Acquisto, F., Seed, M. P., Girol, A. P., et al. (2012). The impact of endogenous annexin A1 on glucocorticoid control of inflammatory arthritis. Ann Rheum Dis (May 5).

Patel, H. B., Montero-Melendez, T., Greco, K. V., \& Perretti, M. (2011). Melanocortin receptors as novel effectors of macrophage responses in inflammation. Front Immunol 2, 41.

Pearson, G., Robinson, F., Beers Gibson, T., Xu, B., Karandikar, M., Berman, K., et al. (2001). Mitogen-activated protein (MAP) kinase pathways: regulation and physiological functions. Endocr Rev 22, 153-183. 
Pederzoli-Ribeil, M., Maione, F., Cooper, D., Al-Kashi, A., Dalli, J., Perretti, M., et al. (2010). Design and characterization of a cleavage-resistant Annexin A1 mutant to control inflammation in the microvasculature. Blood 116, 4288-4296.

Perdiguero, E., Kharraz, Y., Serrano, A. L., \& Muñoz-Cánoves, P. (2012). MKP-1 coordinates ordered macrophage-phenotype transitions essential for stem cell-dependent tissue repair. Cell Cycle 11, 877-886.

Perretti, M. (2012). Editorial: to resolve or not to resolve: annexin A1 pushes resolution on track. J Leukoc Biol 9, 2245-7224.

Perretti, M., \& D'Acquisto, F. (2009). Annexin A1 and glucocorticoids as effectors of the resolution of inflammation. Nat Rev Immunol 9, 62-70.

Peter, C., Wesselborg, S., Herrmann, M., \& Lauber, K. (2010). Dangerous attraction: phagocyte recruitment and danger signals of apoptotic and necrotic cells. Apoptosis $15,1007-1028$.

Petri, B., Phillipson, M., \& Kubes, P. (2008). The physiology of leukocyte recruitment: an in vivo perspective. J Immunol 180, 6439-6446.

Phillips, D. C., Dias, H. K., Kitas, G. D., \& Griffiths, H. R. (2010). Aberrant reactive oxygen and nitrogen species generation in rheumatoid arthritis (RA): causes and consequences for immune function, cell survival, and therapeutic intervention. Antioxid Redox Signal 12, 743-785.

Phillipson, M., Heit, B., Colarusso, P., Liu, L., Ballantyne, C. M., \& Kubes, P. (2006). Intraluminal crawling of neutrophils to emigration sites: a molecularly distinct process from adhesion in the recruitment cascade. J Exp Med 203, 2569-2575.

Pinho, V., de Castro Russo, R., Amaral, F. A., de Sousa, L. P., Barsante, M. M., de Souza, D. G., et al. (2007). Tissue- and stimulus-dependent role of phosphatidylinositol 3-kinase isoforms for neutrophil recruitment induced by chemoattractants in vivo. J Immunol 179, 7891-7898.

Pinho, V., Oliveira, S. H., Souza, D. G., Vasconcelos, D., Alessandri, A. L., Lukacs, N. W., et al. (2003). The role of CCL22 (MDC) for the recruitment of eosinophils during allergic pleurisy in mice. J Leukoc Biol 73, 356-362.

Pinho, V., Souza, D. G., Barsante, M. M., Hamer, F. P., De Freitas, M. S., Rossi, A. G., et al. (2005). Phosphoinositide-3 kinases critically regulate the recruitment and survival of eosinophils in vivo: importance for the resolution of allergic inflammation. J Leukoc Biol 77, 800-810.

Pollock, J. D., Williams, D. A., Gifford, M. A., Li, L. L., Du, X., \& Fisherman, J. (1995). Mouse model of X-linked chronic granulomatous disease, an inherited defect in phagocyte superoxide production. Nat Genet 9, 202-209.

Prieto, P., Cuenca, J., Traves, P. G., Fernandez-Velasco, M., Martin-Sanz, P., \& Bosca, L (2010). Lipoxin A4 impairment of apoptotic signaling in macrophages: implication of the PI3K/Akt and the ERK/Nrf-2 defense pathways. Cell Death Differ 17, 1179-1188.

Prince, L. R., Graham, K. J., Connolly, J., Anwar, S., Ridley, R., Sabroe, I., et al. (2012). Staphylococcus aureus induces eosinophil cell death mediated by alpha-hemolysin. PLoS One 7, e31506.

Prütz, W. A. (1996). Hypochlorous acid interactions with thiols, nucleotides, DNA, and other biological substrates. Arch Biochem Biophys 332, 110-120.

Pupjalis, D., Goetsch, J., Kottas, D. J., Gerke, V., \& Rescher, U. (2011). Annexin A1 released from apoptotic cells acts through formyl peptide receptors to dampen inflammatory monocyte activation via JAK/STAT/SOCS signalling. EMBO Mol Med 3, $102-114$.

Puri, K. D., Doggett, T. A., Douangpanya, J., Hou, Y., Tino, W. T., Wilson, T., et al. (2004). Mechanisms and implications of phosphoinositide 3-kinase delta in promoting neutrophil trafficking into inflamed tissue. Blood 103, 3448-3456.

Quinlan, G. J., Evans, T. W., \& Gutteridge, J. M. (1994). Oxidative damage to plasma proteins in adult respiratory distress syndrome. Free Radic Res 20, 289-298.

Raap, U., Brzoska, T., Sohl, S., Päth, G., Emmel, J., Herz, U., et al. (2003). Alpha-melanocyte-stimulating hormone inhibits allergic airway inflammation. $J$ Immunol 171, 353-359.

Rajakariar, R., Hilliard, M., Lawrence, T., Trivedi, S., Colville-Nash, P., Bellingan, G., et al. (2007). Hematopoietic prostaglandin D2 synthase controls the onset and resolution of acute inflammation through PGD2 and 15-deoxydelta12 14 PGJ2. Proc Natl Acad Sci U S A 104, 20979-20984.

Rajakariar, R., Newson, J., Jackson, E. K., Sawmynaden, P., Smith, A., \& Rahman, F. (2009). Nonresolving inflammation in gp91phox $-/-$ mice, a model of human chronic granulomatous disease, has lower adenosine and cyclic adenosine 5'-monophosphate. J Immunol 182, 3262-3269.

Ramachandran, P., Pellicoro, A., Vernon, M. A., Boulter, L., Aucott, R. L., Ali, A., et al. (2012). Differential Ly-6C expression identifies the recruited macrophage phenotype, which orchestrates the regression of murine liver fibrosis. Proc Natl Acad Sci U S A 109, E3186-E13195.

Renshaw, S. A., Loynes, C. A., Trushell, D. M. I., Elworthy, S., Ingham, P. W., \& Whyte, M. K. B. (2006). A transgenic zebrafish model of neutrophilic inflammation. Blood 108, $3976-3978$

Ricote, M., Li, A. C., Willson, T. M., Kelly, C. J., \& Glass, C. K. (1998). The peroxisome proliferator-activated receptor-gamma is a negative regulator of macrophage activation. Nature 391, 79-82.

Riedl, M. A., \& Nel, A. E. (2008). Importance of oxidative stress in the pathogenesis and treatment of asthma. Curr Opin Allergy Clin Immunol 8, 49-56.

Rodrigues, D. H., Vilela, M. C., Barcelos, L. S., Pinho, V., Teixeira, M. M., \& Teixeira, A. L. (2010). Absence of PI3Kgamma leads to increased leukocyte apoptosis and diminished severity of experimental autoimmune encephalomyelitis. J Neuroimmunol 222, 90-94.

Roffê, E., Rothfuchs, A. G., Santiago, H. C., Marino, A. P., Ribeiro-Gomes, F. L., Eckhaus, M., et al. (2012). IL-10 limits parasite burden and protects against fatal myocarditis in a mouse model of Trypanosoma cruzi infection. J Immunol 188, 649-660.

Rogerio, A. P., Haworth, O., Croze, R., Oh, S. F., Uddin, M., Carlo, T., et al. (2012). Resolvin $\mathrm{d} 1$ and aspirin-triggered resolvin d1 promote resolution of allergic airways responses. J Immunol 189, 1983-1991.
Rossi, A. G., Cousin, J. M., Dransfield, I., Lawson, M. F., Chilvers, E. R., \& Haslett, C. (1995). Agents that elevate cAMP inhibit human neutrophil apoptosis. Biochem Biophys Res Commun 217, 892-899.

Rossi, A. G., Hallett, J. M., Sawatzky, D. A., Teixeira, M. M., \& Haslett, C. (2007). Modulation of granulocyte apoptosis can influence the resolution of inflammation. Biochem Soc Trans 35, 288-291.

Rossi, A., Kapahi, P., Natoli, G., Takahashi, T., Chen, Y., Karin, M., et al. (2000) Anti-inflammatory cyclopentenone prostaglandins are direct inhibitors of IkappaB kinase. Nature 403, 103-108.

Rossi, A. G., MacIntyre, D. E., Jones, C. J., \& McMillan, R. M. (1993). Stimulation of human polymorphonuclear leukocytes by leukotriene B4 and platelet-activating factor: an ultrastructural and pharmacological study. J Leukoc Biol 53, 117-125.

Rossi, A. G., McCutcheon, J. C., Roy, N., Chilvers, E. R., Haslett, C., \& Dransfield, I. (1998). Regulation of macrophage phagocytosis of apoptotic cells by cAMP. J Immunol 160, 3562-3568.

Rossi, A. G., Sawatzky, D. A., Walker, A., Ward, C., Sheldrake, T. A., Riley, N. A., et al (2006). Cyclin-dependent kinase inhibitors enhance the resolution of inflammation by promoting inflammatory cell apoptosis. Nat Med 12, 1056-1064.

Russo, R. C., Garcia, C. C., Barcelos, L. S., Rachid, M. A., Guabiraba, R., Roffe, E., et al. (2011) Phosphoinositide 3-kinase gamma plays a critical role in bleomycin-induced pulmonary inflammation and fibrosis in mice. J Leukoc Biol 89, 269-282.

Ryan, A., \& Godson, C. (2010). Lipoxins: regulators of resolution. Curr Opin Pharmacol $10,166-172$.

Saba-El-Leil, M. K., Vella, F. D. J., Vernay, B., Voisin, L., Chen, L., Labrecque, N., et al 2003). An essential function of the mitogen-activated protein kinase Erk2 in mouse trophoblast development. EMBO Rep 4, 964-968.

Salamone, G., Giordano, M., Trevani, A. S., Gamberale, R., Vermeulen, M., Schettinni, J. et al. (2001). Promotion of neutrophil apoptosis by TNF-alpha. J Immunol 166 3476-3483.

Sallusto, F., \& Baggiolini, M. (2008). Chemokines and leukocyte traffic. Nat Immunol 9, 949-952.

Salojin, K. V., Owusu, I. B., Millerchip, K. A., Potter, M., Platt, K. A., \& Oravecz, T. (2006). Essential role of MAPK phosphatase-1 in the negative control of innate immune responses. J Immunol 176, 1899-1907.

Samson, M., Edinger, A. L., Stordeur, P., Rucker, J., Verhasselt, V., Sharron, M., et al. (1998). ChemR23, a putative chemoattractant receptor, is expressed in monocyte-derived dendritic cells and macrophages and is a coreceptor for SIV and some primary HIV-1 strains. Eur J Immunol 28, 1689-1700.

Sanlioglu, S., Williams, C. M., Samavati, L., Butler, N. S., Wang, G., McCray, P. B., et al 2001). Lipopolysaccharide induces Rac1-dependent reactive oxygen species formation and coordinates tumor necrosis factor-alpha secretion through IKK regulation of NF-kappa B. J Biol Chem 276, 30188-30198.

Santo, L., Vallet, S., Hideshima, T., Cirstea, D., Ikeda, H., Pozzi, S., et al. (2010). AT7519, a novel small molecule multi-cyclin-dependent kinase inhibitor, induces apoptosis in multiple myeloma via GSK-3beta activation and RNA polymerase II inhibition. Oncogene 29, 2325-2336.

Saraiva, M., \& O'Garra, A. (2010). The regulation of IL-10 production by immune cells Nat Rev Immunol 10, 170-181.

Sasaki, T., Irie-Sasaki, J., Jones, R. G., Oliveira-dos-Santos, A. J., Stanford, W. L., Bolon, B., et al. (2000). Function of PI3Kgamma in thymocyte development, T cell activation, and neutrophil migration. Science 287, 1040-1046.

Savill, J. (1997). Apoptosis in resolution of inflammation. J Leukoc Biol 61, 375-380.

Savill, J., Hogg, N., Ren, Y., \& Haslett, C. (1992). Thrombospondin cooperates with CD36 and the vitronectin receptor in macrophage recognition of neutrophils undergoing apoptosis. J Clin Invest 90, 1513-1522.

Sawatzky, D. A., Willoughby, D. A., Colville-Nash, P. R., \& Rossi, A. G. (2006). The involvement of the apoptosis-modulating proteins ERK 1/2, Bcl-xL and Bax in the resolution of acute inflammation in vivo. Am J Pathol 168, 33-41.

Scannell, M., Flanagan, M. B., deStefani, A., Wynne, K. J., Cagney, G., Godson, C., et al. (2007) Annexin-1 and peptide derivatives are released by apoptotic cells and stimulate phagocytosis of apoptotic neutrophils by macrophages. J Immunol 178, 4595-4605.

Scher, J. U., \& Pillinger, M. H. (2005). 15d-PGJ2: the anti-inflammatory prostaglandin? Clin Immunol 114, 100-109.

Schif-Zuck, S., Gross, N., Assi, S., Rostoker, R., Serhan, C. N., \& Ariel, A. (2011) Saturated-efferocytosis generates pro-resolving CD11b low macrophages: modulation by resolvins and glucocorticoids. Eur J Immunol 41, 366-379.

Schmidt, M. V., Brune, B., \& von, K. A. (2010). The nuclear hormone receptor PPARgamma as a therapeutic target in major diseases. Scientific World Journal 10, 2181-2197.

Schottelius, A. J. G., Mayo, M. W., Sartor, R. B., \& Baldwin, A. S. (1999). Interleukin-10 signaling blocks inhibitor of kappa B kinase activity and nuclear factor kappa B DNA binding. J Biol Chem 274, 31868-31874.

Schudt, C., Hatzelmann, A., Beume, R., \& Tenor, H. (2011). Phosphodiesterase inhibitors: history of pharmacology. Handb Exp Pharmacol 204, 1-46.

Schwab, J. M., Chiang, N., Arita, M., \& Serhan, C. N. (2007). Resolvin E1 and protectin D1 activate inflammation-resolution programmes. Nature 447, 869-874.

Segal, M., Niazi, S., Simons, M. P., Galati, S. A., \& Zangrilli, J. G. (2007). Bid activation during induction of extrinsic and intrinsic apoptosis in eosinophils. Immunol Cell Biol 85, 518-524.

Senderowicz, A. M. (2003). Small-molecule cyclin-dependent kinase modulators Oncogene 22, 6609-6620.

Senftleben, U., Cao, Y., Xiao, G., Greten, F. R., Krähn, G., Bonizzi, G., et al. (2001). Activation by IKKalpha of a second, evolutionary conserved, NF-kappaB signaling pathway Science 293, 1495-1499.

Serezani, C. H., Ballinger, M. N., Aronoff, D. M., \& Peters-Golden, M. (2008). Cyclic AMP. Am J Respir Cell Mol Biol 39, 127-132. 
Serhan, C. N. (2007). Resolution phase of inflammation: novel endogenous anti-inflammatory and proresolving lipid mediators and pathways. Annu Rev Immunol 25, 101-137.

Serhan, C. N., \& Chiang, N. (2008). Endogenous pro-resolving and anti-inflammatory lipid mediators: a new pharmacologic genus. Br J Pharmacol 153, S200-S215.

Serhan, C. N., Chiang, N., \& Van Dyke, T. E. (2008). Resolving inflammation: dua anti-inflammatory and pro-resolution lipid mediators. Nat Rev Immunol 8, 349-361.

Serhan, C. N., Dalli, J., Karamnov, S., Choi, A., Park, C. K., Xu, Z. Z., et al. (2012). Macrophage proresolving mediator maresin 1 stimulates tissue regeneration and controls pain. FASEB J 26, 1755-1765.

Serhan, C. N., \& Petasis, N. A. (2011). Resolvins and protectins in inflammation resolution. Chem Rev 111, 5922-5943.

Serhan, C. N., Yang, R., Martinod, K., Kasuga, K., Pillai, P. S., Porter, T. F., et al. (2009). Maresins: novel macrophage mediators with potent antiinflammatory and proresolving actions. J Exp Med 206, 15-23.

Shacter, E. (2000). Quantification and significance of protein oxidation in biologica samples. Drug Metab Rev 32, 307-326.

Siegel, R. M. (2006). Caspases at the crossroads of immune-cell life and death. Nat Rev Immunol 6, 308-317.

Simmons, M. N., Subramanian, V., Crouzet, S., Haber, G. P., Colombo, J. R., Jr., Ukimura O., et al. (2010). Alpha-melanocyte stimulating hormone analogue AP214 protects against ischemia induced acute kidney injury in a porcine surgical model. $J$ Uro 183, 1625-1629.

Simon, H. U. (2001). Regulation of eosinophil and neutrophil apoptosis similarities and differences. Immunol Rev 179, 156-162.

Sina, C., Gavrilova, O., Förster, M., Till, A., Derer, S., Hildebrand, F., et al. (2009). G protein-coupled receptor 43 is essential for neutrophil recruitment during intestinal inflammation. J Immunol 183, 7514-7522.

Sivertson, K. L, Seeds, M. C., Long D. L, Peachman, K. K., \& Bass, D. A. (2007). The differential effect of dexamethasone on granulocyte apoptosis involves stabilization of Mcl-1L in neutrophils but not in eosinophils. Cell Immunol 246, 34-45.

Soderling, S. H., \& Beavo, J. A. (2000). Regulation of cAMP and cGMP signaling: new phosphodiesterases and new functions. Curr Opin Cell Biol 12, 174-179.

Solito, E., Kamal, A., Russo-Marie, F., Buckingham, J. C., Marullo, S., \& Perretti, M. (2003) A novel calcium-dependent proapoptotic effect of annexin 1 on human neutrophils. FASEB J 17, 1544-1546.

Song, G., Ouyang, G., \& Bao, S. (2005). The activation of Akt/PKB signaling pathway and cell survival. J Cell Mol Med 9, 59-71.

Sousa, L. P., Carmo, A. F., Rezende, B. M., Lopes, F., Silva, D. M., Alessandri, A. L., et al. (2009). Cyclic AMP enhances resolution of allergic pleurisy by promoting inflammatory cell apoptosis via inhibition of PI3K/Akt and NF-kappaB. Biochem Pharmacol 78, 396-405.

Sousa, L. P., Lopes, F., Silva, D. M., Tavares, L. P., Vieira, A. T., Rezende, B. M., et al. (2010) PDE4 inhibition drives resolution of neutrophilic inflammation by inducing apoptosis in a PKA-PI3K/Akt-dependent and NF-kappaB-independent manner. J Leukoc Biol 87, 895-904

Souza, D. G., Cassali, G. D., Poole, S., \& Teixeira, M. M. (2001). Effects of inhibition of PDE4 and TNF-alpha on local and remote injuries following ischaemia and reperfusion injury. Br J Pharmacol 134, 985-994.

Souza, D. G., Fagundes, C. T., Amaral, F. A., Cisalpino, D., Sousa, L. P., Vieira, A. T., et al. (2007). The required role of endogenously produced lipoxin A4 and annexin-1 for the production of IL-10 and inflammatory hyporesponsiveness in mice. J Immunol 179, 8533-8543.

Souza, D. G., Vieira, A. T., Soares, A. C., Pinho, V., Nicoli, J. R., Vieira, L. Q., et al. (2004) The essential role of the intestinal microbiota in facilitating acute inflammatory responses. Immunology 173, 4137-4146.

Spite, M., \& Serhan, C. N. (2010). Novel lipid mediators promote resolution of acute inflammation: impact of aspirin and statins. Circ Res 107, 1170-1184.

Squires, M. S., Cooke, L., Lock, V., Qi, W., Lewis, E. J., Thompson, N. T., et al. (2010) AT7519, a cyclin-dependent kinase inhibitor, exerts its effects by transcriptional inhibition in leukemia cell lines and patient samples. Mol Cancer Ther 9, 920-928.

Squires, M. S., Feltell, R. E., Wallis, N. G., Lewis, E. J., Smith, D. M., Cross, D. M. et al. (2009). Biological characterization of AT7519, a small-molecule inhibitor of cyclin-dependent kinases, in human tumor cell lines. Mol Cancer Ther 8, 324-332.

Srinivasan, M., \& Janardhanam, S. (2011). Novel p65 binding glucocorticoid-induced leucine zipper peptide suppresses experimental autoimmune encephalomyelitis. J Biol Chem 286, 44799-44810.

Stables, M. J., Shah, S., Camon, E. B., Lovering, R. C., Newson, J., Bystrom, J., et al. (2011) Transcriptomic analyses of murine resolution-phase macrophages. Blood 118 e192-e208.

Stevenson, M. A., Pollock, S. S., Coleman, C. N., \& Calderwood, S. K. (1994). X-irradiation, phorbol esters, and $\mathrm{H}_{2} \mathrm{O}_{2}$ stimulate mitogen-activated protein kinase activity in NIH-3T3 cells through the formation of reactive oxygen intermediates. Cancer Res 54, 12-15.

Straus, D. S., \& Glass, C. K. (2001). Cyclopentenone prostaglandins: new insights on biological activities and cellular targets. Med Res Rev 21, 185-210.

Suarez, P. E., Rodriguez, E. G., Soundararajan, R., Merillat, A. M., Stehle, J. C., Rotman, S. et al. (2012). The glucocorticoid-induced leucine zipper (gilz/tsc22d3-2) gene locus plays a crucial role in male fertility. Mol Endocrinol 26, 1000-1013.

Surh, Y. J., Na, H. K., Park, J. M., Lee, H. N., Kim, W., Yoon, I. S., et al. (2011) 15-Deoxy-delta(1)(2), (1)(4)-prostaglandin J(2), an electrophilic lipid mediator of anti-inflammatory and pro-resolving signaling. Biochem Pharmacol 82, 1335-1351.

Suzuki, K., Hasegawa, T., Sakamoto, C., Zhou, Y. M., Hato, F., Hino, M., et al. (2001). Cleavage of mitogen-activated protein kinases in human neutrophils undergoing apoptosis: role in decreased responsiveness to inflammatory cytokines. J Immunol 166, 1185-1192.

Suzuki, K., Hino, M., Hato, F., Tatsumi, N., \& Kitagawa, S. (1999). Cytokine-specific activation of distinct mitogen-activated protein kinase subtype cascades in human neutrophils stimulated by granulocyte colony-stimulating factor, granulocytemacrophage colony-stimulating factor, and tumor necrosis factor-alpha. Blood 93, 341-349.

Tait, M. A., Lucas, C. D., Duffin, R., Haslett, C., \& Rossi, A. G. (2012). The novel cyclin-dependent kinase inhibitor, AT7519, overrides neutrophil survival mediated by a major gram positive bacterial cell wall component, lipoteichoic acid. Proc Physiol Soc 27, PC222 (Poster Communications. The Physiological Society).

Takeshita, S., Tsujimoto, H., \& Nakatani, K. (2005). Intravenous immunoglobulin preparations promote apoptosis in lipopolysaccharide-stimulated neutrophils via an oxygen-dependent pathway in vitro. APMIS 113, 269-277.

Talukdar, S., Olefsky, J. M., \& Osborn, O. (2011). Targeting GPR120 and other fatty acid-sensing GPCRs ameliorates insulin resistance and inflammatory diseases. Trends Pharmacol Sci 32, 543-550.

Teixeira, M. M., Gristwood, R. W., Cooper, N., \& Hellewell, P. G. (1997). Phosphodiesterase (PDE)4 inhibitors: anti-inflammatory drugs of the future? Trends Pharmacol Sci 18, 164-171.

Toker, A., \& Cantley, L. C. (1997). Signalling through the lipid products of phosphoinositide-3-OH kinase. Nature 387, 673-676.

Truman, L. A., Ford, C. A., Pasikowska, M., Pound, J. D., Wilkinson, S. J., Dumitriu, I. E., et al. (2008). CX3CL1/fractalkine is released from apoptotic lymphocytes to stimulate macrophage chemotaxis. Blood 112, 5026-5036.

Vago, J. P., Nogueira, C. R., Tavares, L. P., Soriani, F. M., Lopes, F., Russo, R. C., et al. (2012). Annexin A1 modulates natural and glucocorticoid-induced resolution of inflammation by enhancing neutrophil apoptosis. J Leukoc Biol 92, 249-258.

van den Berg, J. M., Weyer, S., Weening, J. J., Roos, D., \& Kuijpers, T. W. (2001). Divergent effects of tumor necrosis factor alpha on apoptosis of human neutrophils. J Leukoc Biol 69, 467-473.

van, E. M., Nieland, L. J., Ramaekers, F. C., Schutte, B., \& Reutelingsperger, C. P. (1998). Annexin V-affinity assay: a review on an apoptosis detection system based on phosphatidylserine exposure. Cytometry 31, 1-9.

Van-Assche, T., Huygelen, V., Crabtree, M. J., \& Antoniades, C. (2011). Gene therapy targeting inflammation in atherosclerosis. Curr Pharm Des 17, 4210-4223.

Vanhaesebroeck, B., Stephens, L., \& Hawkins, P. (2012). PI3K signalling: the path to discovery and understanding. Nat Rev Mol Cell Biol 13, 195-203.

Vanhaesebroeck, B., \& Waterfield, M. D. (1999). Signaling by distinct classes of phosphoinositide 3-kinases. Exp Cell Res 253, 239-254.

Vermi, W., Riboldi, E., Wittamer, V., Gentili, F., Luini, W., Marrelli, S., et al. (2005). Role of ChemR23 in directing the migration of myeloid and plasmacytoid dendritic cells to lymphoid organs and inflamed skin. J Exp Med 201, 509-515.

Vinolo, M. A., Ferguson, G. J., Kulkarni, S., Damoulakis, G., Anderson, K., Bohlooly, Y, et al. (2011a). SCFAs induce mouse neutrophil chemotaxis through the GPR43 receptor. PLoS One 6, e21205.

Vinolo, M. A., Rodrigues, H. G., Nachbar, R. T., \& Curi, R. (2011b). Regulation of inflammation by short chain fatty acids. Nutrients $3,858-876$

Voll, R. E., Herrmann, M., Roth, E. A., Stach, C., Kalden, J. R., \& Girkontaite, I. (1997). Immunosuppressive effects of apoptotic cells. Nature 390, 350-351.

von, K. A., Soller, M., Tzieply, N., Weigert, A., Johann, A. M., Jennewein, C., et al. (2007). PPARgamma1 attenuates cytosol to membrane translocation of PKCalpha to desensitize monocytes/macrophages. J Cell Biol 176, 681-694.

von, G. S., Yousefi, S., Seitz, M., Jakob, S. M., Schaffner, T., Seger, R., et al. (2005). Siglec-9 transduces apoptotic and nonapoptotic death signals into neutrophils depending on the proinflammatory cytokine environment. Blood 106, 1423-1431.

Waldburger, J. M., \& Firestein, G. S. (2009). Garden of therapeutic delights: new targets in rheumatic diseases. Arthritis Res Ther 11, 206.

Wang, K., Hampson, P., Hazeldine, J., Krystof, V., Strnad, M., Pechan, P., et al. (2012). Cyclin-dependent kinase 9 activity regulates neutrophil spontaneous apoptosis. PLoS One 7, e30128.

Wang, J. J., \& Mak, O. T. (2011). Induction of apoptosis by 15d-PGJ2 via ROS formation: an alternative pathway without PPARgamma activation in non-small cell lung carcinoma A549 cells. Prostaglandins Other Lipid Mediat 94, 104-111.

Wang, T., Zhang, X., \& Li, J. J. (2002). The role of NF-kappaB in the regulation of cell stress responses. Int Immunopharmacol 2, 1509-1520.

Ward, C., Chilvers, E. R., Lawson, M. F., Pryde, J. G., Fujihara, S., Farrow, S. N., et al. (1999). NF-kappaB activation is a critical regulator of human granulocyte apoptosis in vitro. J Biol Chem 274, 4309-4318.

Ward, C., Dransfield, I., Murray, J., Farrow, S. N., Haslett, C., \& Rossi, A. G. (2002). Prostaglandin D2 and its metabolites induce caspase-dependent granulocyte apoptosis that is mediated via inhibition of I kappa B alpha degradation using a peroxisome proliferator-activated receptor-gamma-independent mechanism. J Immunol 168, 6232-6243.

Ward, C., Murray, J., Clugston, A., Dransfield, I., Haslett, C., \& Rossi, A. G. (2005). Interleukin-10 inhibits lipopolysaccharide-induced survival and extracellular signal-regulated kinase activation in human neutrophils. Eur J Immunol 35, 2728-2737.

Ward, C., Walker, A., Dransfield, I., Haslett, C., \& Rossi, A. G. (2004). Regulation of granulocyte apoptosis by NF-kappaB. Biochem Soc Trans 32, 465-467.

Wardle, D. J., Burgon, J., Sabroe, I., Bingle, C. D., Whyte, M. K., \& Renshaw, S. A. (2011). Effective caspase inhibition blocks neutrophil apoptosis and reveals Mcl-1 as both a regulator and a target of neutrophil caspase activation. PLoS One 6, e15768.

Weinmann, P., Gaehtgens, P., \& Walzog, B. (1999). Bcl-Xl- and Bax-alpha-mediated regulation of apoptosis of human neutrophils via caspase-3. Blood 93, 3106-3115.

Wen, L, Ley, R. E, Volchkov, P. Y, Stranges, P. B., Avanesyan, L. Stonebraker, A. C., et al. (2008). Innate immunity and intestinal microbiota in the development of Type 1 diabetes. Nature 455, 1109-1113.

Wikberg, J. E., Muceniece, R., Mandrika, I., Prusis, P., Lindblom, J., Post, C., et al. (2000). New aspects on the melanocortins and their receptors. Pharmacol Res 42, 393-420. 
Wittamer, V., Franssen, J. D., Vulcano, M., Mirjolet, J. F., Le, P. E., Migeotte, I., et al. (2003). Specific recruitment of antigen-presenting cells by chemerin, a novel processed ligand from human inflammatory fluids. J Exp Med 198, 977-985.

Xu, Z. Z., Zhang, L., Liu, T., Park, J. Y., Berta, T., Yang, R., et al. (2010). Resolvins RvE1 and RvD1 attenuate inflammatory pain via central and peripheral actions. Nat Med 16(592-7), 1p.

Yang, Y. H., Aeberli, D., Dacumos, A., Xue, J. R., \& Morand, E. F. (2009). Annexin-1 regulates macrophage IL-6 and TNF via glucocorticoid-induced leucine zipper. J Immunol 183, 1435-1445.

Yang, K. Y., Arcaroli, J., Kupfner, J., Pitts, T. M., Park, J. S., Strasshiem, D., et al. (2003). Involvement of phosphatidylinositol 3-kinase gamma in neutrophil apoptosis. Cell Signal 15, 225-233.

Yang, Y. H., Morand, E. F., Getting, S. J., Paul-Clark, M., Liu, D. L., Yona, S., et al. (2004). Modulation of inflammation and response to dexamethasone by Annexin 1 in antigen-induced arthritis. Arthritis Rheum 50, 976-984.

Yang, Y. H., Toh, M. L., Clyne, C. D., Leech, M., Aeberli, D., Xue, J., et al. (2006). Annexin 1 negatively regulates IL-6 expression via effects on p38 MAPK and MAPK phosphatase-1. J Immunol 177, 8148-8153.

Yasui, K., \& Baba, A. (2006). Therapeutic potential of superoxide dismutase (SOD) for resolution of inflammation. Inflamm Res 55, 359-363.

Yasui, K., Kobayashi, N., Yamazaki, T., Agematsu, K., Matsuzaki, S., Ito, S., et al. (2005). Superoxide dismutase (SOD) as a potential inhibitory mediator of inflammation via neutrophil apoptosis. Free Radic Res 39, 755-762.

Yazdi, A. S., Guarda, G., D'Ombrain, M. C., \& Drexler, S. K. (2010). Inflammatory caspases in innate immunity and inflammation. J Innate Immun 2, 228-237.
Yazid, S., Norling, L. V., \& Flower, R. J. (2011). Anti-inflammatory drugs, eicosanoids and the annexin A1/FPR2 anti-inflammatory system. Prostaglandins Other Lipid Mediat 98, 94-100.

Yipp, B. G., Petri, B., Salina, D., Jenne, C. N., Scott, B. N., \& Zbytnuik, L. D. (2012) Infection-induced NETosis is a dynamic process involving neutrophil multitasking in vivo. Nat Med (Aug 26).

Yousefi, S., Mihalache, C., Kozlowski, E., Schmid, I., \& Simon, H. U. (2009). Viable neutrophils release mitochondrial DNA to form neutrophil extracellular traps. Cell Death Differ 16, 1438-1444.

Yum, H. K., Arcaroli, J., Kupfner, J., Shenkar, R., Penninger, J. M., Sasaki, T., et al. (2001). Involvement of phosphoinositide 3-kinases in neutrophil activation and the development of acute lung injury. J Immunol 167, 6601-6608.

Zaytseva, Y. Y., Wang, X., Southard, R. C., Wallis, N. K., \& Kilgore, M. W. (2008). Down-regulation of PPARgamma1 suppresses cell growth and induces apoptosis in MCF-7 breast cancer cells. Mol Cancer 7, 90.

Zhang, Y., Kim, H. J., Yamamoto, S., Kang, X., \& Ma, X. (2010a). Regulation of interleukin-10 gene expression in macrophages engulfing apoptotic cells. J Interferon Cytokine Res 30 113-122.

Zhang, D. W., Shao, J., Lin, J., Zhang, N., Lu, B. J., Lin, S. C., et al. (2009). RIP3, an energy metabolism regulator that switches TNF-induced cell death from apoptosis to necrosis. Science 325, 332-336.

Zhang, F., Yang, H., Pan, Z., Wang, Z., Wolosin, J. M., Gjorstrup, et al. (2010b). Dependence of resolvin-induced increases in corneal epithelial cell migration on EGF receptor transactivation. Invest Ophthalmol Vis Sci 51, 5601-5609. 